PNNL-

\title{
Ion-Exchange Processes and Mechanisms in Glasses
}
B. P. McGrail ${ }^{1}$
M. H. Engelhard ${ }^{1}$
J. P. Icenhower ${ }^{1}$
J. L. Steele ${ }^{1}$
J. G. Darab ${ }^{1}$
D. K. Shuh ${ }^{2}$
E. A. Rodriguez ${ }^{1}$
D. R. Baer ${ }^{1}$
P. Liu
V. Shutthanandan ${ }^{1}$
K. E. Ivanov ${ }^{2}$
S. Thevuthasan ${ }^{1}$
C. H. Booth ${ }^{2}$
P. Nachimuthu ${ }^{3}$

October 2001

Prepared for

the U.S. Department of Energy

under Contract DE-AC06-76RLO 1830

${ }^{1}$ Pacific Northwest National Laboratory

Richland, Washington 99352

${ }^{2}$ Lawrence Berkeley National Laboratory

MS 70A-1150, One Cyclotron Road

Berkeley, CA 94720

${ }^{3}$ University of Nevada Las Vegas

Las Vegas, NV 89154-4003 


\title{
DISCLAIMER
}

This report was prepared as an account of work sponsored by an agency of the United States Covernment. Neither the United States Government nor any agency thereof, nor Battelle Memorial Institute, nor any of their employees, makes any warranty, expressed or implied, or assumes any legal liability or responsibility for the accuracy, completeness, or usefulness of any information, apparatus, product, or process disclosed, or represents that its use would not infringe privately owned rights. Reference herein to any specific commercial product, process, or service by trade name, trademark, manufacturer, or otherwise does not necessarily constitute or imply its endorsement, recommendation, or favoring by the United States Government or any agency thereof, or Battelle Memorial Institute. The views and opinions of authors expressed herein do not necessarily state or reflect those of the United States Government or any agency thereof.

\section{PACIFIC NORTHWEST NATIONAL LABORATORY operated by \\ BATTELLE MEMORIAL INSTITUTE for the \\ UNITED STATES DEPARTMENT OF ENERGY under Contract DE-AC06-76RLO 1830}

Printed in the United States of America

\author{
Available to DOE and DOE contractors from the \\ Office of Scientific and Technical Information, P.O. Box 62, Oak Ridge, TN 37831; \\ prices available from (615) 576-8401.
}

\begin{abstract}
Available to the public from the National Technical Information Service, U.S. Department of Commerce, 5285 Port Royal Rd., Springfield, VA 22161
\end{abstract}




\section{SUMMARY}

Dissolution kinetics four glass Series (I-IV) were tested using single-pass flow-through (SPFT) apparatus in silica saturated solutions. The glass series interogated include a succesion of $\mathrm{AlO}_{4}$ subsituted sodium disilicate (DS; $\mathrm{Na}_{2} \mathrm{Si}_{2} \mathrm{O}_{5}$ ) compositions (Series I), a suite from DS to reed-mergnerite $\left(\mathrm{RD} ; \mathrm{NaBSi}_{3} \mathrm{O}_{8}\right.$ ) (Series II), a set in which $\mathrm{BO}_{4}$ tetrahedra were substituted for $\mathrm{AlO}_{4}$ (Series III), and a sequence of sodium boroaluminosilicates progressively substituted with $\mathrm{HfO}_{2}$ (Series IV). In these four Series we varied either the proportion of non-bridging oxygen (NBO) atoms or the ${ }^{\mathrm{iv}} \mathrm{B}$ to ${ }^{\mathrm{iii}} \mathrm{B}$ ratio to probe the the effects of these parameters on matrix dissolution and sodium exchange kinetics.

SPFT tests with Series I glasses reveal that the release rate for $\mathrm{Na}$ was 10 to 50 times faster than that of matrix dissolution Release of $\mathrm{Na}$ was $30 \%$ slower in $\mathrm{D}_{2} \mathrm{O}$ compared to rates in $\mathrm{H}_{2} \mathrm{O}$, but matrix dissolution rates were unaffected. These results are consistent with rupture of the $\mathrm{O}-\mathrm{H}$ bond as the ratelimiting reaction in $\mathrm{Na}^{+}-\mathrm{H}^{+}$. A simple model was constructed to estimate a structural energy barrier for alkali ion exchange using $\mathrm{Na}-\mathrm{O}$ bond length and coordination as measured by $\mathrm{Na} \mathrm{K}$-edge $\mathrm{x}$-ray absorption spectroscopy, and binding energy shifts for $\mathrm{Si}-\mathrm{O}-\mathrm{Na}$ sites measured by x-ray photoelectron spectroscopy. The calculated ion-exchange enthalpies were then used to calculate $\mathrm{Na}$ ion exchange rates as a function of glass composition. Agreement between the calculated and measured $\mathrm{Na}$ ion exchange rates was excellent.

NMR spectroscopy of Series II compositions indicates the presence of variable proportions of DS, $\mathrm{RD}$, and sodium metaborate $\left(\mathrm{MB}, \mathrm{NaBO}_{2}\right)$ in the glasses as non-crystalline mineral analog moieties. Reaction behavior can be explained by the shifts in the relative proportion of these moieties. Glass compositions containing >3 mol\% (or 15 mass\%) MB component are governed by the reactive nature of this moiety, and their dissolution kinetics become insensitive to the Si content of the solution in contact with the glass. Glass compositions containing only DS and RD components remain sensitive to solution saturation state with respect to amorphous silica.

Specimens of the B-bearing Series III glasses were tested in both $\mathrm{H}_{2} \mathrm{O}$ and $\mathrm{D}_{2} \mathrm{O}$ solutions. Rates of $\mathrm{Na}$ release are a factor of $\sim 100 \mathrm{X}$ faster than matrix dissolution rates. As in the case of the Series I compositions (Al-bearing), the rate of $\mathrm{Na}$ release in $\mathrm{D}_{2} \mathrm{O}$-based solutions was $30 \%$ slower than in $\mathrm{H}_{2} \mathrm{O}$ solutions. Furthermore, rates of matrix dissoluiton, indexed by $\mathrm{B}$ release, were insensitive to the identity of the hydrogen isotope. Therefore, as the case of the Series I glasses, the rate limiting step in the release of $\mathrm{Na}$ is the rupture of the $\mathrm{O}-\mathrm{H}(\mathrm{D})$ bond. To our knowledge, this is the first instance in which an ion exchange reaction has been documented for borosilicate glass compositions at silica saturation.

XAS characterization of Series IV specimens reveals that as $\mathrm{Hf}$ is added to glass, the proportion of ${ }^{\mathrm{iii}} \mathrm{B}$ to ${ }^{\mathrm{iv}} \mathrm{B}$ decreases, yet dissolution kinetics data show that rates decrease. In addition, as the ratio $\mathrm{Na} /\left(\mathrm{Al}+{ }^{\mathrm{iv}} \mathrm{B}\right)$ increases to well above one, the $\mathrm{Na}$ and $\mathrm{B}$ release rates remain equal. This set of data would seem to contradict the hypothesis that as the amount of "excess" $\mathrm{Na}$ increases, the Na-release rate outstrips that of $\mathrm{B}$, due to $\mathrm{Na}$ becoming associated with a larger proportion of non-bridging oxygen (NBO) atoms. This apparent contradiction can be reconciled by the recognition that addition of $\mathrm{Hf}$ results in the glass becoming increasingly resistant to nucleophilic attack by $\mathrm{OH}^{-}$groups. A simple chemical kinetics model shows a logarithmic rate of decrease in glass corrosion rate as a function of $\mathrm{mol} \% \mathrm{HfO}_{2}$. Therefore, addition of even small amounts of high field strength elements (HFSE), such as $\mathrm{Zr}^{4+}$, may result in benefical properties imparted to waste glass. 



\section{CONTENTS}

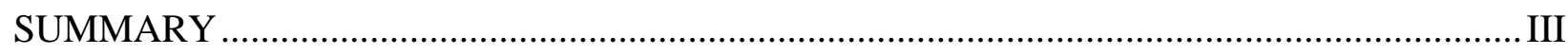

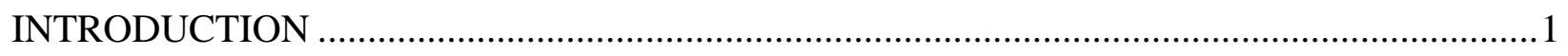

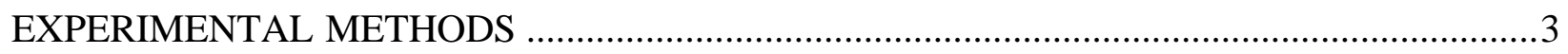

Glass Formulation and Characterization ........................................................................... 3

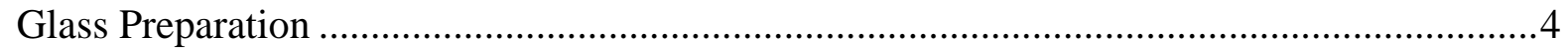

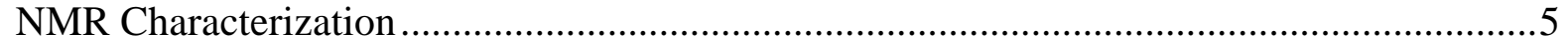

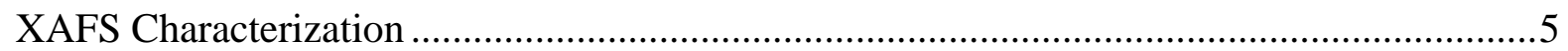

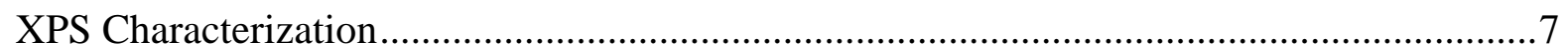

Single-Pass Flow -Through Experiments …………….......................................................

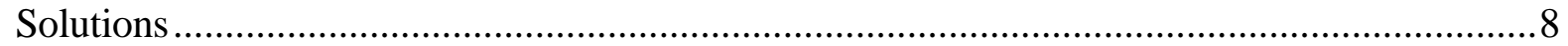

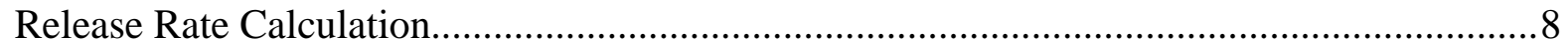

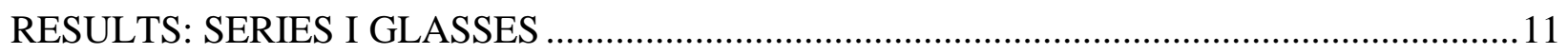

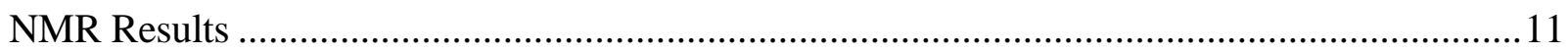

Sodium XAFS Results ................................................................................................

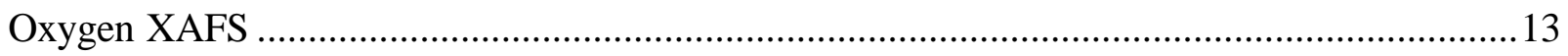

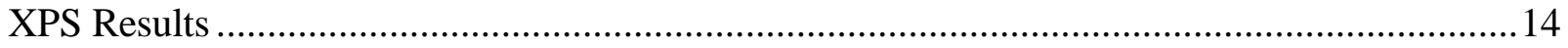

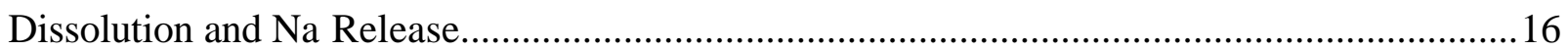

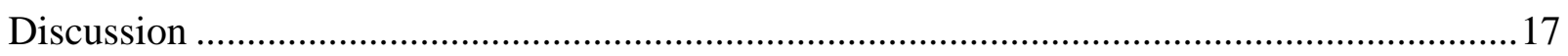

Rate-Limiting Step for Sodium Ion Exchange …………….................................................... 19

Correlation Between Glass Structure and Exchange Kinetics ....................................................19

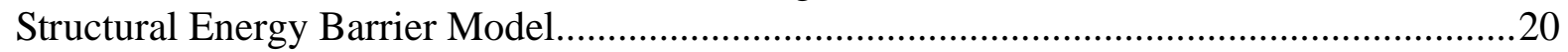

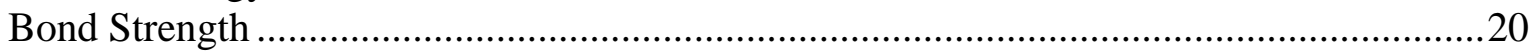

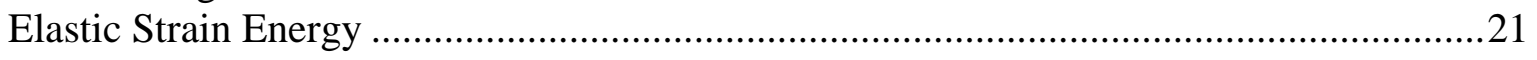

Ion-Exchange Rate Calculation.......................................................................................2

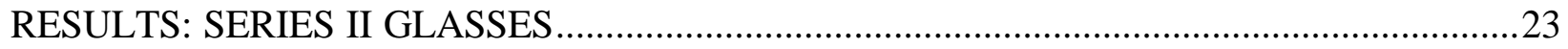

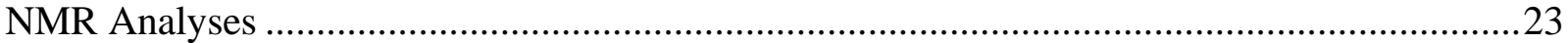

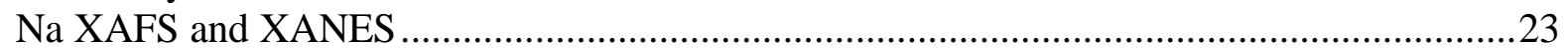

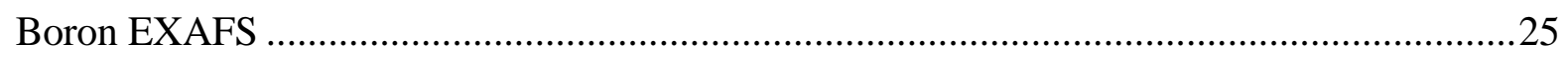

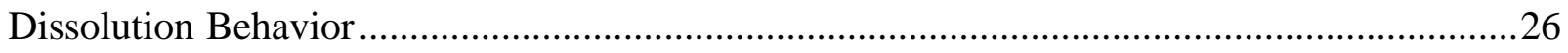

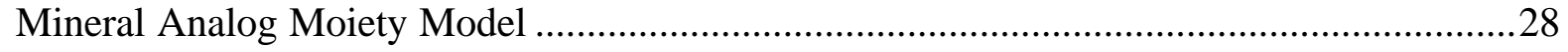

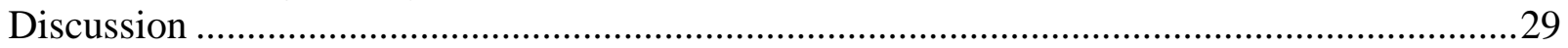

RESULTS: SERIES III GLASSES …………………......................................................

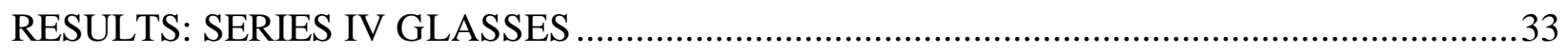

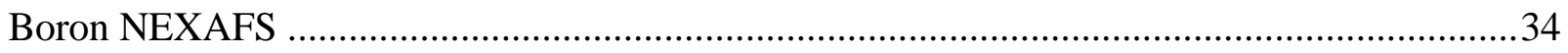

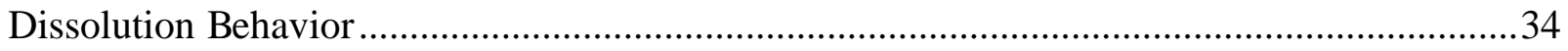

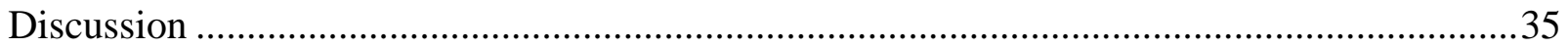

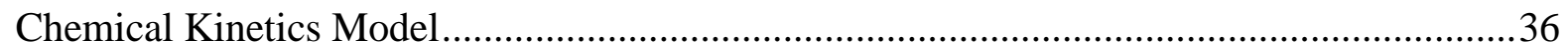




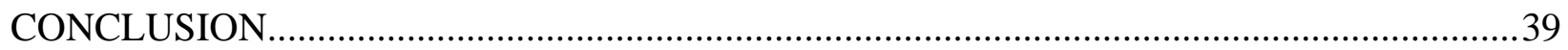

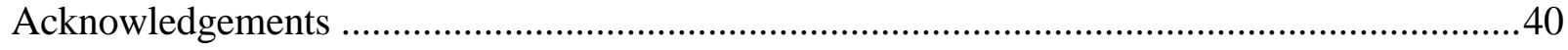

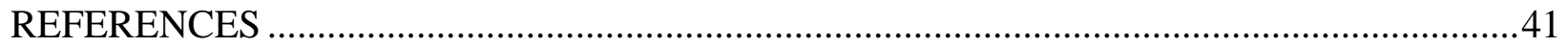

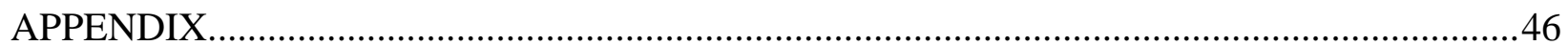




\section{FIGURES}

Figure 1. Composition Space Investigated for Series I and Series II Glasses ...........................3

Figure 2. Schematic of Multichamber Flow-Through Column for Ion-Exchange Kinetics Tests .7

Figure 3. Sodium K edge XANES spectra collected at ALS Beamline 8.0 from the glasses and hydrated sodium silicate reference material in the total electron yield mode. The spectra have not had backgrounds removed and have been normalized to the amplitude of the largest feature, respectively.

Figure 4. Na K-edge $\chi^{3}$-weighted EXAFS (upper) and Fourier Transforms (FTs) (lower) of the EXAFS collected on ALS Beamline 6.3.1 from the glasses.

Figure 5. Oxygen K-edge absorption spectra collected at ALS Beamline 6.3.1 from the $\mathrm{NaSiO}-x \mathrm{Al}$ glasses

Figure 6. Example of Fit to O 1s XPS Photopeaks for the NaSiO-10Al Glass

Figure 7. XPS Binding Energy Shift As a Function of Alumina Content .16

Figure 8. Plot of Normalized Release Rates (Mo and $\mathrm{Na}$ ) in $\mathrm{H}_{2} \mathrm{O}$ and $\mathrm{D}_{2} \mathrm{O}$ as a Function of $\mathrm{Al}_{2} \mathrm{O}_{3}$ Content

Figure 9. Sodium Ion-Exchange Rate as a Function of ${ }^{29} \mathrm{Si}$ Chemical Shift Value as Determined by MAS-NMR

Figure 10. Comparison of Calculated and Predicted $\mathrm{Na}$ Ion Exchange Rate as a Function of $\mathrm{Al}_{2} \mathrm{O}_{3}$ Content in NaSiO- $x \mathrm{Al}$ Glasses

Figure 11. Sodium K edge XANES spectra collected at ALS Beamline 6.3.1 from the second glass series and an anhydrous sodium silicate reference material in the TEY mode

Figure 12. Fluorescence yield $\mathrm{Na} \mathrm{K}$ edge EXAFS spectra from the reference materials and second series of glasses....

Figure 13. Fourier transforms of the EXAFS spectra for the reference materials in panel (a); black is $\mathrm{NaNO}_{3}$ (well ordered $\mathrm{NaO}_{6}$ octahedron), red is $\mathrm{NaBrO}_{3}$ (distorted $\mathrm{NaO}_{6}$ octahedron) and green is $\mathrm{Na}_{2} \mathrm{SiO}_{3}$ (distorted and 5-fold).

Figure 14. Boron K edge NEXAFS TEY spectra from the boron reference materials and two compositionally-simple borosilicate glasses..

Figure 15. Boron K edge TEY NEXAFS spectra from the second series glasses collected at Beamline 6.3.2

Figure 16. Plot of $\log \mathrm{Na}$ and $\mathrm{B}$ release rates for the reedmergnerite (RD) series glasses at silica saturation, $\mathrm{pH}=9$.

Figure 17. Plots of log element release rates versus the activity of silicic acid in solution for the $\mathrm{MB}_{0.03}$ and $\mathrm{MB}_{0.07}$ glass compositions, $\mathrm{pH}=9, \mathrm{~T}=40^{\circ} \mathrm{C}$.

Figure 18. Plot of ${ }^{29}$ Si Chemical Shift Measured by MAS-NMR and Calculated with a Rule of Mixtures for Mineral Analog Moieties 
Figure 19: Plot of normalized log rate versus the boron concentration in the glass specimens.

Solutions are silica saturated $\mathrm{H}_{2} \mathrm{O}$ - or $\mathrm{D}_{2} \mathrm{O}$-based and $\mathrm{pH}=\mathrm{pD}=8$

Figure 20. Boron K edge NEXAFS spectra collected in FY mode at Beamline 7.0

of the ALS for a series of non-ideal glasses. The left panel has spectra from several reference materials and glass formations containing hafnium.

Figure 21. Plot of log release rate of $\mathrm{Na}$ and $\mathrm{B}$ versus concentration of hafnium in glass for experiments in dilute and in silica saturated solutions

Figure 22. Plot of dissolution rate versus activity of silicic acid in solution for glass compositions BAS-0Hf and BAS-5Hf, $\mathrm{pH}=9, \mathrm{~T}=23^{\circ} \mathrm{C}$.

Figure 23. Calculated Normalized Rate of Metaborate Reaction as a Function of Mol

Fraction of $\mathrm{HfO}_{2}$ in the BAS- $x \mathrm{Hf}$ Series of Glasses.

\section{TABLES}

Table 1. Glass Compositions Examined in this Study Along with ${ }^{29} \mathrm{Si}$ NMR Results 4

Table 2. XAS Results, and Na Ion-exchange Rate $\left(r_{x}\right)$ at $23^{\circ} \mathrm{C}, \mathrm{pH}=8$ for NaSiO- $x \mathrm{Al}$ Glasses ...11

Table 3. Raw XPS Data and Peak Fitting Results for NaSiO- $x \mathrm{Al}$ Series of Glasses ..... 15

Table 4. Experimental Conditions and Measured Apparent Dissolution Rates of NaSiO- $x \mathrm{Al}$ Glasses at $\mathrm{pH} 8$, Silica-saturated $\mathrm{H}_{2} \mathrm{O}$ at $23^{\circ} \mathrm{C}$ .16

Table 5. Experimental Conditions and Measured Apparent Dissolution Rates of NaSiO- $x \mathrm{Al}$ Glasses in Silica-saturated $\mathrm{D}_{2} \mathrm{O}$ Solution at $\mathrm{pD}=8,23^{\circ} \mathrm{C}$

Table 6. Parameters for Calculating Activation Enthalpy and Sodium Ion Exchange Rate

Table 7. Results obtained from curve fitting ${ }^{29} \mathrm{Si}$ NMR spectra obtained for some of the glasses studied here along with some literature values.

Table 8. Metrical Na-O structural parameters derived from the Na K-edge EXAFS of Series II glasses.....

Table 9. Proportion of tetrahedral boron $\left({ }^{\mathrm{iv}} \mathrm{B}\right)$ derived from peak-fitting of the B K edge TEY NEXAFS Spectra Using the Method in Ref. [33]...

Table 10. Calculated Distribution (mol fraction) of Mineral Analog Moieties in Series I, II, and II Glasses and Calculated ${ }^{29}$ Si NMR Chemical Shift Based on Rule of Mixtures Model .....29

Table 11. Proportion of tetrahedral boron derived from peak-fitting of the B K edge fluorescence yield NEXAFS spectra from the BAS- $x$ Hf glass series with increasing Hf content using the method in Ref. [33] and normalization to a $72.5 \%{ }^{\text {iv }} \mathrm{B}$ content in glass BAS-0Hf 


\section{INTRODUCTION}

Leaching of alkalis from glass is widely recognized as an important mechanism in the initial stages of glass-water interactions. Pioneering experimental studies [1-3] nearly thirty-five years ago established that alkali (designated as $\mathrm{M}^{+}$) are lost to solution more rapidly than network-forming cations. The overall chemical reaction describing the process can be written as:

$$
\equiv \mathrm{Si}-\mathrm{O}-\mathrm{M}+\mathrm{H}^{+} \rightarrow \equiv \mathrm{Si}-\mathrm{OH}+\mathrm{M}^{+}
$$

or

$\equiv \mathrm{Si}-\mathrm{O}-\mathrm{M}+\mathrm{H}_{3} \mathrm{O}^{+} \rightarrow \equiv \mathrm{Si}-\mathrm{OH}+\mathrm{M}^{+}+\mathrm{H}_{2} \mathrm{O}$.

Doremus and coworkers [4-7] fashioned a quantitative model where $\mathrm{M}^{+}$ions in the glass are exchanged for counter-diffusing $\mathrm{H}_{3} \mathrm{O}^{+}$or $\mathrm{H}^{+}$. Subsequent investigations [8], which have relied heavily on reaction layer analysis, recognized the role of $\mathrm{H}_{2} \mathrm{O}$ molecules in the alkali-exchange process, without minimizing the importance of charged hydrogen species.

Beginning in the 1980s, however, interest in $\mathrm{M}^{+}-\mathrm{H}^{+}$exchange reactions in silicate glasses diminished considerably because important experimental observations showed that network hydrolysis and dissolution rates were principally controlled by the chemical potential difference between the glass and solution (chemical affinity) [9]. For nuclear waste glasses, formation of alteration products or secondary phases that remove important elements from solution, particularly $\mathrm{Si}$, was found to have very large impacts on glass dissolution rates [10,11]. Consequently, recent work on glass/water interactions has focused on understanding this process and incorporating it into models [12]. The ionexchange process has been largely ignored because it has been thought to be a short duration, secondary or tertiary process that had little or no bearing on long-term corrosion or radionuclide release rates from glasses [13].
The only significant effect identified in the literature that is attributed to alkali ion exchange is an increase in solution $\mathrm{pH}$ in static laboratory tests conducted at high surface area-to-volume ratios $[14,15]$.

Renewed interest in alkali ion exchange reactions has come about because of interest in development of durable Na-rich silicate glasses for immobilization of low-activity waste (LAW) at Hanford, Washington [16] and high-level wastes in China [17]. In reactive transport simulations of a LAW glass disposed in a shallow subsurface facility, Chen, McGrail, and Engel [18] showed that ion-exchange reactions increased the radionuclide release rate by over two orders of magnitude when compared with simulations where ion exchange was excluded. Sheng, Luo, and Tang [17] conducted static tests in a simulated groundwater and showed that alkali ion exchange was the dominant release mechanism over a large temperature range.

Although the significance of alkali ionexchange reactions in long-term disposal system performance has now been recognized, the fundamental processes and mechanisms controlling the exchange reactions are still remarkably poorly understood, especially with regard to how glass structure affects alkali ion exchange kinetics. Experimental studies of Na release from various simple silicate glasses are numerous [19-23]. However, in all previous studies of which we are aware, no attempt was made to distinguish between $\mathrm{M}^{+}$release through alkali exchange versus matrix dissolution. The release rate of alkali in all of the early work was convoluted by contributions from matrix dissolution, which dominates in dilute solutions. Also, none of the previous studies attempted to define the relationship, if any, between glass structure (composition) and the kinetics of the ionexchange reaction. The motivation behind 
this Environmental Management Science Project (EMSP) is to develop a better understanding of how glass structure impacts sodium ion exchange so that improved glasses can be developed. Development of low ion-exchange rate glasses may also permit engineers to use higher loadings in nuclear waste glasses, which would result in substantial savings in production and disposal costs.
This report summarizes the experimental data, and the interpretation and analysis of this data that was collected over the duration of the project from 1997 to 2001 . Three silicate glass systems were investigated: 1) $\mathrm{Na}_{2} \mathrm{O}-\mathrm{Al}_{2} \mathrm{O}_{3}-\mathrm{SiO}_{2}$ system, 2) $\mathrm{Na}_{2} \mathrm{O}-\mathrm{B}_{2} \mathrm{O}_{3}-$ $\mathrm{SiO}_{2}$ system, and the 3) $\mathrm{Na}_{2} \mathrm{O}-\mathrm{Al}_{2} \mathrm{O}_{3}-\mathrm{B}_{2} \mathrm{O}_{3^{-}}$ $\mathrm{HfO}_{2}-\mathrm{SiO}_{2}$ system. 



\section{EXPERIMENTAL METHODS}

\section{GLASS FORMULATION AND CHARACTERIZATION}

The objective of the glass formulation scheme used in this work was to allow for sufficient variation in the distribution of $\mathrm{Na}^{+}$ between ${ }^{\mathrm{Q} 3} \mathrm{Si}$ and ${ }^{\mathrm{Q}} \mathrm{Si}$ non-bridging oxygens, four-coordinated $\mathrm{B}^{3+}$, and four-coordinated $\mathrm{Al}^{3+}$ to assess the affect of glass structure and the local environment of sodium on the rate that $\mathrm{Na}$ could be removed from the glass via alkali ion exchange. The first set of glasses (Series I) consisted of four glasses in the $\mathrm{Na}_{2} \mathrm{O}-\mathrm{Al}_{2} \mathrm{O}_{3}-\mathrm{SiO}_{2}$ system along the sodium disilicate $\left(\mathrm{Na}_{2} \mathrm{O} \cdot 2 \mathrm{SiO}_{2}\right)-\mathrm{NaAlO}_{2}$ join as illustrated in Figure 1 and designated as $\mathrm{Na}$ $\mathrm{SiO}-x \mathrm{Al}$ glasses, where $x$ refers to the mol\% $\mathrm{Al}_{2} \mathrm{O}_{3}$. The glass compositions (see Table 2) vary in $\mathrm{Al}_{2} \mathrm{O}_{3}$ content between 0 and $15 \mathrm{~mol} \%$ while keeping the ratio of ${ }^{\mathrm{Q} 3} \mathrm{Si}$ [silicate sites with one non-bridging oxygen (NBO) charge compensated by $\mathrm{Na}^{+}$] to ${ }^{\mathrm{Q}} \mathrm{Si}$ (bridging oxygen site) near unity. This was done to monitor the effect of decreasing concentration of NBO sites as the available $\mathrm{Na}^{+}$is used to form network repolymerizing $\mathrm{AlO}_{2} \mathrm{Na}\left({ }^{\mathrm{iv}} \mathrm{Al}\right)$ tetrahedral sites without changing the overall ratio of ${ }^{\mathrm{Q} 3} \mathrm{Si} /{ }^{\mathrm{Q} 4} \mathrm{Si}$ in the glass. These glasses were also doped with a small amount of Mo (0.1 $\mathrm{mol} \% \mathrm{MoO}_{3}$ ) that was used as a tracer of matrix dissolution. Molybdenum was selected because it is quite soluble under oxidizing conditions and the predominant aqueous species at $\mathrm{pH}>5$ is $\mathrm{MoO}_{4}{ }^{2-}$, which will not adsorb to the negatively charged surface of silicate glass. Molybdenum can also be detected to $<1$ ppb using inductively coupled plasma mass spectrometry (ICP-MS).

The Series II set of glasses (shown in Figure 1) was formulated along the join between $\mathrm{Na}_{2} \mathrm{O} \cdot 2 \mathrm{SiO}_{2}$ and reedmergnerite (RE), $\mathrm{NaBSi}_{3} \mathrm{O}_{8}$ or $\mathrm{Na}_{2} \mathrm{O} \cdot \mathrm{B}_{2} \mathrm{O}_{3} \cdot 6 \mathrm{SiO}_{2}$ and along the join between reedmergnerite and sodium metaborate $\left(\mathrm{Na}_{2} \mathrm{O} \cdot \mathrm{B}_{2} \mathrm{O}_{3}\right)$. The end-member

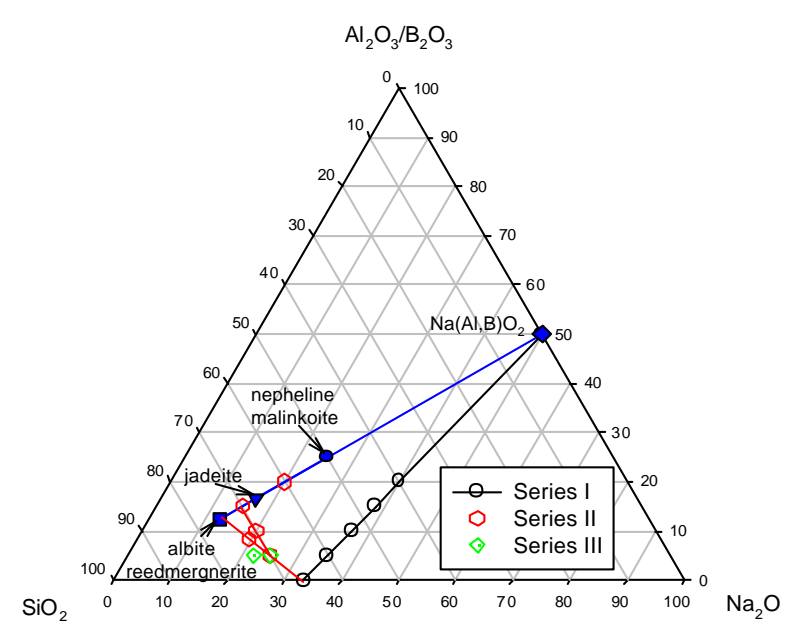

Figure 1. Composition Space Investigated for Series I and Series II Glasses

composition in this series corresponds to mineral malinkoite $\left(\mathrm{NaBSiO}_{4}\right)$ [24].

The final set of glasses (Series IV), was prepared in the $\mathrm{Na}_{2} \mathrm{O}-\mathrm{Al}_{2} \mathrm{O}_{3}-\mathrm{B}_{2} \mathrm{O}_{3}-\mathrm{HfO}_{2}-\mathrm{SiO}_{2}$ system according to the formula

$$
\begin{aligned}
& (1-n) \mathrm{Na}_{2} \mathrm{O} \cdot \frac{1}{4}(1-n) \mathrm{Al}_{2} \mathrm{O}_{3} . \\
& \frac{3}{4}(1-n) \mathrm{B}_{2} \mathrm{O}_{3} \cdot 5 n \mathrm{HfO}_{2} \cdot 3(1-n) \mathrm{SiO}_{2}
\end{aligned}
$$

where $0 \leq n \leq 0.2$. The intent in this series was to examine the effect of substitution of $\mathrm{HfO}_{2}$, which is a chemical analog of $\mathrm{Zr}$ that has a $\mathrm{pK}_{\mathrm{a}}$ over 17 versus 9.5 for $\mathrm{SiO}_{2}$ [25]. Similar glasses have been studied as part of a separate EMSP project examining solubility effects in glasses for $\mathrm{Pu}$ immobilization where Hf is a strong neutron absorber [26]. Table 1 provides the specific as-batched composition for each of the glasses examined in this study. 
Table 1. Glass Compositions Examined in this Study Along with ${ }^{29} \mathrm{Si}$ NMR Results

\begin{tabular}{|c|c|c|c|c|c|c|}
\hline \multirow[t]{2}{*}{ Glass ID } & \multicolumn{5}{|c|}{$\begin{array}{c}\text { Composition } \\
(\mathrm{mol} \%)\end{array}$} & \multirow{2}{*}{$\begin{array}{c}\text { Ave. }{ }^{29} \text { Si Peak } \\
\text { Position } \\
(\mathrm{ppm})^{(\mathrm{a})}\end{array}$} \\
\hline & $\mathrm{Na}_{2} \mathrm{O}$ & $\mathrm{Al}_{2} \mathrm{O}_{3}$ & $\mathrm{~B}_{2} \mathrm{O}_{3}$ & $\mathrm{HfO}_{2}$ & $\mathrm{SiO}_{2}$ & \\
\hline \multicolumn{7}{|l|}{ Series I } \\
\hline $\mathrm{NaSiO}-0 \mathrm{Al}$ & 33.30 & - & - & - & 66.60 & $-87 \pm 1$ \\
\hline $\mathrm{NaSiO}-5 \mathrm{Al}$ & 34.96 & 5.00 & - & - & 59.94 & $-86 \pm 1$ \\
\hline NaSiO-10Al & 36.63 & 10.00 & - & - & 53.28 & $-81 \pm 1$ \\
\hline NaSiO-15Al & 38.29 & 15.00 & - & - & 46.62 & $-78 \pm 1$ \\
\hline \multicolumn{7}{|l|}{ Series II } \\
\hline $\mathrm{NaBSi}-\mathrm{RD}_{40}$ & 25.00 & - & 5.00 & - & 70.00 & $-94 \pm 1$ \\
\hline NaBSi-RD 66 & 19.44 & - & 8.34 & - & 72.22 & \\
\hline NaBSi-RD ${ }_{100}$ & 12.50 & - & 12.50 & - & 75.00 & \\
\hline $\mathrm{NaBSi}-\mathrm{MB}_{0.03}$ & 20.00 & - & 10.00 & & 70.00 & $-96 \pm 1$ \\
\hline NaBSi-MB 0.07 & 15.00 & - & 15.00 & - & 70.00 & $-100 \pm 1$ \\
\hline $\mathrm{NaBSi}_{-} \mathrm{MB}_{20}$ & 20.00 & - & 20.00 & - & 60.00 & \\
\hline $\mathrm{NaBSi}^{-\mathrm{MB}_{33}}$ & 25.00 & - & 25.00 & - & 50.00 & \\
\hline \multicolumn{7}{|l|}{ Series III } \\
\hline BAS-1 & 22.00 & 2.50 & 2.50 & - & 73.00 & $-97 \pm 1$ \\
\hline BAS-2 & 22.00 & - & 5.00 & - & 73.00 & $-96 \pm 1$ \\
\hline BAS-3 & 22.00 & 5.00 & - & - & 73.00 & $-95 \pm 1$ \\
\hline BAS-4 & 22.00 & - & - & - & 78.00 & $-97 \pm 1$ \\
\hline BAS-5 & 25.00 & 2.50 & 2.50 & - & 70.00 & $-92 \pm 1$ \\
\hline BAS-6 & 25.00 & 5.00 & - & - & 70.00 & $-93 \pm 1$ \\
\hline \multicolumn{7}{|l|}{ Series IV } \\
\hline BAS-OHf & 20.00 & 5.00 & 15.00 & 0.00 & 60.00 & \\
\hline BAS-5Hf & 19.00 & 4.75 & 14.25 & 5.00 & 57.00 & \\
\hline BAS-10Hf & 18.00 & 4.50 & 13.50 & 10.00 & 54.00 & \\
\hline BAS-15Hf & 17.00 & 4.25 & 12.75 & 15.00 & 51.00 & \\
\hline BAS-20Hf & 16.00 & 4.00 & 12.00 & 20.00 & 48.00 & \\
\hline
\end{tabular}

\section{Glass Preparation}

Each of the glasses were batched in $100+$ gram quantities using reagent grade $\mathrm{Al}_{2} \mathrm{O}_{3}$, $\mathrm{MoO}_{3}, \mathrm{Na}_{2} \mathrm{CO}_{3}, \mathrm{H}_{3} \mathrm{BO}_{3}, \mathrm{HfO}_{2}$, and $\mathrm{SiO}_{2}$ and melted to as high as $1,500^{\circ} \mathrm{C}$ for 1 hour in air in a covered Pt-Rh crucible, then quenched on a stainless steel plate. The resulting material was ground and re-melted in a covered Pt-Rh crucible. After an additional hour at melt temperature, the melt was poured into a mold to yield bars with approximate dimensions of $1.5 \mathrm{~cm} \times 1.5 \mathrm{~cm} \times 3.8 \mathrm{~cm}$. The bars were then annealed for 2 hours in a box furnace at a temperature of $560-570^{\circ} \mathrm{C}$, depending on the glass composition. After the $2 \mathrm{hr}$ anneal, the furnace was turned off and the bars allowed to cool to ambient temperature overnight. All melts were visually homogeneous, readily pourable, and yielded a clear, visibly homogenous glass.

For tests where glass coupons were used, the surface area of the specimen was calculated from measurements of the dimensions of coupon. Coupons were cut from glass bars on an Isomet saw with dimensions approximately $20 \mathrm{~mm} \times 20 \mathrm{~mm} \times 1 \mathrm{~mm}$ and polished using 
200 grit sandpaper. Coupons that were used for reaction layer analysis were given an additional polish with $\mathrm{CeO}_{2}(<1 \mu \mathrm{m})$ paste. Measurements of the coupon dimensions were performed using an electronic caliper. Because the mass of the specimen could also be easily measured, we were able to calculate the apparent density of the glass. The value of the density could then be compared against the density of the glass determined by independent methods (Archimedes or $\mathrm{Hg}$ pycnometry). In all cases, the calculated density was within $5 \%$ of the measured density of the glass.

For tests where crushed glass was used, a ceramic ball mill produced the samples of glass powders used in this study. The crushed glass was sieved to separate the particles into a variety of size fractions; in this study, only the 149 to $75 \mu \mathrm{m}$ diameter $(-100+200 \mathrm{mesh})$ size fraction was used. Powdered samples were then sonicated in deionized water (DIW) and rinsed in ethanol to remove any adhering particles outside the desired size fraction. After drying in a $90^{\circ} \mathrm{C}$ oven for several hours, the powder was kept in a desiccator until used in an experiment. The specific surface area of the glass samples was estimated based on the following geometric formula [27]:

$$
s=\frac{3 m}{\rho r}
$$

where $m$ is the mass of glass particles $(\mathrm{g}), \rho$ is the glass density $\left(\mathrm{g} \mathrm{m}^{-3}\right)$, and $r$ is the average particle radius in meters. Applying this formula for glasses in this size fraction yields a specific surface area of $0.020 \pm 0.003 \mathrm{~m}^{2} / \mathrm{g}$. McGrail et al. [28] discuss experiments with similar glass compositions conclusively showing that the surface area estimated from Equation (4) more accurately represents the true surface area in dissolution tests than the surface area determined by BET methods.

\section{NMR Characterization}

Room temperature ${ }^{11} \mathrm{~B},{ }^{29} \mathrm{Si}$ and ${ }^{27} \mathrm{Al}$ magic angle spinning nuclear magnetic resonance (MAS-NMR) spectra were obtained on a Varian VXR-300 spectrometer at $7.05 \mathrm{~T}$ using high-speed probes manufactured by Doty Scientific, Inc. Silicon nitride rotors (5 $\mathrm{mm}$ diameter) or sapphire rotors $(7 \mathrm{~mm} \mathrm{d-}$ ameter) with Vespel or Kel-F polymer end caps were used.

Boron-11 spectra were collected at 96.23 $\mathrm{MHz}$ using a single pulse excitation (SPE) of $5.0 \mu \mathrm{s}$, with a delay of $30 \mathrm{~s}$. Samples were spun at $10 \mathrm{kHz}$ in $\mathrm{Si}_{3} \mathrm{~N}_{4}$ rotors. Borax (disodium tetraborate) was used as an external chemical shift standard.

Silicon-29 spectra were collected at 59.59 $\mathrm{MHz}$ using a SPE of $8.0 \mu$ s with a pulse delay of $60 \mathrm{~s}$. Samples were typically spun at 4.5 $\mathrm{kHz}$. The ${ }^{29} \mathrm{Si}$ NMR peak associated with the $\mathrm{Si}_{3} \mathrm{~N}_{4}$ rotor was in a considerably different position from that of the glass samples, and was used in some cases as an "internal" chemical shift standard. Tetrakis (trimethylsilyl) silane was used in other cases as an additional internal chemical shift standard with the sapphire rotor.

Aluminum-27 spectra were collected at $78.15 \mathrm{MHz}$ with an SPE of $5.0 \mu$ s and a pulse delay of $0.5 \mathrm{~s}$. Spectra were taken in either the $5 \mathrm{~mm}$ or $7 \mathrm{~mm}$ probes and spun at $10 \mathrm{kHz}$ or $4.5 \mathrm{kHz}$, respectively. Corundum was used as an external chemical shift standard for the ${ }^{27} \mathrm{Al}$ spectra.

\section{XAFS Characterization}

Soft x-ray synchrotron radiation (SR) $\mathrm{x}$ ray absorption fine structure (XAFS) techniques can provide element-specific information about the speciation of low $\mathrm{Z}$ constituents in a range of glass compositions. Many light element constituents (B, O, alkali metals, Al, and $\mathrm{Si}$ ) of glass present challenges for speciation since there is no long-range order, there- 
fore methodologies capable of nondestructively elucidating the local structural environments of these elements are particularly valuable. The respective core-electron binding energies (i.e., the $1 s$ or $K$ edges) of these elements reside in the soft $x$-ray region and are well-separated from one another. Thus, XAFS studies of the aforementioned glass constituents can be investigated by utilizing the third-generation Advanced Light Source (ALS) which is optimized in the soft $\mathrm{x}$-ray region.

Currently, structural issues in glasses with the low- $Z$ elements are investigated primarily by NMR [29,30], optical spectroscopy, scanning electron microscopy (SEM), and transmission electron microscopy (TEM) techniques [31]. The capability of the ALS to study these low- $Z$ species by XAFS furnishes essential information for sodium and provides complementary results to those obtained from NMR studies. However, the $\mathrm{K}$ edges of these elements in common formulations of waste form glasses have not been fully studied as a function of composition for glass materials [32-42]. Such studies will also develop means to conduct structural investigations of more complex glasses containing paramagnetic waste materials in the future.

The soft x-ray XAFS spectra were collected on Beamlines 8.0, 6.3.1, and 6.3.2 of the ALS at Lawrence Berkeley National Laboratory (LBNL). Sodium K edge (1071 $\mathrm{eV})$ spectra were collected on both undulator Beamline 8.0 and bend magnet Beamline 6.3.1. Boron K edge $(191 \mathrm{eV})$ spectra were recorded on undulator Beamline 7.0 and bend magnet Beamline 6.3.2. Oxygen K-edge $(531 \mathrm{eV})$ spectra were acquired on all beamlines with the exception of Beamline 6.3.2. The x-ray emission spectrometer end stations were employed on the undulator beamlines that both collect light downstream of spherical grating monochromators (SGM) and 5.0 $\mathrm{cm}$ period undulators $[43,44]$. Beamlines 6.3.1 and 6.3.2 utilize a variable line space
(VLS) monochromator on a bend magnet source and a multi-purpose end station [45]. A non-biased, solid state diode fluorescence detector was purchased and installed in Beamline 6.3.1 for the total fluorescence yield measurements at the $\mathrm{Na} \mathrm{K}$ edge.

The structural environment of sodium in glasses has received only limited study by the extended x-ray absorption fine structure (EXAFS) technique. The potential utility of the Na K-edge (1071 eV) EXAFS investigations was realized $[39,40,42,46]$ early in the study of glasses but technical difficulties in obtaining monochromatized synchrotron radiation (SR) in this energy region has limited its application.

Sodium K-edge EXAFS spectra were collected on Beamline 6.3.1 of the Advanced Light Source at Lawrence Berkeley National Laboratory. Beamline 6.3.1 utilizes a variable line space (VLS) monochromator on a bend magnet source to provide photons with energies from $100 \mathrm{eV}$ to $2200 \mathrm{eV}$ into a multipurpose endstation that is similar to the endstation on Beamline 6.3.2 [45]. All the glass specimens were powders pressed into In metal foils and then attached to the sample holders. Reference Na spectra were also collected from $\mathrm{NaNO}_{3}, \quad \mathrm{NaBrO}_{3}, \quad$ and $\mathrm{Na}_{2} \mathrm{SiO}_{3} \cdot 5 \mathrm{H}_{2} \mathrm{O}$ model materials prepared in a similar manner (obtained from Alfa Aesar). Spectra were collected at room temperature in the total electron yield (TEY) mode with the signal obtained from the sample drain current. No substantial charging problems were detected. The glasses had no appreciable surface reaction layers visible by optical microscopy and were kept in a desiccator prior to measurement.

The Na K-edge EXAFS spectra reported were recorded with a resolution of better than $1.0 \mathrm{eV}$ and typically consist of the average of five scans. Data was collected from $1045 \mathrm{eV}$ to $1300 \mathrm{eV}$ because the signal beyond 1300 $\mathrm{eV}$ did not have a useful signal to noise ratio 
and the glasses have trace amounts of $\mathrm{Mg}$ that caused interferences.

\section{XPS Characterization}

X-ray photoelectron spectroscopy (XPS) measurements were made on a Physical Electronics Quantum 2000 Scanning ESCA Microprobe. The glass coupons $(\approx 2 \mathrm{~mm} \mathrm{x} \approx 5$ $10 \mathrm{~mm} \mathrm{x} \approx 10 \mathrm{~mm}$ ) were mounted on a small stainless steel vice and then placed on the Quantum sample holder. The samples were scored at the vice surface and broken in the spectrometer when the vacuum was $3 \times 10^{-9}$ mbar or less. The Quantum uses a focused beam of monochromatic $\mathrm{Al} \mathrm{K} \alpha$ x-rays $(1486.7 \mathrm{eV})$ for excitation and a spherical section analyzer. The instrument has a 16element multichannel detection system. The x-ray beam was $35 \mathrm{~W}$ with a $200 \mu \mathrm{m}$ diameter beam spot. The $\mathrm{x}$-ray beam is incident normal to the sample and the $\mathrm{x}$-ray detector is at $45^{\circ}$ away from the normal. The areas to be analyzed were identified by looking at the secondary electron image generated by scanning the x-ray beam over the fractured surface. High energy-resolution multplex scans were collected using a pass energy of 23.5 $\mathrm{eV}$. For the $\mathrm{Ag} 3 \mathrm{~d} 5 / 2$, these conditions produce FWHM of better than $0.75 \mathrm{eV}$.

The spectrometer is calibrated to an energy scale with binding energies for $\mathrm{Cu} 2 \mathrm{p} 3 / 2$ at $932.67 \pm 0.05 \mathrm{eV}$ and $\mathrm{Au} 4 \mathrm{f}$ at $84.0 \pm 0.05$ $\mathrm{eV}$. Because the glasses tend to build up a surface charge, the advanced neutralization system available in the Quantum involving both low energy electrons and argon ions was used to set a stable potential on the specimen surface for analysis. It has been demonstrated by several workers that best line shapes and most stable signals are produced when the surface charge is "over compensated" resulting in a shift of the apparent binding energies to low values. To correct for this over compensation, all peaks are referenced to the $\mathrm{Si}$ $2 \mathrm{p}$ peak assumed to be at $102.7 \mathrm{eV}$ for all samples used in this study, consistent with commonly used methods [47]. Although we were not focused on quantification of the elements, it appeared that $\mathrm{Na}$ sensitivity factors in the Quantum 2000 were somewhat inconsistent with the expected compositions of the glasses. Therefore a $\mathrm{NaCl}$ standard was run to derive a new sensitivity factor for use in this work.

Although observations of peak shifts as a function of composition is relatively straight forward, a significant portion of our interest was looking at the $\mathrm{O} 1 \mathrm{~s}$ photopeaks. This region of the spectra involves peaks associated with $\mathrm{Si}-\mathrm{O}-\mathrm{Na}, \mathrm{Si}-\mathrm{O}-\mathrm{Al}$, and $\mathrm{Si}-\mathrm{O}-\mathrm{Si}$ peaks. Because of peak overlap, the interesting information about these peaks requires use of a fitting procedure. We used the non-linear least squares fitting program contained in the Phi Multipak program (version 6.1A) that is associated with the Quantum 2000. Because peak fitting involves a significant number of assumptions, these details will be discussed later.

\section{SINGLE-PASS FLOW-THROUGH EXPERIMENTS}

The kinetics of glass matrix dissolution and $\mathrm{Na}$ ion exchange were determined by single pass flow-through (SPFT) experiments. Two different types of reactors were utilized,

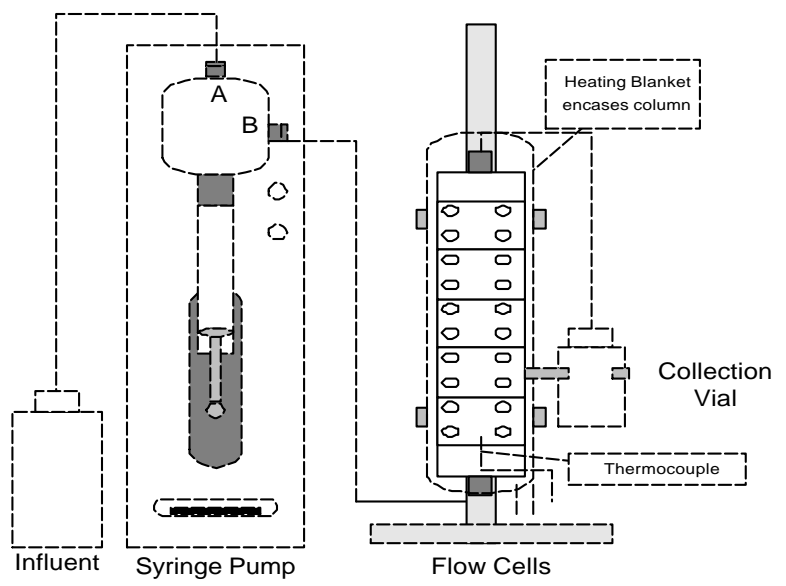

Figure 2. Schematic of Multichamber FlowThrough Column for Ion-Exchange Kinetics Tests 
depending on the nature of the experiment. For experiments in which reaction layer analyses were anticipated (see Ref. [48] for details), we utilized the multi-cell SPFT system shown in Figure 2. Glass coupons (up to five) were placed into a column machined from polyetheretherketone (PEEK) containing five individual cells. Each coupon is situated diagonally within a cell to maximize the exposed surface area. The cells are interconnected by a $1 / 16^{\text {th }}$-inch diameter port that passes from the bottom to the top of the column, allowing solutions to flow from the reservoir, past each coupon, and out of the column into the sample collection vial. In this manner, the solution reacts with the glass samples and individual coupons can be removed from the column for reaction layer analysis without disrupting the other coupons. In experiments for which only reaction kinetics were sought, we utilized standard Teflon $\mathrm{PFA}^{(\mathrm{a})}$ reactors of approximately $40 \mathrm{~mL}$ internal volume. The top cap contains two ports that accommodate $1 / 16^{\text {th }}$ inch Teflon tubing for the ingress and egress of solution. Glass coupons (up to five) were placed horizontally on a Teflon basket, and submerged within the reactor. The baskets are grated, allowing the maximum amount of coupon surface area to be exposed to solution.

\section{Solutions}

Experiments were performed under controlled conditions of constant $\mathrm{pH}$, temperature, and solution composition. Solutions were made from either $\mathrm{H}_{2} \mathrm{O}$ or $\mathrm{D}_{2} \mathrm{O}$. THAM (tris hydroxymethyl aminomethane) was added to $\mathrm{H}_{2} \mathrm{O}$ and $\mathrm{D}_{2} \mathrm{O}$ to make either 0.01 or $0.05 \mathrm{M}$ TRIS buffered solutions. Ultra-pure nitric acid was then added to the $\mathrm{H}_{2} \mathrm{O}$ solution to bring the solution $\mathrm{pH}$ to the desired value of 8 . In the case of $\mathrm{D}_{2} \mathrm{O}$ solutions, $\mathrm{DCl}$ was added to manipulate $\mathrm{pD}$. Measured solution $\mathrm{pH}$ was corrected for the offset in electrode

\footnotetext{
${ }^{(a)}$ Perfluoroalkoxy polymer of Teflon
}

reference junction potential in $\mathrm{D}_{2} \mathrm{O}$ by the formula $\mathrm{pD}=\mathrm{pH}+0.4$ [49]. In all cases, we set $\mathrm{pH}=\mathrm{pD}=8$.

For most of our experiments, silicon was added to all input solutions such that they were slightly oversaturated with respect to amorphous silica, thereby minimizing glass matrix hydrolysis and dissolution and maximizing the signal from the $\mathrm{Na}$ ion-exchange reaction. Silicon was added in the form of silicic acid powder $\left(\mathrm{SiO}_{2} \cdot 2 \mathrm{H}_{2} \mathrm{O}\right)$, which required heating to $87^{\circ} \mathrm{C}$ for at least three days to facilitate complete dissolution. The amount of Si added to the solutions depended on the temperature of the experiment. Silicon was added to solution as a percentage of saturation with respect to amorphous silica. In other words, $\left(\mathrm{a}_{\mathrm{H} 4 \mathrm{SiO}_{4}} / \mathrm{a}^{*}{ }_{\mathrm{H} 4 \mathrm{SiO} 4}\right) \times 100$, where $\mathrm{a}_{\mathrm{H} 4 \mathrm{SiO} 4}$ is the activity of silicic acid in solution, $\mathrm{a}^{*}{ }_{\mathrm{H} 4 \mathrm{SiO} 4}$ is the concentration of silicic acid in equilibrium with amorphous silica, $\mathrm{SiO}_{2}(\mathrm{am})$. For example, because $\mathrm{a}_{\mathrm{H} 4 \mathrm{SiO} 4}$ increases with temperature, a solution that is within $10 \%$ saturation at $23^{\circ} \mathrm{C}$ is far less saturated when the temperature is raised to $90^{\circ} \mathrm{C}$. Therefore, the range of $\mathrm{Si}$ concentrations added to solutions varied from approximately 10 to 150 ppm Si.

For a select set of experiment, $\mathrm{Al}$ was also added to the input solutions. Aluminum was added in the form of water soluble $\mathrm{Al}\left(\mathrm{NO}_{3}\right)_{3} \cdot 9 \mathrm{H}_{2} \mathrm{O}$, which rapidly dissolved leaving no residue. These solutions calculate as being supersaturated with respect to polymorphs of $\mathrm{Al}(\mathrm{OH})_{3}$ (e.g., gibbsite), especially in experiments with solutions that were nearneutral $\mathrm{pH}$. As in the case of silicon, the amount of aluminum added depended upon the temperature of the experiment but can be summarized as from 10 to $150 \mu$ molal Al.

\section{Release Rate Calculation}

Experiments were terminated when the concentrations of elements in the effluent solution became invariant with respect to time 
(steady-state conditions). Typically, this would take from one to three weeks, depending upon the temperature of the experiments. For example, in order for boron concentrations to exceed its detection threshold, flowthrough rates for experiments at $23^{\circ} \mathrm{C}$ were relatively slow $\left(<20 \mathrm{~mL} \mathrm{~d}^{-1}\right)$. In contrast, the concentration of boron in experiments at $40^{\circ} \mathrm{C}$ was typically well above detection threshold, even with flow-through rates as fast as $60 \mathrm{~mL}$ $\mathrm{d}^{-1}$. Since it typically takes exchange of seven reactor volumes to achieve steady-state conditions [50,51], the duration of an experiment at $23^{\circ} \mathrm{C}$ is longer than that at $40^{\circ} \mathrm{C}$.

Reaction kinetics was calculated from effluent samples analyzed for concentrations of $\mathrm{Na}, \mathrm{Al}, \mathrm{B}$, and Si using inductively coupled plasma optical emission spectroscopy (ICPOES) and Mo with ICP-MS. Normalized element release rates are calculated from the expression:

$$
r_{i}=\frac{\left(c_{i}^{\text {out }}-c_{i}^{\text {in }}\right) q}{f_{i} S}
$$

where

$r_{i}=$ normalized rate of release of element $i$ per unit area of glass $\left(\mathrm{g} \mathrm{m}^{-2} \mathrm{~d}^{-1}\right)$

$c_{i}^{\text {out }}=$ the concentration of element $i$ in the effluent $(\mathrm{g} / \mathrm{L})$

$c_{i}^{i n}=$ the concentration of element $i$ at input $(\mathrm{g} / \mathrm{L})$

$q=$ solution flow-through rate $(\mathrm{L} / \mathrm{d})$

$f_{i}=$ the fraction of element $i$ in glass (dimensionless)

$S=$ the surface area of the glass sample $\left(\mathrm{m}^{2}\right)$.

The background concentration of the element of interest is determined, as previously discussed, by analyses of the starting input solution and the blank solutions. Typically, background concentrations of elements are below their respective detection threshold.
The detection threshold of any element is defined here as the lowest calibration standard that can be determined reproducibly during an analytical run within $10 \%$. Therefore, the detection threshold can be higher or lower for the same element on two separate analytical runs. For example, the detection threshold for boron may be as high as 100 ppb (parts per billion) or as low as $5 \mathrm{ppb}$, depending how well the ICP-OES instrument operates on any particular day. In cases where the analyte is below the detection threshold, the background concentration of the element is set at the value of the detection threshold.

Uncertainty estimates for the calculated rates were determined by standard error propagation methods, assuming uncorrelated random errors. In this case, the standard deviation of a function $f\left(x_{1}, x_{2}, \ldots x_{\mathrm{n}}\right)$ is given by:

$$
\sigma_{f}=\sqrt{\sum_{i=1}^{n}\left(\frac{\partial f}{\partial x_{i}}\right)^{2} \sigma_{i}^{2}}
$$

where

$\sigma_{f}=$ standard deviation of the function $f$

$x_{i}=$ parameter $i$

$\sigma_{i}=$ standard deviation of parameter $i$.

Substituting (5) into (6) and converting to relative standard deviation, $\sigma_{r} / r$, gives:

$\hat{\sigma}_{r}=\sqrt{\frac{\left(\hat{\sigma}_{c} c_{i}^{\text {out }}\right)^{2}+\left(\hat{\sigma}_{b} c_{i}^{\text {in }}\right)^{2}}{\left(c_{i}^{\text {out }}-c_{i}^{\text {in }}\right)^{2}}+\hat{\sigma}_{q}^{2}+\hat{\sigma}_{f_{i}}^{2}+\hat{\sigma}_{S}^{2}}$

Relative errors $\hat{\sigma}_{c}, \hat{\sigma}_{b}, \hat{\sigma}_{q}, \hat{\sigma}_{f_{i}}$, and $\hat{\sigma}_{S}$ are estimated at 10\%, 10\%, 5\%, 3\%, and $15 \%$, respectively. Although the relative error in $f_{i}$ is likely to be significantly higher than $3 \%$, this error is non-systematic and so does not contribute significantly to sample-tosample uncertainty, which is the principal error of interest here. In experiments using coupons rather than powders, the surface area of the glass specimen is better known than 
that of the powders. Therefore, $\hat{\sigma}_{S}$ in tests using coupons is approximately 5\%. The conservative appraisal of errors assigned to the parameters in Equation (7), in addition to the practice of imputing detection threshold values to background concentrations, results in maximum uncertainties of approximately $\pm 35 \%$ on the dissolution rate. In many cases, however, the experimental uncertainty is on the order of $\pm 20 \%$ relative.

Because the dissolution rate is sensitive to the concentration of dissolved $\mathrm{Si}$ in solution, we analyzed all effluent solutions for silicon to ensure the experiments remained supersaturated with respect to amorphous silica. To further ensure the accuracy of our dissolution rates, we ran one blank reactor alongside the reactors containing glass samples. In this way, we were able to keep a running blank throughout the duration of the experiment. The input solutions were found to contain trace amounts (0.5 ppb, average) of Mo, which originated from the organic THAM buffer. Continuous monitoring of the Mo concentrations in the running blanks therefore became important, especially when evaporation of the input solution in the reservoir during long-term dissolution experiments caused Mo concentrations to rise. Concentrations of $\mathrm{Na}$ and $\mathrm{Al}$ in the blank solution samples were below their respective detection thresholds.

Even in a silica-saturated solution, silicate glasses continue to dissolve at a slow but finite rate because of the inherent thermodynamic instability of the glasses when contacted by water. Sodium release into solution therefore results from both glass matrix dissolution and ion exchange. Calculation of the $\mathrm{Na}$ release rate from ion exchange was performed by subtracting the Na release contribution from matrix dissolution from the total $\mathrm{Na}$ release rate. Matrix dissolution rate was indexed by the rate of Mo release for the boron-free $\mathrm{NaSiO}-x \mathrm{Al}$ glasses and by $\mathrm{B}$ release for the borosilicate glasses. 


\section{RESULTS: SERIES I GLASSES}

\section{NMR RESULTS}

As with other low-level waste based glass compositions studied by this group [52], each of the glasses studied here exhibited only a single, broad, asymmetric ${ }^{27} \mathrm{Al}$ NMR peak at $\sim 61 \pm 1 \mathrm{ppm}$. A peak at this position is indicative of tetrahedrally coordinated $\mathrm{Al}$ as opposed to octahedrally coordinated Al that occurs at $12 \mathrm{ppm}$. These ${ }^{27} \mathrm{Al}$ NMR results confirm that all of the $\mathrm{Al}$ in these glasses $\propto c$ curs as tetrahedrally coordinated network forming sites, presumably by association with charge compensating $\mathrm{Na}^{+}$ions.

The ${ }^{29} \mathrm{Si}$ MAS-NMR spectra obtained from the glasses studied consist of a broad resonance, due to the incompletely resolved presence of ${ }^{\mathrm{Q} 4} \mathrm{Si}$ and ${ }^{\mathrm{Q}} \mathrm{Si}$ sites [53]. For simplicity, the average ${ }^{29} \mathrm{Si}$ chemical shift from that of tetramethylsilane (TMS) for each sample was determined from the average of the integrated resonance. These data are displayed in Table 2 and indicate a progressive change in ${ }^{29} \mathrm{Si}$ chemical shift with Al-content.

Tetrahedrally coordinated ${ }^{\text {iv }} \mathrm{Al}$ (chemically represented by $\mathrm{AlO}_{2}{ }^{-}$) sites are chargecompensated through association with alkali

Table 2. XAS Results, and $\mathrm{Na}$ Ion-exchange Rate $\left(r_{x}\right)$ at $23^{\circ} \mathrm{C}, \mathrm{pH}=8$ for $\mathrm{NaSiO}-x \mathrm{Al}$ Glasses

\begin{tabular}{|c|c|c|c|c|}
\hline Glass ID & $\mathrm{Na}-\mathrm{O}$ & $\mathrm{Na}-\mathrm{O}$ & $\mathrm{Na}-\mathrm{O}$ & $r_{x}$ \\
\hline $\mathrm{NaSiO}-$ & $\mathrm{r}(\AA)^{*}$ & $\sigma(\AA)^{*}$ & $N^{* *}$ & $\left(\mathrm{~mol} \mathrm{~m}^{-2} \mathrm{~s}^{-1}\right)$ \\
\hline $0 \mathrm{Al}$ & 2.38 & 0.16 & 4.5 & $6.7 \times 10^{-6} \pm 3 \times 10^{-6}$ \\
\hline $5 \mathrm{Al}$ & 2.37 & 0.16 & 4.5 & $8.2 \times 10^{-7} \pm 3 \times 10^{-7}$ \\
\hline $10 \mathrm{Al}$ & 2.37 & 0.16 & 4.5 & $2.0 \times 10^{-8} \pm 8 \times 10^{-9}$ \\
\hline $15 \mathrm{Al}$ & 2.36 & 0.17 & 4.5 & $5.4 \times 10^{-9} \pm 2 \times 10^{-9}$ \\
\hline
\end{tabular}

*Error in the $\mathrm{r}(\AA)$ is $\pm 0.01 \AA$ relative and $\pm 0.02 \AA$ absolute, error in $\sigma$ is $\pm 0.02 \AA$, error in $N$ is \pm 0.6 .

${ }^{* * *} \mathrm{~N}$ represents the number of $\mathrm{O}$ neighbors within $\sigma$ of the average bond length not the total $\mathrm{Na}-\mathrm{O}$ coordination.
$\left(\mathrm{Na}^{+}\right)$cations. Any excess $\mathrm{Na}^{+}$ions are then likely associated with $\mathrm{NBO}$ sites such as ${ }^{\mathrm{Q} 3} \mathrm{Si}$ (e.g., $\mathrm{SiO}_{2.5} \mathrm{Na}$ ) and ${ }^{\mathrm{Q} 2} \mathrm{Si}$ (e.g., $\mathrm{SiO}_{3} \mathrm{Na}_{2}$ ). Based on the summary by Eckert [54] and the concentration of the sodium-gettering $\mathrm{Al}_{2} \mathrm{O}_{3}$ components in the glasses examined in this work, the distribution of silicon species will occur predominantly between ${ }^{\mathrm{Q} 4} \mathrm{Si}$ and ${ }^{\mathrm{Q} 3} \mathrm{Si}$ with much less than $10 \%$ as ${ }^{\mathrm{Q} 2} \mathrm{Si}$ and close to zero ${ }^{\mathrm{Q}} \mathrm{Si}$. For simplicity, we have assumed that silicon occurs as ${ }^{\mathrm{Q} 4} \mathrm{Si}$ and ${ }^{\mathrm{Q}} \mathrm{Si}$ species only. The $\mathrm{Na}^{+}$ions in these glasses are thus distributed between the ${ }^{\mathrm{Q}} \mathrm{Si} \mathrm{NBO}$ and ${ }^{\text {iv }} \mathrm{Al}$ sites.

\section{SODIUM XAFS RESULTS}

Figure 1 shows the Na K edge $x$-ray absorption near edge structure (XANES) spectra collected at Beamline 8.0 from the NaSiO- $x \mathrm{Al}$ glasses and for comparison, the spectrum from a very hydrous $\mathrm{Na}_{2} \mathrm{SiO}_{3} \cdot 5 \mathrm{H}_{2} \mathrm{O}$. These spectra resemble $\mathrm{Na}$ XANES collected in previous studies $[39,40,46]$ and exhibit the same general features. The resolution of the measurements resolves some of the spectral features, in particular the features on the lowenergy side of the white line peak. Both the energy position and magnitude of the XANES features remains the same as the $\mathrm{Al}$ content of the glass is increased. The XANES signal strength also properly tracks the $\mathrm{Na}$ concentrations of the glasses. Thus, solely from the XANES spectra, the local environment around the $\mathrm{Na}$ in the glasses appears remarkably similar. 


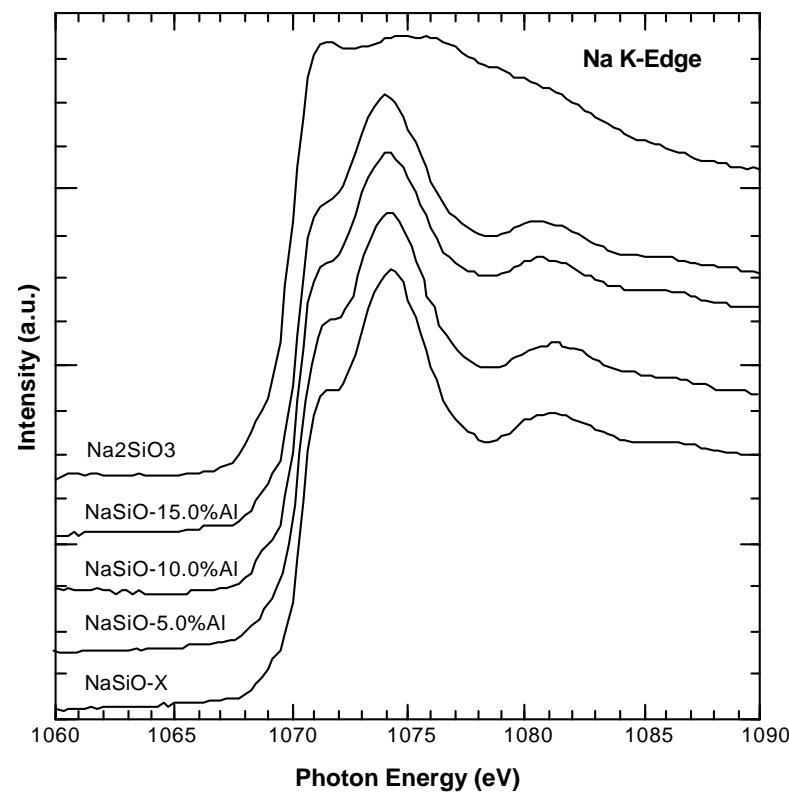

Figure 3. Sodium K edge XANES spectra collected at ALS Beamline 8.0 from the glasses and hydrated sodium silicate reference material in the total electron yield mode. The spectra have not had backgrounds removed and have been normalized to the amplitude of the largest feature, espectively.

The EXAFS data were processed and fit in real space using standard procedures $[55,56]$. However, since the data were collected in TEY and had a difficult background from inelastic contributions, the additional procedures of Erbil et al. [57] and Stohr [58] were followed. The EXAFS oscillations, $\chi(\mathrm{k})$, were calculated using the modified EXAFS equation given by Erbil et al. [57]. The data were transformed and fit in real space between 2.0 and $7.5 \AA^{-1}$, Gaussian narrowed by $0.3 \AA^{-1}$. The Fourier Transforms (FTs) of the $\mathrm{k}^{3} \chi(\mathrm{k})$ from the model compounds were as expected with the nearest neighbor $\mathrm{Na}-\mathrm{O}$ peak being the largest from the symmetric $\mathrm{NaO}_{6}$ octahedron in $\mathrm{NaNO}_{3}$, smaller for the distorted $\mathrm{NaO}_{6}$ octahedron in $\mathrm{NaBrO}_{3}$, and much smaller for the highly distorted five-fold coordinated $\mathrm{Na}$ in $\mathrm{Na}_{2} \mathrm{SiO}_{3} \cdot 5 \mathrm{H}_{2} \mathrm{O}$. The amplitude reduction factor, $\mathrm{S}_{0}{ }^{2}$, was obtained from fits of the better oriented model compounds, $\mathrm{NaNO}_{3}$ and $\mathrm{NaBrO}_{3}$, using phases and amplitudes gener-
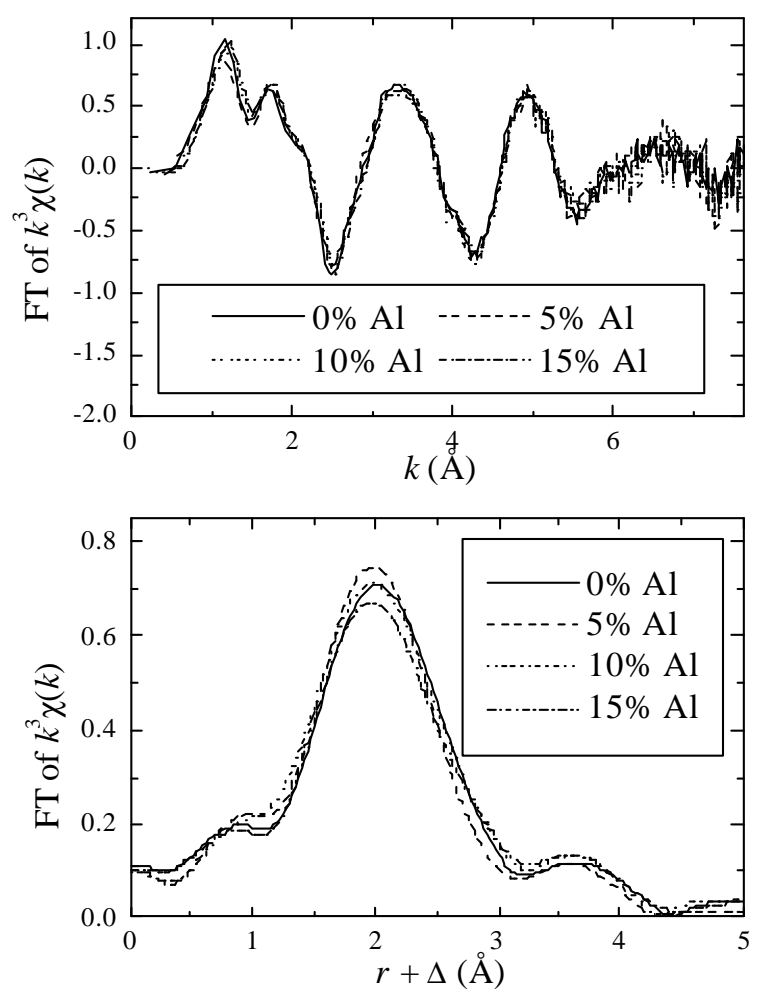

Figure 4. Na K-edge $\chi^{3}$-weighted EXAFS (upper) and Fourier Transforms (FTs) (lower) of the EXAFS collected on ALS Beamline 6.3.1 from the glasses. The FTs were taken over 2.0-7.5 $\AA^{-1}$ and Gaussian narrowed by $0.3 \AA^{-1}$.

ated from the FEFF8 code [59]. The amplitude ratios of the fitted pairs were constrained to those expected from the nominal crystal structures and included pairs up to the $\mathrm{Na}-\mathrm{Na}$ pair at about $4.05 \AA$. These fits were of good quality and $\mathrm{S}_{0}{ }^{2}$ was determined to be 0.31 \pm 0.03 . The small $S_{0}{ }^{2}$ appears to be unusual in comparison to those commonly measured in the x-ray region $[56,60]$. However, the apparatus used for this experiment is such that a measured $\mathrm{S}_{0}{ }^{2}$ can only apply to this given set of data, i.e. subsequent verification experiments have produced identical results to those reported here, except with different measures of $\mathrm{S}_{0}{ }^{2}$.

The Na K-edge $k^{3}$-weighted EXAFS and their respective FTs from each of the glasses are shown in Figure 4. Upon inspection, the raw EXAFS and real space data from the glasses is quite similar. The FTs have a large 
feature at a distance of about $2 \AA$ that results from $\mathrm{Na}-\mathrm{O}$ scattering with a bond length of about $2.37 \AA$. Other much smaller peaks are observed at higher $r$. The maximum difference between the glasses in the $\mathrm{Na}-\mathrm{O}$ peak amplitude in the FTs is only $14 \%$ and is within the estimated error based on the noise level determined from the higher $r$ part of the FT. In particular, the EXAFS shows that different glass compositions have both similar disorder (decay of oscillations with $k$ ) and coordination (amplitudes of the first two oscillations). Note that bond length distribution widths indicate strong anharmonic vibrations. Unfortunately, the short $\mathrm{k}$ range of the EXAFS data prevents fitting for higher order cumulants.

Detailed fits were performed to the $\mathrm{Na}-\mathrm{O}$ peak with the assumption that it can be successfully described within a single harmonic $\mathrm{Na}-\mathrm{O}$ shell. A series of fits were performed in which the amplitude, the bond length, and the energy origin were allowed to vary. The results are summarized in Table 2 along with the respective errors. These results are in agreement with earlier $\mathrm{Na}$ K-edge EXAFS investigations $[39,40,42,46]$, with a recent NMR study by Angeli et al. [61] who reported a Na-O bond length of $2.4 \AA$ for $\mathrm{Na}_{2} \mathrm{O} \cdot 2 \mathrm{SiO}_{2}$ glass, and with molecular dynamics calculations [62]. The fits show no change in $\mathrm{Na}-\mathrm{O}$ distance with increasing $\mathrm{Al}_{2} \mathrm{O}_{3}$ content within the measurement error of $\pm 0.02 \AA$. Little change in $\mathrm{Na}-\mathrm{O}$ distance would be expected because ${ }^{\mathrm{Q}} \mathrm{Al}$ units are being substituted for ${ }^{\mathrm{Q}} \mathrm{Si}$ units, which are nearly identical in size [63]. The lack of change in the bond length puts a tight constraint on the maximum change in the number of $\mathrm{Na}-\mathrm{O}$ neighbors: Using the bond-valence sum method [64], a change of $0.02 \AA$ implies a maximum change of about $0.4 \pm 0.2$ neighbors.

Although considering further neighbors is not formally justified by the data quality, the fit residuals indicate more weight in the main $\mathrm{Na}-\mathrm{O}$ shell than simple single shell harmonic assumptions permit. This weight is consistent with additional $\mathrm{Na}-\mathrm{O}$ pairs at about $3.0 \AA$, although this could possibly result from $\mathrm{Na}-\mathrm{Si}$ or $\mathrm{Na}-\mathrm{Al}$ scattering as well. If an extra $\mathrm{Na}-\mathrm{O}$ shell is included, the $\mathrm{Na}$ coordination number is closer to 6. Therefore, the aforementioned fits should be interpreted as $4.5 \pm 0.6 \mathrm{Na}-\mathrm{O}$ neighbors within the Debye-Waller factor $(\sigma)$ of the average bond position and not as the total $\mathrm{Na}-\mathrm{O}$ coordination. In addition, a fairly prominent peak at about $3.8 \AA$ (uncorrected for phase) in the FT is fit well by a Na-Na interaction at $4.1 \AA$.

\section{OXYGEN XAFS}

Similar to the situation of sodium speciation, few experimental techniques other than NMR and TEM can determine the local coordination environment around oxygen in glasses. The coordination characteristics of oxygen are particularly important since the ratio of bridging oxygen (BO) and nonbridging oxygen (NBO) is an important factor that determines various glass properties [65]. Thus, it is desirable to examine methodologies that could help provide a greater understanding of the local oxygen environments in glasses. As part of the overall soft x-ray investigations, $\mathrm{O} \mathrm{K}$ edge NEXAFS were collected to determine if spectral trends could be observed as a function of glass composition. 
The oxygen $\mathrm{K}$ edge NEXAFS from the $\mathrm{NaSiO}-x \mathrm{Al}$ series of alumonosilicate glasses is shown in Figure 5. The $\mathrm{O} \mathrm{K}$ edge spectra from the glasses are comprised of two spectral regions; the prominent low-energy portion that results from $\pi^{*}$ transitions, a broader, higher-energy manifold of peaks that are characteristic of transitions to sigma states, and finally to the continuum [66,67]. The overall spectral features of the base glass and $10 \% \mathrm{Al}$ glass are similar with the exception of the low-energy side of the $\pi^{*}$ peak (533.9 $\mathrm{eV})$. The base glass spectrum shows evidence for a feature located at $532.3 \mathrm{eV}$. The $15 \% \mathrm{Al}$ glass spectrum is much different than either of the other glasses, with substantial differences on the low-energy side of the $\pi^{*}$ peak, the $\pi^{*}$ peak itself, and slightly higher intensity throughout the higher-energy manifold region. The magnitude of the feature at the low-energy side of the $\pi^{*}$ peak clearly diminishes with the increasing $\mathrm{Al}$ content of the glasses. Although the $\pi^{*}$ peaks of the base and $10 \% \mathrm{Al}$ glass are nearly identical, the magnitude of this peak is substantially reduced in the $15 \%$ Al glass. Based on the assignments in Ref. [68], these low-energy features (532.3 eV and $533.9 \mathrm{eV})$ and or their ratios, may indicate a redistribution of weight from NBO's (Si-O-Na) to BO's or to another NBO configuration (e.g., Al-O-Na). Furthermore, this is supported by the shift of spectral weight from the $\pi^{*}$ region peaks to the $\sigma$-like manifold in the $15 \% \mathrm{Al}$ glass. The relationship between all of these features is complex and further studies will be needed to firmly characterize the behavior observed from the NEXAFS from these glasses.

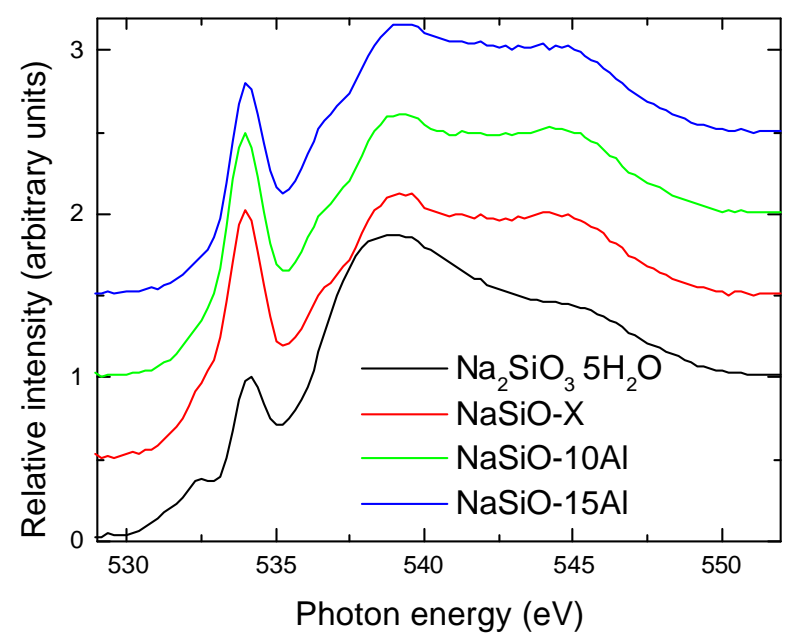

Figure 5. Oxygen K-edge absorption spectra collected at ALS Beamline 6.3.1 from the NaSiO- $x \mathrm{Al}$ glasses. Spectra were energy calibrated with respect to the $\mathrm{O} \mathrm{K}$-edge $\pi^{*}$ feature of $\mathrm{O}_{2}$ gas at 531 $\mathrm{eV}$. The spectra were normalized to equal background heights at $555 \mathrm{eV}$.

\section{XPS RESULTS}

As will be discussed below, the primary question we are asking of the XPS data concerns changes in the nature of the $\mathrm{Si}-\mathrm{O}-\mathrm{Na}$ bond for the non-bridging oxygen site. For each fractured glass surface, data were collected from the $\mathrm{Na} 1 \mathrm{~s}, \mathrm{Si} 2 \mathrm{p}$ and $\mathrm{O} 1 \mathrm{~s}$ core levels. For most but not all samples, data were also collected for the $\mathrm{Na} 2 \mathrm{~s}$ core level. As stated earlier, the Si 2 p peaks were shifted (charge corrected) to an energy of $102.7 \mathrm{eV}$. Although the exact value of this energy makes little difference to the following analysis, this energy is consistent with $\mathrm{NaAlSi}_{3} \mathrm{O}_{8}$ (albite) at $102.6 \mathrm{eV}$ and $\mathrm{AlSiO}_{5}$ (sillimanite) at 102.7 $\mathrm{eV}$ but differs from $\mathrm{SiO}_{2}$, which is generally near $103.6 \mathrm{eV}$ [69]. Because we are interested in the small changes, several sets of data were collected for each glass. 
A summary of the raw XPS data collected and peak fitting results are shown in Table 3. The binding energy of the $\mathrm{Si} 2 \mathrm{p}$ photopeak as collected is also shown. All other peaks have been shifted by the amount of energy needed to adjust the Si $2 p$ to $102.7 \mathrm{eV}$. The position of the $\mathrm{Si}$ and $\mathrm{Al}$ photopeaks was determined from single Gaussian fits of the peaks. As can be seen in Table 3 , the $\mathrm{Na} 1$ s shifts significantly $(+0.55 \pm 0.04 \mathrm{eV})$ as the $\mathrm{Al}$ concentration in the glass increases. The Al $2 p$ binding energy shifts only slightly $(\approx+0.1$ $\pm 0.02 \mathrm{eV}$ ) with increasing Al.

Figure 6 shows a typical spectrum and peak deconvolution for the NaSiO-10Al glass. The peaks were fit with two different sets of assumptions. Approach \#1 assumed that both the $\mathrm{Si}-\mathrm{O}-\mathrm{Si}$ and $\mathrm{Si}-\mathrm{O}-\mathrm{Al}$ photopeaks were at a constant energy with respect to glass composition. Thus, the line-widths and peak positions of these peaks were held constant. The position of the Si-O-Si peak was initially determined from the fit to the $0 \% \mathrm{Al}$ glass. The energy and amplitude of the $\mathrm{Si}-\mathrm{O}-\mathrm{Na}$ peak

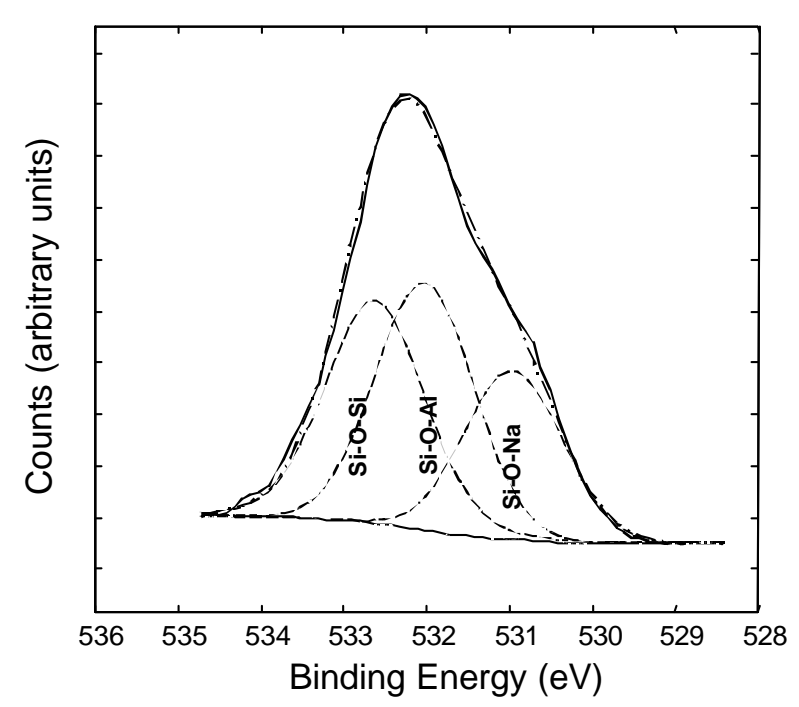

Figure 6. Example of Fit to $\mathrm{O}$ 1s XPS Photopeaks for the NaSiO-10Al Glass. The dashed lines are the fits for the $\mathrm{Si}-\mathrm{O}-\mathrm{Si}, \mathrm{Si}-\mathrm{O}-\mathrm{Al}$ and $\mathrm{Si}-$ $\mathrm{O}-\mathrm{Na}$ peaks. The solid line is the experimental data while the dot and dashed lines is the overall fit to the data.

was allowed to vary during the fit process. In the second approach, only the $\mathrm{Si}-\mathrm{O}-\mathrm{Al}$ peak was held at a fixed position along with the line-widths of all peaks.

Table 3. Raw XPS Data and Peak Fitting Results for NaSiO- $x$ Al Series of Glasses. Photopeak for Si-O$\mathrm{Al}$ held fixed at $532 \mathrm{eV}$.

\begin{tabular}{|c|c|c|c|c|c|c|c|c|c|c|}
\hline $\begin{array}{l}\mathrm{mol} \% \\
\mathrm{Al}_{2} \mathrm{O}_{3}\end{array}$ & \multicolumn{6}{|c|}{ Raw Binding Energy (BE), eV } & Fit 1 & Fit 2 & Fit 1 & Fit 2 \\
\hline & Si $2 p$ BE & FWHM $^{*}$ & $\begin{array}{c}\mathrm{BE} \\
\mathrm{Na} 1 \mathrm{~s}\end{array}$ & FWHM & $\begin{array}{c}\mathrm{BE} \mathrm{Al} \\
2 \mathrm{p}\end{array}$ & FWMH & $\mathrm{Si}-\mathrm{O}-\mathrm{Na}$ & $\mathrm{Si}-\mathrm{O}-\mathrm{Na}$ & $\mathrm{Si}-\mathrm{O}-\mathrm{Si}$ & $\mathrm{Si}-\mathrm{O}-\mathrm{Si}$ \\
\hline 0 & 100.19 & 1.66 & 1072.34 & 1.86 & & & 530.63 & 530.63 & 532.58 & 532.58 \\
\hline 0 & 100.23 & 1.67 & 1072.31 & 1.82 & & & 530.63 & 530.63 & 532.59 & 532.59 \\
\hline 0 & 100.34 & 1.64 & 1072.40 & 1.87 & & & 530.65 & 530.65 & 532.62 & 532.62 \\
\hline 0 & 100.43 & 1.63 & 1072.42 & 1.87 & & & 530.65 & 530.65 & 532.61 & 532.61 \\
\hline 5 & 100.09 & 1.71 & 1072.55 & 1.85 & 74.91 & 1.34 & 530.82 & 530.78 & 532.59 & 532.69 \\
\hline 5 & 100.12 & 1.71 & 1072.56 & 1.86 & 74.93 & 1.47 & 530.79 & 530.76 & 532.61 & 532.66 \\
\hline 5 & 100.22 & 1.72 & 1072.55 & 1.86 & 74.91 & 1.29 & 530.79 & 530.74 & 532.59 & 532.70 \\
\hline 10 & 99.57 & 1.69 & 1072.95 & 1.88 & 75.01 & 1.40 & 530.97 & 530.96 & 532.60 & 532.69 \\
\hline 10 & 99.69 & 1.71 & 1072.84 & 1.96 & 75.01 & 1.39 & 530.90 & 530.86 & 532.58 & 532.69 \\
\hline 10 & 99.94 & 1.75 & 1072.93 & 1.94 & 75.04 & 1.36 & 530.93 & 530.88 & 532.58 & 532.71 \\
\hline 15 & 99.51 & 1.72 & 1072.97 & 1.89 & 75.06 & 1.43 & 530.95 & 530.91 & 532.58 & 532.66 \\
\hline 15 & 100.02 & 1.68 & 1072.99 & 1.83 & 75.01 & 1.41 & 531.04 & 531.02 & 532.60 & 532.63 \\
\hline 15 & 99.98 & 1.70 & 1072.98 & 1.81 & 75.05 & 1.39 & 530.97 & 530.98 & 532.61 & 532.60 \\
\hline
\end{tabular}

The fit FWHM for Si-O-Na, Si-O-Si, and Si-O-Al was fixed at $1.4 \mathrm{eV}$ 
The binding energy shifts for the Si-O-Na peak as determined by the fitting approaches $\# 1$ and \#2 are shown in Figure 7 . Shifts of up to $+0.4 \mathrm{eV}$ were observed for the $\mathrm{Si}-\mathrm{O}-\mathrm{Na}$ peak. The relatively small scatter in the data suggests good data precision. We note that most of these data were collected over a three-day period, more than one data point was collected per glass sample, and more than one sample was used. The trends in the binding energy shift for the $\mathrm{Si}-\mathrm{O}-\mathrm{Na}$ peak were essentially independent of the approach taken for the fitting. The differences between fit approach \#1 and fit approach \#2 involve some movement of the Si-O-Si peak. Because of complications involving initial states, final states, and polarization of the neighboring atoms, it is not possible to definitively determine what might cause changes in the measured binding energies. However, although the changes are small, it is clear that measured binding energy of the oxygen associated with $\mathrm{Si}-\mathrm{O}-\mathrm{Na}$ sites is shifting relative to the $\mathrm{Si} 2 \mathrm{p}$ peak and relative to the $\mathrm{Si}-\mathrm{O}-\mathrm{Si}$ peak, however it is fit.

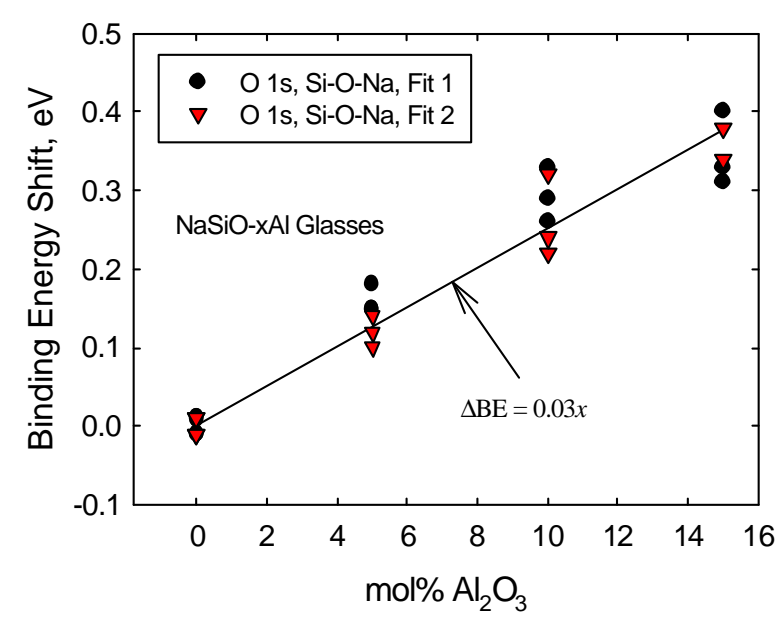

Figure 7. XPS Binding Energy Shift As a Function of Alumina Content. Line shown is a linear regression including data from both XPS peak-fitting methods.

Normalized dissolution and sodium release rates in $\mathrm{H}_{2} \mathrm{O}$ and $\mathrm{D}_{2} \mathrm{O}$ are listed in Tables 3 and 4, respectively. Also tabulated are the experimental conditions, including element concentrations, flow-through rates, and coupon surface areas. Concentrations of $\mathrm{Al}$ were below detection level for all experiments and are therefore not reported. Experimental

\section{DISSOLUTION AND Na RELEASE}

Table 4. Experimental Conditions and Measured Apparent Dissolution Rates of NaSiO- $x \mathrm{Al}$ Glasses at $\mathrm{pH} 8$, Silica-saturated $\mathrm{H}_{2} \mathrm{O}$ at $23^{\circ} \mathrm{C}$

\begin{tabular}{|ccccccc|}
\hline $\begin{array}{c}\mathrm{mol} \% \\
\mathrm{Al}_{2} \mathrm{O}_{3}\end{array}$ & $\begin{array}{c}\text { Flow rate } \\
(\mathrm{mL} / \mathrm{d})\end{array}$ & $\begin{array}{c}\text { Surface } \\
\text { Area } \\
\left(\mathrm{m}^{2}\right)\end{array}$ & $\begin{array}{c}\text { Avg. } \\
\text { Conc. Mo Conc. } \mathrm{Na} \\
(\mu \mathrm{g} / \mathrm{L})\end{array}$ & $\begin{array}{c}\text { Avg. } \\
(\mathrm{mg} / \mathrm{L})\end{array}$ & $\begin{array}{c}\text { Mo Rate } \\
\left(\mathrm{g} \mathrm{m}^{-2} \mathrm{~d}^{-1}\right)\end{array}$ & $\begin{array}{c}\text { Na Rate } \\
\left(\mathrm{g} \mathrm{m}^{-2} \mathrm{~d}^{-1}\right)\end{array}$ \\
\hline \hline 0 & 37.2 & $1.03 \times 10^{-3}$ & 174 & 371 & $4.0 \pm 1.0$ & $53 \pm 10$ \\
0 & 55.6 & $9.55 \times 10^{-4}$ & 94 & 258 & $3.5 \pm 0.9$ & $60 \pm 10$ \\
& & & & & & \\
5 & 20 & $7.60 \times 10^{-4}$ & 3.60 & 58 & $0.062 \pm 0.002$ & $6.0 \pm 1.0$ \\
5 & 20 & $5.04 \times 10^{-4}$ & 3.38 & 60 & $0.089 \pm 0.002$ & $6.3 \pm 1.0$ \\
5 & 27.8 & $1.21 \times 10^{-3}$ & 4.00 & 44 & $0.060 \pm 0.002$ & $3.9 \pm 0.66$ \\
& & & & & & \\
10 & 2 & $1.31 \times 10^{-3}$ & 1.57 & 24 & $1.6 \times 10^{-3} \pm 4.1 \times 10^{-4}$ & $0.14 \pm 0.026$ \\
10 & 3 & $5.68 \times 10^{-4}$ & $*$ & 8 & & $0.16 \pm 0.028$ \\
10 & 3 & $5.70 \times 10^{-4}$ & $*$ & 8 & & $0.16 \pm 0.028$ \\
& & & & & & \\
15 & 1 & $1.31 \times 10^{-3}$ & 1.37 & 13 & $7.3 \times 10^{-4} \pm 1.2 \times 10^{-4}$ & $3.8 \times 10^{-2} \pm 6.8 \times 10^{-3}$ \\
15 & 3 & $4.99 \times 10^{-4}$ & $*$ & 2 & & $4.6 \times 10^{-2} \pm 8.1 \times 10^{-3}$ \\
\hline
\end{tabular}

"Below detection limit 
Table 5. Experimental Conditions and Measured Apparent Dissolution Rates of NaSiO- $x \mathrm{Al}$ Glasses in Silica-saturated $\mathrm{D}_{2} \mathrm{O}$ Solution at $\mathrm{pD}=8,23^{\circ} \mathrm{C}$

\begin{tabular}{|ccccccc|}
\hline $\begin{array}{c}\mathrm{mol} \% \\
\mathrm{Al}_{2} \mathrm{O}_{3}\end{array}$ & $\begin{array}{c}\text { Flow rate } \\
(\mathrm{mL} / \mathrm{d})\end{array}$ & $\begin{array}{c}\text { Surface } \\
\text { Area } \\
\left(\mathrm{m}^{2}\right)\end{array}$ & $\begin{array}{c}\text { Avg. } \\
\text { Conc. Mo Conc. Na } \\
(\mu \mathrm{g} / \mathrm{L})\end{array}$ & $\begin{array}{c}\text { Avg. } \\
(\mathrm{mg} / \mathrm{L})\end{array}$ & $\begin{array}{c}\text { Mo Rate } \\
\left(\mathrm{g} \mathrm{m}^{-2} \mathrm{~d}^{-1}\right)\end{array}$ & $\begin{array}{c}\text { Na Rate } \\
\left(\mathrm{g} \mathrm{m}^{-2} \mathrm{~d}^{-1}\right)\end{array}$ \\
\hline \hline 0 & 63.3 & $1.02 \times 10^{-3}$ & 66 & 109 & $2.6 \pm 0.6$ & $27 \pm 4.5$ \\
5 & 31.5 & $1.21 \times 10^{-3}$ & 3.20 & 22 & $0.055 \pm 0.011$ & $2.2 \pm 0.4$ \\
10 & 2 & $1.31 \times 10^{-3}$ & 2.25 & 9 & $2.3 \times 10^{-3} \pm 5.4 \times 10^{-4}$ & $5.3 \times 10^{-2} \pm 9.1 \times 10^{-3}$ \\
15 & 1 & $1.31 \times 10^{-3}$ & 1.84 & 5 & $9.8 \times 10^{-4} \pm 2.3 \times 10^{-4}$ & $1.5 \times 10^{-2} \pm 2.8 \times 10^{-3}$ \\
\hline
\end{tabular}

*The fit FWHM for Si-O-Na, Si-O-Si, and Si-O-Al was fixed at $1.4 \mathrm{eV}$

uncertainties are listed as $2 \sigma_{r_{i}}$ errors.

Dissolution and Na-release rates in $\mathrm{H}_{2} \mathrm{O}$ solutions both decrease with increasing Alcontent of glass (Table 4). For the NaSiOOAl glass composition, the average dissolution rate is $8 \mathrm{~g} \mathrm{~m}^{-2} \mathrm{~d}^{-1}$. The dissolution rate of the NaSiO-15Al glass composition is $9.5 \times 10^{-4}$ $\mathrm{g} \mathrm{m}^{-2} \mathrm{~d}^{-1}$. Thus, over the glass composition range studied, dissolution rates decrease by $\sim 8,000 \mathrm{X}$ as $\mathrm{Al}_{2} \mathrm{O}_{3}$ concentrations increase from 0 to $15 \mathrm{~mol} \%$. In contrast, $\mathrm{Na}-\mathrm{H}^{+}$exchange rates decrease by only about $1000 \mathrm{X}$ over the same composition range (see Table 2 ), confirming that an independent reaction mechanism is controlling $\mathrm{Na}$ release from these glasses.

Figure 8 shows the $\log _{10}$ normalized rate ( $\mathrm{Na}$ and $\mathrm{Mo}$ ) versus the Al-content of the glasses. Dissolution rates, based on effluent concentrations of $\mathrm{Mo}$, in silica-saturated $\mathrm{H}_{2} \mathrm{O}$ and $\mathrm{D}_{2} \mathrm{O}$ solutions are identical within experimental uncertainty $\left(\begin{array}{lll}18 \% & 2 \sigma_{r_{i}}\end{array}\right)$ over the entire composition range. In contrast, $\mathrm{Na}$ release rates in $\mathrm{D}_{2} \mathrm{O}$-based solutions (Table 5) are on average $30 \%$ slower compared to rates in $\mathrm{H}_{2} \mathrm{O}$. The measurable difference in $\mathrm{Na}$ release rates between $\mathrm{H}_{2} \mathrm{O}$ and $\mathrm{D}_{2} \mathrm{O}$ solutions reveals an important mechanism for $\mathrm{Na}^{+}-\mathrm{H}^{+}$ exchange, discussed below. The significant feature illustrated in Figure 8 is that over the range of glass compositions studied, matrix dissolution rates are much too slow to account for the Na released from these glasses, proving that $\mathrm{Na}-\mathrm{H}$ exchange is the dominant mechanism releasing $\mathrm{Na}$ to solution under silica-saturated conditions.

\section{DISCUSSION}

Although the SPFT experiments were conducted in Si-saturated solutions, bulk hydrolysis and dissolution of the glasses clearly continued as evidenced by the rate of Mo release. The alkali ion exchange reaction

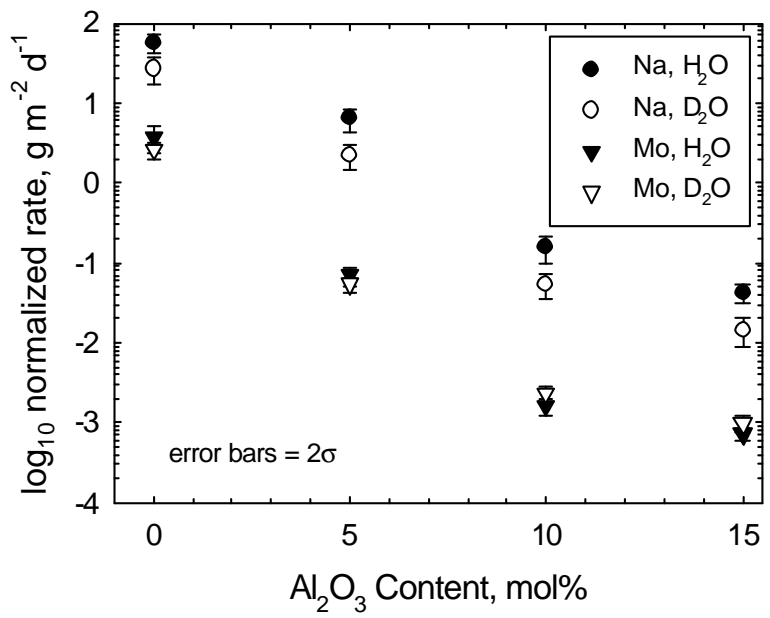

Figure 8. Plot of Normalized Release Rates (Mo and $\mathrm{Na}$ ) in $\mathrm{H}_{2} \mathrm{O}$ and $\mathrm{D}_{2} \mathrm{O}$ as a Function of $\mathrm{Al}_{2} \mathrm{O}_{3}$ Content. Test conditions are $\mathrm{T}=23^{\circ} \mathrm{C}, \mathrm{pH}=\mathrm{pD}=8$, silica-saturated solution. Note that Na-release rates are $\sim 30 \%$ slower in $\mathrm{D}_{2} \mathrm{O}$ compared to $\mathrm{H}_{2} \mathrm{O}$. 
$\equiv \mathrm{Si}-\mathrm{O}^{-} \mathrm{Na}^{+}+\mathrm{H}^{+} \rightarrow \equiv \mathrm{Si}-\mathrm{O}^{-} \mathrm{H}^{+}+\mathrm{Na}^{+}$

produces a silanol group and increases the local $\mathrm{pH}$, thus catalyzing the irreversible hydrolysis reaction

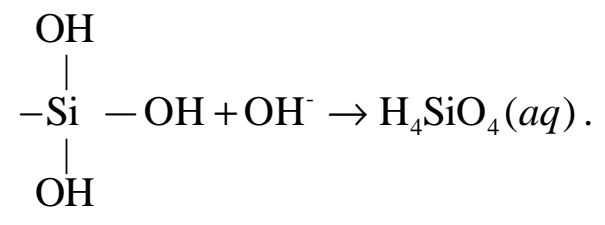

Reaction (8) affects the overall rate at which reaction (9) proceeds because it impacts the rate at which $\mathrm{Si}-\mathrm{OH}$ groups are produced. However, three silanol groups must be formed before the last anchoring bond is broken [70], releasing a silicic acid $\left(\mathrm{H}_{4} \mathrm{SiO}_{4}\right)$ molecule into solution. The degree of polymerization in the glass obviously significantly impacts the overall hydrolysis rate. Reactions (8) and (9), therefore, are linked but can proceed at different rates, consistent with the data shown in Figure 5. As will be discussed below, the reaction scheme is also consistent with the observed kinetic isotope effect in $\mathrm{D}_{2} \mathrm{O}$.

Reactions (8) and (9) have important ramifications beyond the alkali ion exchange mechanism itself. Modeling of silicate glass dissolution is widely done by adopting principles from transition state theory (TST) as developed for silicate mineral dissolution by Aagaard and Helgeson [71] and later adapted by Grambow [9] for waste glasses. For glasses, the overall Gibbs free energy change of the reaction $\left(\Delta G_{r}\right)$ is associated with a reversible microscopic reaction that is rate limiting and not the macroscopic glass/water reaction itself. The reversible reaction most often considered is

$$
\mathrm{SiO}_{2}(a m)+2 \mathrm{H}_{2} \mathrm{O} \rightleftharpoons \mathrm{H}_{4} \mathrm{SiO}_{4}(a q)
$$

The rate of glass dissolution, therefore, is simply determined by the degree of departure from equilibrium with respect to reaction(10). According to this model, the glass dissolution rate in our experiments, conducted at saturation with respect to $\mathrm{SiO}_{2}(\mathrm{am})$, should have been very close to zero. Instead, we observe substantial rates of glass dissolution for all the test glasses (see Figure 5). As discussed above, under silica-saturated conditions, the "secondary" reaction mechanism of $\mathrm{Na}$ ion exchange affects the glass dissolution rate via the irreversible reaction (9). Since the rate of ion-exchange is not affected by saturation state of the aqueous phase with respect to reactions such as (10), a TST rate law based solely on assessment of the aqueous phase saturation state with respect to a microscopic reaction such as (10) fails to accurately predict dissolution kinetics under near-saturation conditions. However, near-saturation conditions are precisely the state under which most waste glasses are expected to be stored.

If our arguments regarding the effect of alkali-H exchange are correct, then some of the reported [72,73] deviations from chemical affinity-based rate laws are due to alkali-H exchange, which is not considered in TST theory, and not from a fundamental discrepancy per se with the rate law itself. Alkali ion exchange may also provide a mechanistic basis for the empirical "residual" rate of reaction appended to the TST rate law by Grambow [74]. The residual rate was appended to prevent calculated glass dissolution rates from dropping to zero under silica-saturated conditions, which is not in accord with experime ntal observations [74]. As we have demonstrated, alkali ion exchange proceeds independent of the saturation state of the aqueous solution, raises the solution $\mathrm{pH}$, and so causes additional glass dissolution via reaction (9). The "residual" rate, therefore, is simply the net rate of glass dissolution controlled by the rate at which the ion exchange reaction proceeds. Consideration of secondary reaction mechanisms, such as alkali-H exchange, would appear to be a fruitful area for research and development of improved kinetic rate laws for glass dissolution. 


\section{RATE-LIMITING STEP FOR SODIUM ION EXCHANGE}

As shown in Figure 8, sodium release rates in $\mathrm{D}_{2} \mathrm{O}$ are slower by $\sim 30 \%$ than rates in $\mathrm{H}_{2} \mathrm{O}$. Pederson [21] also reported $30 \%$ slower $\mathrm{D}^{+}$versus $\mathrm{H}^{+}$uptake in his $\mathrm{pH}$ stat experiments with a sodium silicate glass. He attributed these differences in relative exchange rates to reduction in the vibrational frequency of the $\mathrm{O}-\mathrm{D}$ versus $\mathrm{O}-\mathrm{H}$ bond, where rupture of the $\mathrm{O}-\mathrm{H}(\mathrm{D})$ bond is the rate controlling step in the reaction. In this case, the vibrational frequency differs by the square root of the rest mass ratio of the two species $(1 / 2)^{1 / 2}$, giving a kinetic isotope effect (rate in $\mathrm{H}_{2} \mathrm{O}$ versus $\mathrm{D}_{2} \mathrm{O}$ ) of about $29 \%$, consistent with experimental observations. However, if diffusion of $\mathrm{H}_{2} \mathrm{O}$ were the rate-limiting step, the rate in $\mathrm{D}_{2} \mathrm{O}$ would be $(18 / 20)^{1 / 2}$ or $95 \%$ of the rate in $\mathrm{H}_{2} \mathrm{O}$. In a similar fashion, if diffusion of $\mathrm{H}_{3} \mathrm{O}^{+}$were the rate-limiting step, the rate in $\mathrm{D}_{2} \mathrm{O}$ would be $(19 / 22)^{1 / 2}$ or $93 \%$ less than the rate in $\mathrm{H}_{2} \mathrm{O}$. Note that in both of these examples, the difference in rates is within the experimental uncertainty $(\sim 18 \%)$ and would not be detected. That is why no kinetic isotope effect is observed for the matrix dissolution rate (as indexed by Mo released) shown in Figure 5. The hydrolysis reaction (9) has several steps involving $\mathrm{OH}^{-}\left(\right.$or $\left.\mathrm{H}_{2} \mathrm{O}\right)$ and so no kinetic isotope effect would be detectable.

Pederson and coworkers [23] reported the disappearance of a kinetic isotope effect in glasses containing $\mathrm{Al}_{2} \mathrm{O}_{3}$. The investigators rationalized these results as a change in the rate-limiting mechanism for the glasses that contained $\mathrm{Al}_{2} \mathrm{O}_{3}$; however, this seems highly unlikely. In contrast, a kinetic isotope effect is maintained in our experiments, even in glasses with $15 \mathrm{~mol} \% \mathrm{Al}_{2} \mathrm{O}_{3}$. The results of Pederson et al. [23] can now be understood because the experiments were not conducted in silica-saturated solutions. Consequently, the sodium contribution to solution was from both matrix dissolution and alkali exchange. The much lower dissolution and exchange rate in the glasses with added $\mathrm{Al}_{2} \mathrm{O}_{3}$ caused the solution to remain more undersaturated than in his experiments with $\mathrm{Na}_{2} \mathrm{O} \cdot 3 \mathrm{SiO}_{2}$ glass. Matrix hydrolysis and dissolution will dominate under these conditions and a kinetic isotope effect specific to the ion-exchange reaction would not be detected. Because we took steps to correct for sodium release from matrix dissolution reactions, this work conclusively shows the same reaction mechanism controlling alkali ion exchange in the $\mathrm{Na}_{2} \mathrm{O}$ $\mathrm{Al}_{2} \mathrm{O}_{3}-\mathrm{SiO}_{2}$ glass system.

\section{CORRELATION BETWEEN GLASS STRUCTURE AND EXCHANGE KINETICS}

The results of the SPFT tests show that addition of $\mathrm{Al}$ to glass decreases both the $\mathrm{Na}-$ hydrogen exchange and matrix dissolution rates. Hamilton and Pantano [75] attribute similar experimental observations to changes in the concentration of NBOs in their glasses. Assuming that every $\mathrm{Al}$ atom eliminates one NBO [76], the calculated population density of NBO sites varies from a high of 1 NBO site per mole for the NaSiO-0Al glass to 0.70 NBO sites per mole for the NaSiO- $15 \mathrm{Al}$ glass, a $30 \%$ change. By comparison, the $\mathrm{Na}$ ion-exchange rate changes by over 3 orders of magnitude for these glasses. Clearly, additional glass structure factors need to be considered in addition to the concentration of NBOs to explain the change in $\mathrm{Na}$ ionexchange rate.

Figure 9 shows the variation in $\mathrm{Na}$ ionexchange rate as a function of the ${ }^{29} \mathrm{Si}$ chemical shift determined from NMR measurements. The plot shows a log-linear relationship where as the chemical shift becomes less negative, the $\mathrm{Na}$ release rate decreases. Because Si represents the majority of network forming species in typical waste glass formulations, the ${ }^{29} \mathrm{Si}$ chemical shift value should give a reasonable indication of the average chemical bond strength of the glass network. Variation in the bonding of $\mathrm{Na}$ 


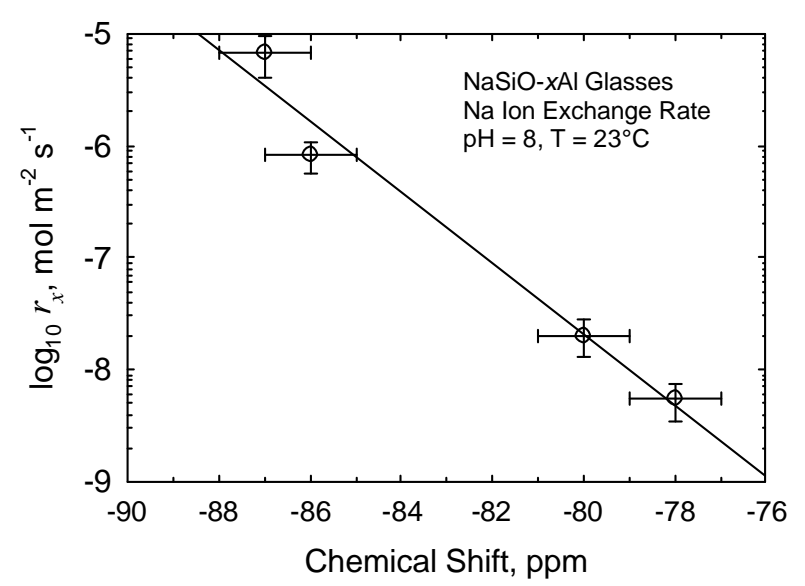

Figure 9. Sodium Ion-Exchange Rate as a Function of ${ }^{29} \mathrm{Si}$ Chemical Shift Value as Determined by MAS-NMR

in the glass network, therefore, might explain the observed changes in $\mathrm{Na}$ ion-exchange rate as the $\mathrm{Al}_{2} \mathrm{O}_{3}$ in the glasses increases.

\section{Structural Energy Barrier Model}

Consider a model where the $\mathrm{Na}^{+}-\mathrm{H}^{+}$exchange is treated as an ion hopping process. Because $\mathrm{H}$ is much lighter than $\mathrm{Na}$, the number of attempts for a $\mathrm{H}$ ion to jump into a site containing a $\mathrm{Na}$ atom will be proportional to the vibrational frequency of the $\mathrm{O}-\mathrm{H}$ bond $\left(v_{H}\right)$ associated with the hydronium ion. Assuming NBO sites are the only sites susceptible to ion exchange, the exchange attempt frequency $(\omega)$ will be proportional to

$$
\omega \propto \mathrm{v}_{\mathrm{H}} c_{\mathrm{H}^{+}} c_{\mathrm{NBO}}
$$

where $c_{\mathrm{H}^{+}}$is the hydrogen ion concentration in adsorbed water molecules on the glass surface [70], and $c_{\mathrm{NBO}}$ is the number of $\mathrm{NBO}$ sites per mole of glass. The probability of a successful jump will depend upon the structural energy barrier $\left(E_{x}\right)$ associated with removing a $\mathrm{Na}$ atom from its $\mathrm{NBO}$ site. Following Hsieh and Jain [47], the energy barrier for $\mathrm{Na}^{+}-\mathrm{H}^{+}$exchange can be estimated by combining: 1$)$ the bond energy $\left(E_{b}\right)$ of the $\mathrm{Na}$ atom on the NBO site with 2) the elastic strain energy $\left(E_{s}\right)$ associated with the distortion of the glass network required to remove the $\mathrm{Na}$ atom from its equilibrium position. Thus we have

$$
E_{x}=E_{b}+E_{s}
$$

As ion exchange is a thermally activated process, we can write

$$
r_{x}=\omega \exp \left(-E_{x} / \mathrm{RT}\right)
$$

where $\mathrm{R}$ is the gas constant $\left(\mathrm{kJ} \mathrm{mol}^{-1} \mathrm{~K}^{-1}\right)$, and $\mathrm{T}$ is the temperature $(\mathrm{K})$. As $c_{\mathrm{H}^{+}}$is fixed in our experiments, $\omega$ will depend only on the number of NBO sites in the glass. Equation (13) can then be normalized to give

$$
r_{x}=\omega_{x} f_{\mathrm{O}} \exp \left(-E_{x} / \mathrm{RT}\right)
$$

where $\omega_{x}$ is a constant $\left(\mathrm{mol} \mathrm{m} \mathrm{m}^{-2}\right)$, and $f_{\mathrm{O}}$ is the fraction of NBO sites in the glass relative to the NaSiO-0Al glass, with $f_{\mathrm{O}}=1$ for the $\mathrm{NaSiO}-0 \mathrm{Al}$ glass and 0.70 for the NaSiO$15 \mathrm{Al}$ glass.

Equation (14) provides a means to account for effects of glass structure on the rate of $\mathrm{Na}$ ion exchange. Because the preexponential factor involves a term proportional to the vibrational frequency of the $\mathrm{O}$ $\mathrm{H}(\mathrm{D})$ bond $\left(\omega_{x}\right)$, the model will also correctly predict the $30 \%$ reduction in $\mathrm{Na}$ exchange rate in $\mathrm{D}_{2} \mathrm{O}$ as compared with $\mathrm{H}_{2} \mathrm{O}$. However, application of Equation (14) requires a method for determining the bond strength $\left(E_{b}\right)$ and strain energy $\left(E_{s}\right)$ terms. Our approach for calculating these terms is discussed next.

\section{Bond Strength}

For an ionic bond, the bond strength can be approximated from the Coulombic potential and by remembering Pauling's electrostatic valence principle where average bond strength is given by the valence of the cation divided by the coordination number [77]. An approximation for $E_{b}$ is therefore

$$
E_{b}=\frac{q_{1} q_{2} e^{2}}{4 \pi \varepsilon_{\mathrm{o}} \varepsilon_{g} d_{a} N}
$$


where $q_{z}$ is the valence of the cation-anion pair, $e$ is the standard unit of charge $(1.602 \mathrm{x}$ $\left.10^{-19} \mathrm{C}\right), d_{\mathrm{a}}$ is the average bond distance, $N$ is the coordination number, $\varepsilon_{\mathrm{o}}$ is the vacuum permittivty $\left(8.854 \times 10^{-12} \mathrm{~J}^{-1} \mathrm{C}^{2} \mathrm{~m}^{-1}\right)$, and $\varepsilon_{g}$ is the glass dielectric constant.

As $\mathrm{Al}$ is substituted into the glass, the binding energy associated with $\mathrm{Si}-\mathrm{O}^{-} \mathrm{Na}^{+}$sites increases (see Figure 7). We assume the observed binding energy shifts result from decreased ionicity (increased covalency) of the bond as charge is transferred to $\mathrm{Na}$ atoms acting as charge compensating centers for $\mathrm{AlO}_{4}$ units, although as noted previously, other factors could account for the observed energy shifts. Consequently, an energy shift term $\left(\Delta E_{c}\right)$ is added to Equation (15) to give

$$
E_{b}=\frac{q_{1} q_{2} e^{2}}{4 \pi \varepsilon_{\mathrm{o}} \varepsilon_{g} d_{a} N}+\Delta E_{c} .
$$

Parameterization of Equation (16) is accomplished by noting that $q_{1}=1, q_{2}=2, \varepsilon_{g}=$ 8.9 for $\mathrm{Na}_{2} \mathrm{O} \cdot 2 \mathrm{SiO}_{2}$ glass [78], $d_{a}$ is given in Table 1 ( $\mathrm{Na}-\mathrm{O}$ bond length), and $\Delta E_{c}$ is given by the regression line shown in Figure 7 . For coordination number, we assumed the $\mathrm{NaSiO}$ $0 \mathrm{Al}$ glass has $N=5$ and the $\mathrm{NaSiO}-15 \mathrm{Al}$ glass has $N=4.4$, with the $N$ decreasing by 0.2 for every $5 \mathrm{~mol} \%$ change in $\mathrm{Al}_{2} \mathrm{O}_{3}$ content. This range of coordination number is within the measurement uncertainty from the EXAFS measurements. The resulting $E_{b}$ value for each glass is given in Table 6.

\section{Elastic Strain Energy}

The elastic strain energy associated with removing a $\mathrm{Na}$ atom from an NBO site can be estimated by developing a simple conceptual model for the network distortion required to remove a $\mathrm{Na}$ atom from its equilibrium position in the glass network. We require the $\mathrm{Na}^{+}$ (and $\mathrm{H}^{+}$) ions to pass through a network doorway of average radius $r_{d}$. The average jump distance $\lambda$ then defines a cylindrical displacement volume $V_{d}$ associated with the jump, which is simply

$$
V_{d}=\pi\left(r_{i}-r_{d}\right)^{2} \lambda
$$

where $r_{i}$ is the ionic radius of the $\mathrm{Na}$ atom (assumed to be $1.16 \AA$ ). The strain energy is then given by

$$
E_{s}=\mu V_{d}=\pi \mu\left(r_{i}-r_{d}\right)^{2} \lambda
$$

where $\mu$ is the shear modulus of the glass.

The shear modulus of our glasses was calculated using the model of Rocherulee et al. [79] and the calculated values are given in Table 6. Values for $r_{d}$ are also given in Table 6 and were calculated from

$$
r_{d}=\left(V_{\mathrm{v}} / \mathrm{N}_{\mathrm{A}}\right)^{1 / 3}
$$

where $V_{\mathrm{v}}$ is the total molar void volume in the glass and $\mathrm{N}_{\mathrm{A}}$ is Avogadro's number. The void volume was calculated using the method outlined by Hsieh and Jain [47]. As was noted previously, the similar size of the ${ }^{\mathrm{Q} 4} \mathrm{Al}$ and ${ }^{\mathrm{Q}} \mathrm{Si}$ units results in very little change in the calculated $r_{d}$ with increasing $\mathrm{Al}_{2} \mathrm{O}_{3}$ con-

\begin{tabular}{|c|c|c|c|c|c|c|c|c|c|}
\hline & $f_{\mathrm{O}}$ & $\mathrm{N}$ & $\begin{array}{c}E_{c} \\
\mathrm{~kJ} \mathrm{~mol}^{-1}\end{array}$ & $\begin{array}{l}E_{b} \\
\mathrm{~mol}^{-1}\end{array}$ & $\begin{array}{c}\mu \\
\mathrm{GPa}\end{array}$ & $\begin{array}{l}r_{d} \\
\AA \\
\AA\end{array}$ & $\begin{array}{c}E_{s} \\
\mathrm{~kJ} \text { mol }\end{array}$ & $\begin{array}{c}E_{x} \\
\mathrm{~kJ}^{\mathrm{mol}^{-1}}\end{array}$ & $\begin{array}{r}r_{x}, \\
\text { mol }\end{array}$ \\
\hline I & & & 0 & 25.8 & 25.7 & .976 & $\overline{7.8}$ & 33.6 & \\
\hline $\mathrm{Al}$ & 08 & 4 & 0 & 30.4 & 26.0 & 975 & 7. & 38.4 & \\
\hline & 0.79 & 4. & .3 & 35.0 & 26.5 & & 8.2 & 43.2 & \\
\hline $\mathrm{TaSiO}-1$ & 0.70 & 4.4 & 9.9 & 39.9 & 27.3 & 0.973 & 8.58 & 48.5 & $9.1 \times 10^{-9}$ \\
\hline
\end{tabular}
tent for these glasses.

After substituting the appropriate values

Table 6. Parameters for Calculating Activation Enthalpy and Sodium Ion Exchange Rate 
into Equation (18), the calculated $E_{s}$ value as a function of glass composition is given in Table 6. A jump distance $(\lambda)$ of twice the $\mathrm{Na}-\mathrm{O}$ bond length was used in the calculation. The calculated elastic strain energy accounts for about $20 \%$ of the total exchange enthalpy. Pederson [21] reported an activation enthalpy of $47.3 \mathrm{~kJ} \mathrm{~mol}^{-1}$ for $\mathrm{Na}-\mathrm{H}$ exchange with $\mathrm{Na}_{2} \mathrm{O} \cdot 3 \mathrm{SiO}_{2}$ glass and $\mathrm{McGrail}$ et al. [80] reported an $E_{x}$ value of $52.4 \mathrm{~kJ} \mathrm{~mol}^{-1}$ for a complex low-activity waste glass. These values are very similar to the calculated values for our $\mathrm{NaSiO}-\mathrm{xAl}$ series of glasses reported in Table 6.

\section{Ion-Exchange Rate Calculation}

Using the $E_{x}$ value given in Table 6 for the NaSiO-0Al glass, $\omega_{x}$ was calculated to match the observed $\mathrm{Na}$ ion exchange rate for this glass. The ion exchange rate for the 5, 10, and $15 \mathrm{~mol} \% \quad \mathrm{Al}_{2} \mathrm{O}_{3}$ glasses was then calculated via Equation (14) using the fitted value for $\omega_{x}$ and the $E_{x}$ values given in Table 6. A comparison between the measured and calculated $\mathrm{Na}$ ion-exchange rate is given in Figure 10. The plot shows how the calculated exchange reaction enthalpy increases with increasing $\mathrm{Al}_{2} \mathrm{O}_{3}$ content in the glasses,

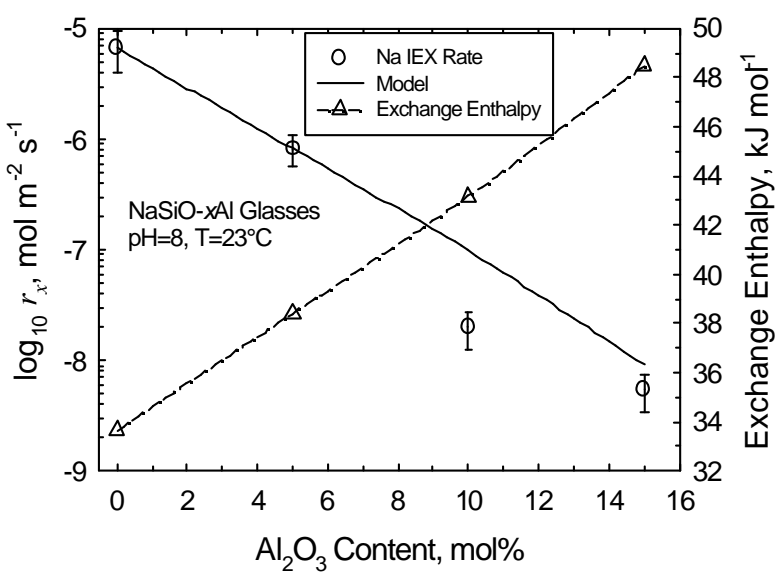

Figure 10. Comparison of Calculated and Predicted $\mathrm{Na}$ Ion Exchange Rate as a Function of $\mathrm{Al}_{2} \mathrm{O}_{3}$ Content in NaSiO- $x \mathrm{Al}$ Glasses. The solid line is the predicted $\mathrm{Na}$ ion exchange rate as calculated from Equation (12) using the enthalpy values shown and $\omega_{x}=6.6 \mathrm{~mol} \mathrm{~m}^{-2} \mathrm{~s}^{-1}$.

consistent with stronger bonding of $\mathrm{Na}$ on the NBO site and increasing shear strength of the glass as the $\mathrm{Al}$ content increases. The solid line in Figure 10 represents the calculated variation in $\mathrm{Na}$ ion exchange rate as a function of $\mathrm{Al}_{2} \mathrm{O}_{3}$ content in the glasses. The calculated and measured $\mathrm{Na}$ exchange rates show excellent agreement across the composition range. 


\section{RESULTS: SERIES II GLASSES}

\section{NMR Analyses}

As was the case for the $\mathrm{NaSiO}-x \mathrm{Al}$ series glasses, a systematic change in the glass composition from that of $\mathrm{Na}_{2} \mathrm{O} \cdot 2 \mathrm{SiO}_{2}$ to $\mathrm{Na}_{2} \mathrm{O} \cdot \mathrm{B}_{2} \mathrm{O}_{3} \cdot 6 \mathrm{SiO}_{2}$ is believed to cause an increasing amount of the $\mathrm{Na}^{+}$to be transferred from association with $\mathrm{Si}$ non-bridging oxygen sites to association with network forming ${ }^{\text {iv }} \mathrm{B}$ sites. Samples of these glasses as well as reference materials were analyzed using ${ }^{11} \mathrm{~B}$ solid state NMR to indirectly confirm this distribution of $\mathrm{Na}^{+}$. Only a single symmetric, narrow ${ }^{11} \mathrm{~B}$ NMR peak was observed, indicating, at least initially, that tetrahedrally coordinated $\mathrm{B}$ as opposed to 3-coordinated $\mathrm{B}$ (which has a broad quadrapole split resonance superimposed on the narrow resonance) is present in these glasses. Although no ${ }^{\text {iii }} \mathrm{B}$ was detected in these glasses by NMR, XAFS measurements discussed below indicate the definite presence of ${ }^{\mathrm{iii}} \mathrm{B}$. Using higher field NMR, others [81] have indicated that reedmergnerite has approximately $30 \%{ }^{\mathrm{iii}} \mathrm{B}$, occurring most likely as B-rich regions. This discrepancy between our NMR results and the results of high field NMR may simply be due to a resolution problem: the ${ }^{\mathrm{iii}} \mathrm{B}$ in our glasses may not be resolvable for the NMR experiments we performed. We shall assume that about $30 \%$ of the B is three coordinate.

Table 7. Results obtained from curve fitting ${ }^{29} \mathrm{Si}$ NMR spectra obtained for some of the glasses studied here along with some literature values.

\begin{tabular}{|c|c|c|c|c|c|}
\hline \multirow{2}{*}{ Sample } & \multicolumn{2}{|c|}{ peak 1} & \multicolumn{2}{|c|}{ peak 2} & \multirow{2}{*}{$\begin{array}{l}\text { ave. } \\
\text { ppm }\end{array}$} \\
\hline & ppm & $\%$ & ppm & $\%$ & \\
\hline NaSiO-0Al & - & - & -87 & 100 & -87 \\
\hline $\mathrm{NaBSi} \mathrm{RD}_{40}$ & -101 & 22 & -90 & 78 & -94 \\
\hline NaBSi-MB ${ }_{0.03}$ & -102 & 50 & -91 & 50 & -96 \\
\hline $\mathrm{NaBSi}-\mathrm{MB}_{0.07}$ & -103 & 60 & -94 & 40 & -100 \\
\hline $\mathrm{NaBSi}_{3} \mathrm{O}_{8}[81]$ & -103 & 100 & - & - & -103.4 \\
\hline $\mathrm{NaAlSi}_{3} \mathrm{O}_{8}[81]$ & -98.7 & 100 & - & - & -98.7 \\
\hline
\end{tabular}

In contrast to the $\mathrm{NaSiO}-x \mathrm{Al}$ series glasses, ${ }^{29} \mathrm{Si}$ solid state NMR spectra obtained from the $\mathrm{NaBSi}-\mathrm{RD} / \mathrm{MB}$ series glasses indicate that resonance position becomes more negative with increasing B content (see Table 1, above). Also, at least two different ${ }^{29} \mathrm{Si}$ NMR peaks are resolved. We calculated and average chemical shift from a fit to these two peaks. The results, along with some literature values for reference minerals [81], are listed in Table 7.

\section{Na XAFS and XANES}

The Na XAFS spectra of this second glass series were also collected on ALS Beamline 6.3.1. The XANES spectra from these glasses were collected at lower resolution than the previous set on Beamline 8.0 and are presented in Figure 11. These Na XANES spectra are displayed over an expanded energy range as well. The XANES spectra for glasses $\mathrm{RD}_{40}$ and BAS-5 are nearly indistinguishable, whereas the spectra from glasses

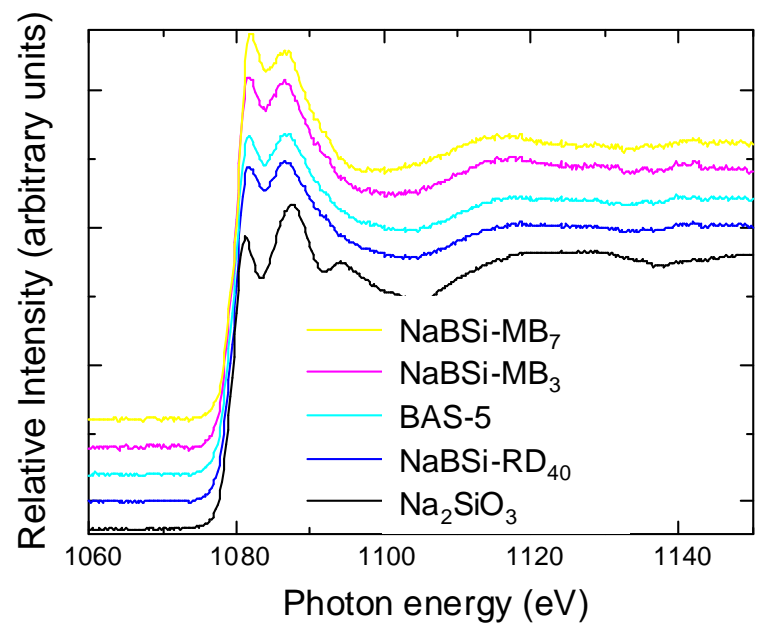

Figure 11. Sodium K edge XANES spectra collected at ALS Beamline 6.3.1 from the second glass series and an anhydrous sodium silicate reference material in the TEY mode. The spectra have not had backgrounds removed and have been normalized to the background amplitude and offset for clarity, respectively. 


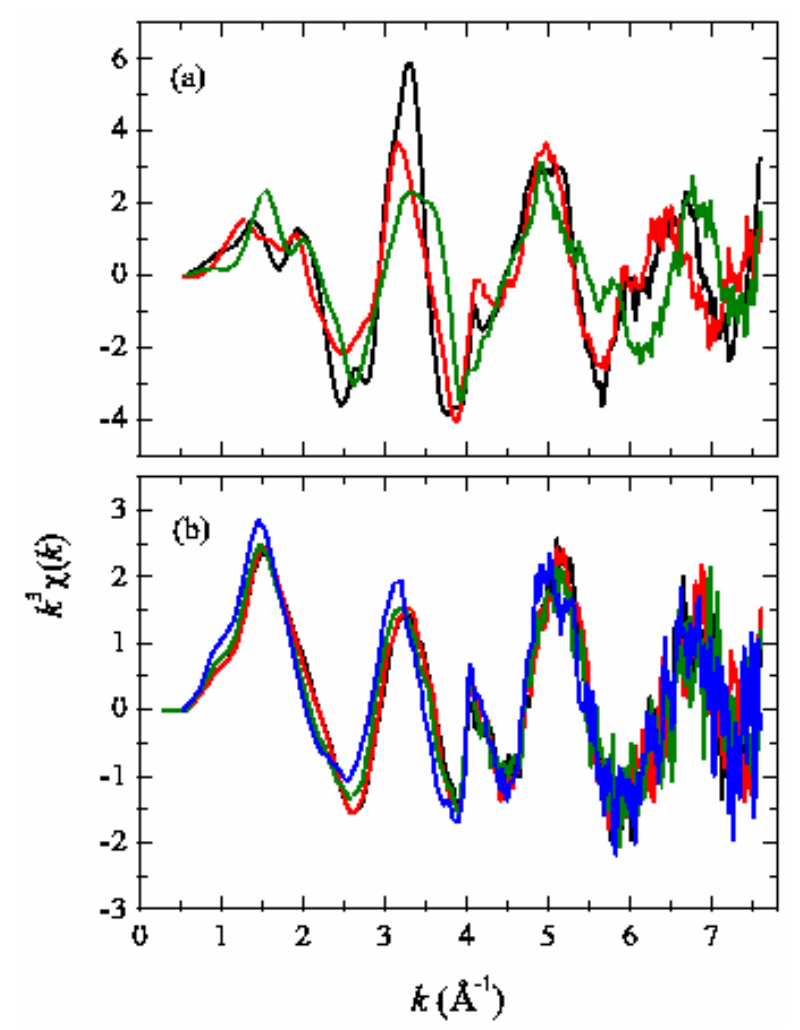

Figure 12. Fluorescence yield $\mathrm{Na} \mathrm{K}$ edge EXAFS spectra from the reference materials and second series of glasses. In the upper panel (a) black is $\mathrm{NaNO}_{3}$ (well ordered $\mathrm{NaO}_{6}$ octahedron), red is $\mathrm{NaBrO}_{3}$ (distorted $\mathrm{NaO} 6$ octahedron) and green is $\mathrm{Na}_{2} \mathrm{SiO}_{3}$ (distorted and 5-fold). In the lower panel (b) black is glass $\mathrm{NaBSi}-\mathrm{RD}_{40}$, red is glass BAS-5, green is glass BAS-6 and blue is glass BAS-3.

$\mathrm{MB}_{3}$ and $\mathrm{MB}_{7}$ have a slightly different amplitude ratio for the first two peaks.

The EXAFS data were reduced and fit as per the standard procedures used for the earlier series of aforementioned glasses. In addition, since data were collected in fluorescence yield (FY), corrections for self-absorption were applied [82]. The self-absorption correction $(\mathrm{SAB})$ was calculated for the reference materials based on their known atomic concentrations and density. However, the correction made for the glass samples assumes the same nominal concentrations and density as $\mathrm{Na}_{2} \mathrm{SiO}_{3}$. The correction is $k$ dependent and at $5 \AA^{-1}$ the correction coefficient is 1.62. The information depth (depth

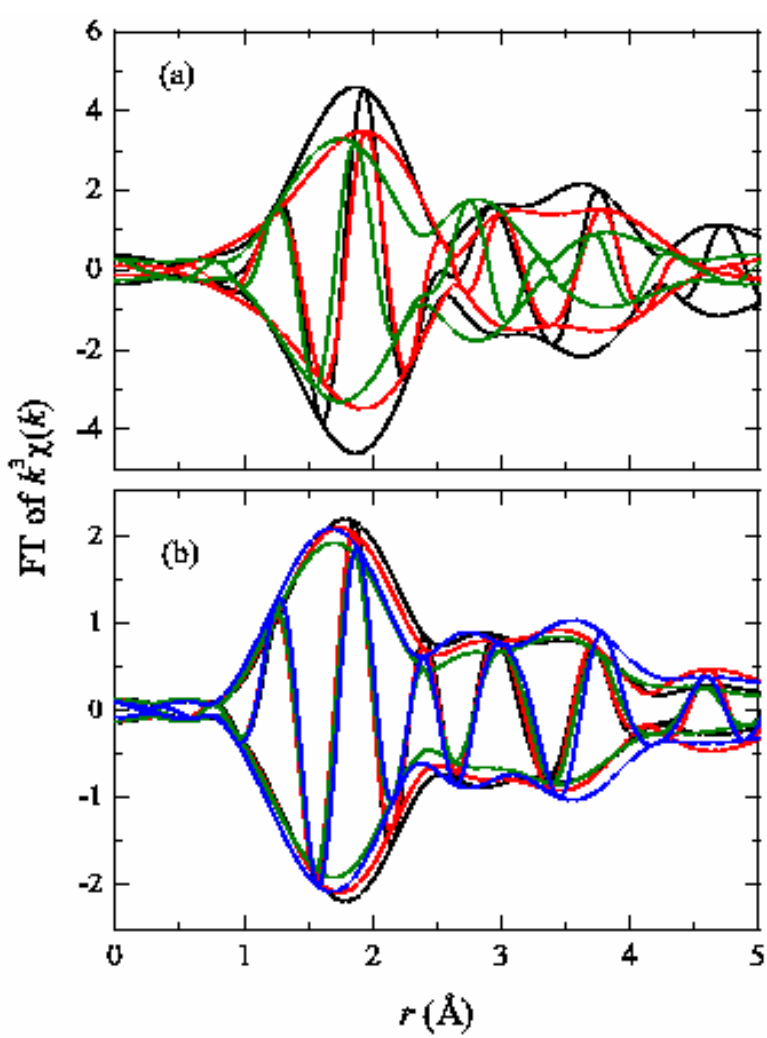

Figure 13. Fourier transforms of the EXAFS spectra for the reference materials in panel (a); black is $\mathrm{NaNO}_{3}$ (well ordered $\mathrm{NaO}_{6}$ octahedron), red is $\mathrm{NaBrO}_{3}$ (distorted $\mathrm{NaO}_{6}$ octahedron) and green is $\mathrm{Na}_{2} \mathrm{SiO}_{3}$ (distorted and 5-fold). Fourier transforms of the EXAFS spectra for the glasses in panel (b); Black is glass $\mathrm{RD}_{40}$, red is glass BAS-5, green is glass BAS- 6 and blue is glass BAS-3.

into the sample from where the mean measured photon comes from) at the same wave vector is $4544 \AA$. The corresponding SAB correction for the $\mathrm{NaNO}_{3}$ and $\mathrm{NaBrO}_{3}$ reference materials is 1.33 .

All Fourier transforms and fits were over a transform range of 2.5-7.6 $\AA^{-1}$, Gaussian narrowed by $0.3 \AA^{-1}$. The quality of the spectra is reasonable as shown in Figure 12. Figure 13 shows the Fourier transforms of the EXAFS spectra. The EXAFS reference materials were fit in two ways. First, all of the scattering paths up to the $\mathrm{Na}-\mathrm{Na}$ pairs near 4 $\AA$ were fit, constraining the ratios of the amplitudes to be consistent with that expected 
Table 8. Metrical Na-O structural parameters derived from the Na K-edge EXAFS of Series II glasses. Fits are from $1.25-2.20 \AA$ in the FT of $\mathrm{k}^{3} \chi(\mathrm{k})$, transformed from 2.5-7.6 $\AA^{-1}$ with a Gaussian narrowing of $0.3 \AA^{-1}$. Only the first shell Na$\mathrm{O}$ pair were included in the fit, since the identity of the farther neighbors is uncertain. $\mathrm{S}_{0}{ }^{2}=0.89$ \pm 0.12 . Errors are based partially on those given by a Monte Carlo method and by constraining the fits to be within physically possible limits.

\begin{tabular}{|c|c|c|c|}
\hline Glass & $\sigma(\AA \mathbf{A})$ & $\mathbf{r}(\AA)^{*}$ & $\mathbf{C N}^{* *}$ \\
\hline $\mathrm{RD}_{40}$ & 0.14 & 2.25 & $3.5 \pm 1.0$ \\
\hline$\# 2$ & 0.14 & 2.23 & $3.5 \pm 1.0$ \\
\hline $\mathrm{MB}_{0.03}$ & 0.14 & 2.21 & $3.5 \pm 1.0$ \\
\hline $\mathrm{MB}_{0.07}$ & 0.14 & 2.22 & $3.5 \pm 1.0$ \\
\hline
\end{tabular}

*Error in the $\mathrm{r}(\mathrm{A})$ is $+/-0.01 \mathrm{~A}$ relative and +/- $0.02 \AA$ absolute.

$* * \mathrm{CN}$ represents the number of $\mathrm{O}$ neighbors within $\sigma$ of the average bond length, $r$ (not the total $\mathrm{Na}-\mathrm{O}$ coordination).

for the nominal crystal structures. All free fit parameters compared well with the nominal structures. The reference spectra were also fit using only the first $\mathrm{Na}-\mathrm{O}$ peak to mimic the method that is used below to fit the glass data. The average $\mathrm{S}_{0}{ }^{2}$ from this procedure for the $\mathrm{NaNO}_{3}$ and the $\mathrm{NaBrO}_{3}$ materials was 0.89 \pm 0.12 .

The glass data were fit in the same fashion as the reference materials. The results were somewhat peculiar in that the Na-O DebyeWaller factor $(\sigma)$ was unphysically low (between 0.03 and $0.07 \AA$ for the glasses, whereas the thermal contribution should give at least $0.10 \AA$ ). This yielded a $\mathrm{Na}-\mathrm{O}$ coordination measurement of $1.5 \pm 0.2$ that is certainly too low. To better model this $\sigma /$ coordination number correlation, fits were also done in which $\sigma$ was constrained to a fairly large value of $0.16 \AA$ that is consistent with the previous $\mathrm{Na}$ measurements. These two methods result in an overall $\mathrm{Na}-\mathrm{O}$ coordination of $3.5 \pm 1.0$. The metrical parameters derived from the EXAFS results for this glass series are summarized in Table 8 .
EXAFS spectra were also recorded simultaneously in the TEY mode and the spectra were of similar quality to the FY data. These TEY measurements also included the aforementioned aluminoborosilicate glasses to verify the reproducibility of the original sodium EXAFS results. Although the overall amplitudes were different than before, the relative amplitudes were the same, thereby confirming the earlier results except that $\mathrm{S}_{0}{ }^{2}$ is larger in the latest measurements. The TEY and the FY yield results from the original glasses are similar, thus the local $\mathrm{Na}$ environment in the near surface region is similar to that of the bulk glass. However, the TEY and FY amplitudes in the second glass series differ. The effective amplitude in TEY for the second series of glasses samples is larger than the FY. This is indicative of greater sodium coordination by oxygen in the near surface region of the glass.

\section{Boron EXAFS}

The only common methods to obtain useful local structural information from boron are NMR or TEM techniques. The focus of boron studies in glasses is to determine the amount of three-coordinate $\left({ }^{\mathrm{iii}} \mathrm{B}\right)$ relative to fourcoordinate $\left({ }^{\mathrm{iv}} \mathrm{B}\right)$ boron species. The near-edge XAFS (NEXAFS) spectroscopy of the B K edge has been well-characterized and the distinctive $\pi^{*}$ electronic feature characteristic of trigonal boron environment, coupled with the $\sigma^{*}$ manifold signal from tetrahedral boron, provides a method for establishing the amount of tetrahedrally-coordinated boron in glasses [38,83-85].

The soft $x$-ray NEXAFS measurements at the B K edge $(191 \mathrm{eV})$ of the reference boron materials, plus two glasses containing paramagnetic constituents referred to as BG3 and BG16, are shown in Figure 14. These spectra were collected at Beamline 6.3.2 in the TEY mode from powdered glasses pressed into indium. The reference spectra illustrate the differences between the response from ${ }^{\text {iv }} \mathrm{B}$ and 


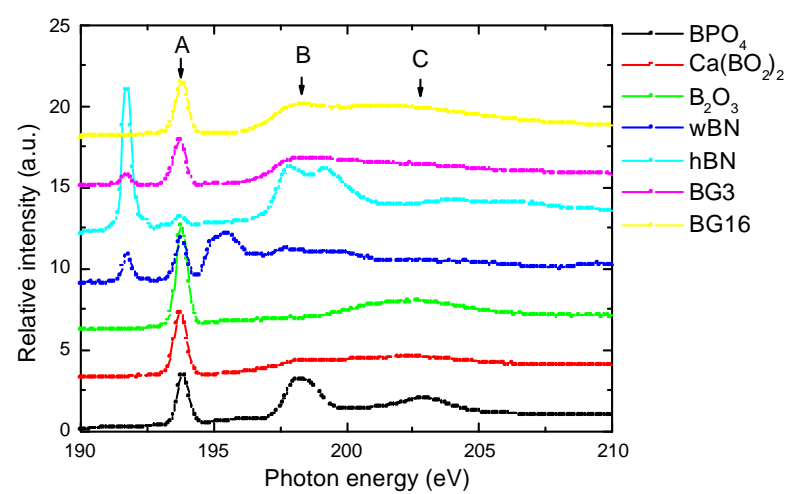

Figure 14. Boron K edge NEXAFS TEY spectra from the boron reference materials and two compositionally-simple borosilicate glasses. The spectra have been normalized to the background amplitude and offset. Spectral features identified are the primary coordination environments of the reference materials.

${ }^{i i i}$ B boron species. Furthermore, the capability to successfully obtain coordination information from glasses without the need for special formulation to permit analysis is also clearly demonstrated. Note that in the BG3 glass spectrum of Figure 14, there is a feature present that is normally associated with hexagonal $\mathrm{BN}$ or may be an unusual arrangement of some of the boron in this glass.

The NEXAFS spectra from the first series aluminosilicate glasses had an insufficient signal to noise ratio resulting from the low concentration of boron in the glasses. Although there were differences between the glasses evident from the spectra, reliable quantitative information could not be extracted (spectra not shown). The NEXAFS spectra from the second series glasses are presented in Figure 15. The NEXAFS spectra

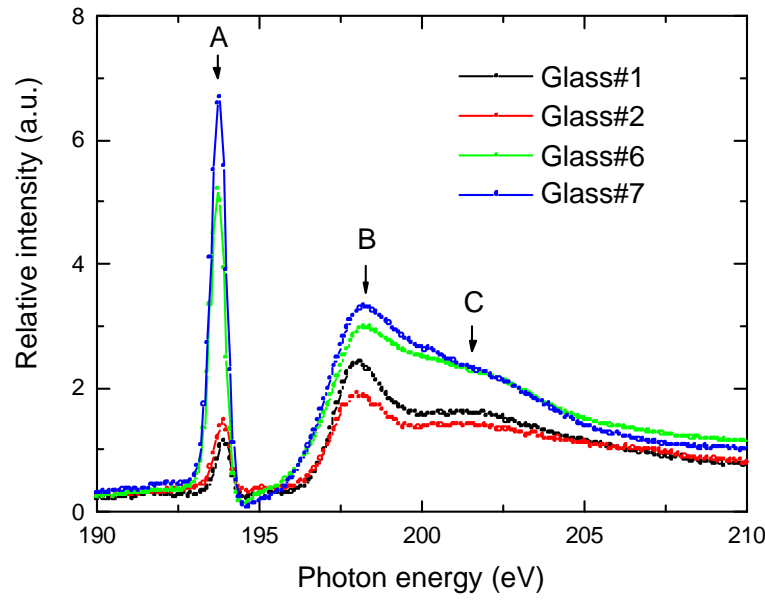

Figure 15. Boron K edge TEY NEXAFS spectra from the second series glasses collected at Beamline 6.3.2. The boron spectra have been normalized to equivalent background amplitudes at $220 \mathrm{eV}$. The features used to quantitatively determine boron coordination are indicated $\mathrm{A}\left({ }^{\mathrm{iii}} \mathrm{B}\right.$, $\pi^{*}$ feature), B ( ${ }^{\mathrm{iv}} \mathrm{B}$ feature), and $\mathrm{C}$ (combined ${ }^{\mathrm{iii}} \mathrm{B}$ and ${ }^{\text {iv }} \mathrm{B}$ feature).

were fit (the deconvoluted spectra are not shown) after the subtraction of an arctangent function, as per the method in Ref. [33], and the spectral parameters derived are summarized in Table 9. The resulting fraction of ${ }^{\text {iv }} \mathrm{B}$ to total boron in the respective glass formulations is listed in the final column. The location of the three spectral features used in this fitting procedure are indicated $\mathrm{A}, \mathrm{B}$, and $\mathrm{C}$ in Figure 15.

\section{DISSOLUTION BEHAVIOR}

The Series II set of glasses were actually the last set of glasses that were formulated and tested in this project. Dissolution testing is complete for the NaBSi-RD ${ }_{40}, \mathrm{NaBSi}-\mathrm{MB}_{3}$

Table 9. Proportion of tetrahedral boron $\left({ }^{\mathrm{iv}} \mathrm{B}\right)$ derived from peak-fitting of the B K edge TEY NEXAFS Spectra Using the Method in Ref. [33]

\begin{tabular}{|c|c|c|c|c|c|c|c|}
\hline Glass & \multicolumn{2}{|c|}{ Peak A } & \multicolumn{2}{c|}{ Peak B } & \multicolumn{2}{c|}{ Peak C } & Tetrahedral \\
& $(\mathrm{eV})$ & Area & $(\mathrm{eV})$ & Area & $(\mathrm{eV})$ & Area & Boron (B/B+A) \\
\hline NaBSi-RD $_{40}$ & 193.88 & 0.50 & 198.04 & 2.13 & 201.33 & 5.71 & 0.81 \\
\hline BAS-5 & 193.95 & 0.65 & 198.00 & 1.42 & 201.41 & 4.26 & 0.69 \\
\hline NaBSi-MB $_{3}$ & 193.71 & 2.83 & 197.94 & 3.30 & 200.83 & 8.23 & 0.54 \\
\hline NaBSi-MB $_{7}$ & 193.74 & 3.91 & 198.06 & 4.59 & 201.04 & 8.05 & 0.54 \\
\hline
\end{tabular}




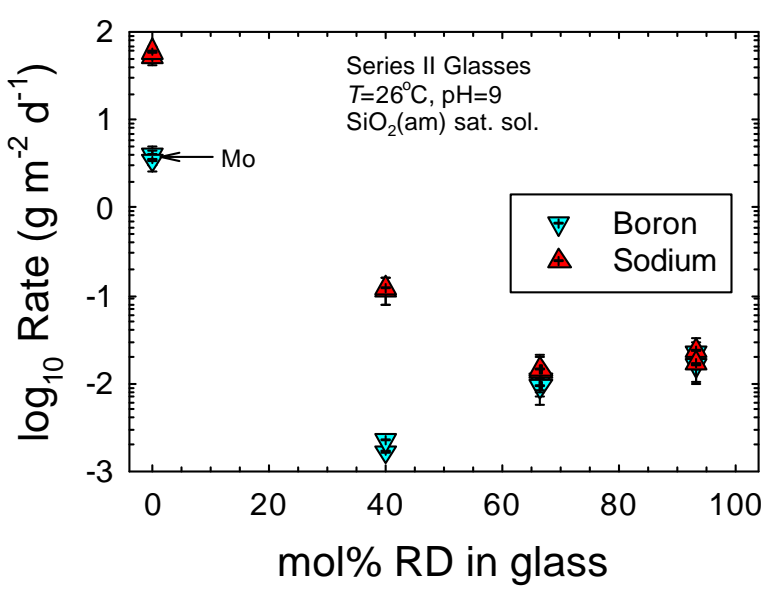

Figure 16. Plot of $\log \mathrm{Na}$ and $\mathrm{B}$ release rates for the reedmergnerite (RD) series glasses at silica saturation, $\mathrm{pH}=9$.

and $\mathrm{NaBSi}-\mathrm{MB}_{7}$ glasses at this time. Testing with the other glasses is still in progress. Nevertheless, significant findings are apparent from the available data.

The first set of experiments was conducted in silica-saturated solutions, $\mathrm{pH}=9$, at room temperature. Figure 16 summarizes the results of these experiments. The glass compositions are expressed in terms of the calculated percentage of the mineral analog moiety, reedmergnerite (see Mineral Analog Moiety Model section for details). The matrix dissolution rate for the sodium disilicate and the $\mathrm{RD}_{40}$ glasses are slower than the Na release rate, indicating significant rates of $\mathrm{Na}$ ion exchange as expected.

Upon the addition of $5 \mathrm{~mol} \% \quad \mathrm{~B}_{2} \mathrm{O}_{3}$ to $\mathrm{Na}_{2} \mathrm{O} \cdot 2 \mathrm{SiO}_{2}$ glass, we see from Figure 16 that $\mathrm{Na}$ release rate drops by a factor of 400 . In contrast, the addition of $5 \mathrm{~mol} \% \mathrm{Al}_{2} \mathrm{O}_{3}$ only caused a 10X decline in Na release rate (see Table 4). Because the Al/B additions were made along two different joins, the NaBSi$\mathrm{RD}_{40}$ glass has $25 \%$ less $\mathrm{Na}_{2} \mathrm{O}$ than in $\mathrm{NaSiO}-$ $5 \mathrm{Al}$ glass. Consequently, the "equivalent" decrease in Na release rate for the borosilicate glass is approximately $300 \mathrm{X}$, still a much greater change than occurred for the $\mathrm{Al}_{2} \mathrm{O}_{3}$ addition. This result is consistent with expectations from the structural bond strength model discussed in detail previously (see Structural Energy Barrier Model). According to our ${ }^{11} \mathrm{~B}$ NMR results and the model of Dell, Bray, and Xiao [86], almost all the boron in the NaBSi-RD ${ }_{40}$ glass should be tetrahedrally coordinated. The radius of ${ }^{\text {iv }} \mathrm{B}$ is less than half that of ${ }^{\mathrm{Q} 4} \mathrm{Si}$ groups. This causes the glass network to become more compact with $\mathrm{B}_{2} \mathrm{O}_{3}$ additions in contrast to $\mathrm{Al}_{2} \mathrm{O}_{3}$ additions where ${ }^{\text {iv }} \mathrm{Al}$ units are almost identical in size to ${ }^{\mathrm{Q} 4} \mathrm{Si}$ [47]. Consequently, $\mathrm{B}_{2} \mathrm{O}_{3}$ additions decrease the void diameter through which $\mathrm{Na}$ ionexchange reactions occur. Since the strain energy for a jump increases with the square of the void radius [see Equation (18)], a much larger drop in $\mathrm{Na}$ ion-exchange rate is predicted from our model with the addition of $\mathrm{B}_{2} \mathrm{O}_{3}$ to the glass.

One of the underlying tenets of this model is that glass compositions characterized by molar $\mathrm{Na}>(\mathrm{Al}+\mathrm{B})$ are vulnerable to $\mathrm{Na}^{+}-\mathrm{H}^{+}$ exchange reactions in solutions near saturation with respect to amorphous silica. This is due to the relatively high proportion of sodium atoms associated with non-bridging oxygen (NBO) atoms in such glass compositions. When the proportion of molar $\mathrm{Na}$ is equal to the sum of $\mathrm{Al}$ and $\mathrm{B}$, the network forming atoms $(\mathrm{B}, \mathrm{Al}$, and $\mathrm{Si})$ are organized in a polymeric structure in which nearly all the $\mathrm{SiO}_{4}{ }^{4-}, \mathrm{AlO}_{4}{ }^{5-}$, and $\mathrm{BO}_{4}{ }^{5-}$ polyhedra are interconnected with few non-bridging oxygen atoms. The end member example of this in the aluminosilicate system is albite $\left(\mathrm{NaAlSi}_{3} \mathrm{O}_{8}\right)$ glass, in which the network polyhedra form six-member rings surrounding the sodium atoms [87] and reedmergnerite $\left(\mathrm{NaBSi}_{3} \mathrm{O}_{8}\right)$ in the borosilicate system. Removing a sodium ion from an associated nonbridging oxygen site is much easier than removing sodium from an extensively polymerized glass.

In accordance with this hypothesis, as the percentage of the reedmergnerite moiety exceeds $50 \%$, differential rates of release for boron and sodium release disappear, as shown 
in Figure 16. However, further additions of $\mathrm{B}_{2} \mathrm{O}_{3}$ actually cause both $\mathrm{B}$ and $\mathrm{Na}$ release rates to increase, which was not expected.

To gain more insight into the dissolution behavior of the $\mathrm{MB}_{0.03}$ and $\mathrm{MB}_{0.07}$ glass compositions, we subjected these compositions to a set of experiments at $40^{\circ} \mathrm{C}$ over a solution composition from no added Si up to saturation with respect to amorphous silica. Figure $17 \mathrm{a}, \mathrm{b}$ illustrates the results of these experiments. For both glass compositions and with two different flow-through rates, the steadystate element release rates $(\mathrm{Na}$ and $\mathrm{B})$ are identical across the range of silicic acid activities. These data indicate that another mechanism, other than $\mathrm{Na}$ ion exchange, is governing the release of elements to solution.

\section{Mineral Analog Moiety Model}

Unlike the additions of $\mathrm{Al}$, which enters the glass almost entirely 4-coordinated and so supports network cross-linking, additions of $\mathrm{B}$ to $\mathrm{Na}_{2} \mathrm{O} \cdot 2 \mathrm{SiO}_{2}$ glass do not necessarily lead to $100 \%$ of the B in 4-fold coordinated sites $[81,86]$. Separation of B into borate rich regions in borosilicate glasses is widely reported [88-90] and a large immiscibility region is known [91]. The size of phase separated regions in borosilicate glasses can be quite small, on the order of $1 \mathrm{~nm}$ in airquenched glasses [90]. Phase separation on this scale is very difficult to detect and is well below the limit of quantification for RayleighBrillouin light-scattering $(\sim 10 \mathrm{~nm})$ [73].

To quantitatively assess macromolecular phase separation in our glasses, we have apportioned them into mineral analog moieties (MAM): sodium disilicate (DS), sodium metasilicate (MS), reedmergnerite (RD), sodium metaborate $(\mathrm{MB})$, albite $(\mathrm{AB})$, nepheline $(\mathrm{NE})$, sodium aluminate (NA), and quartz (Q). For example, the MAM distribution in the

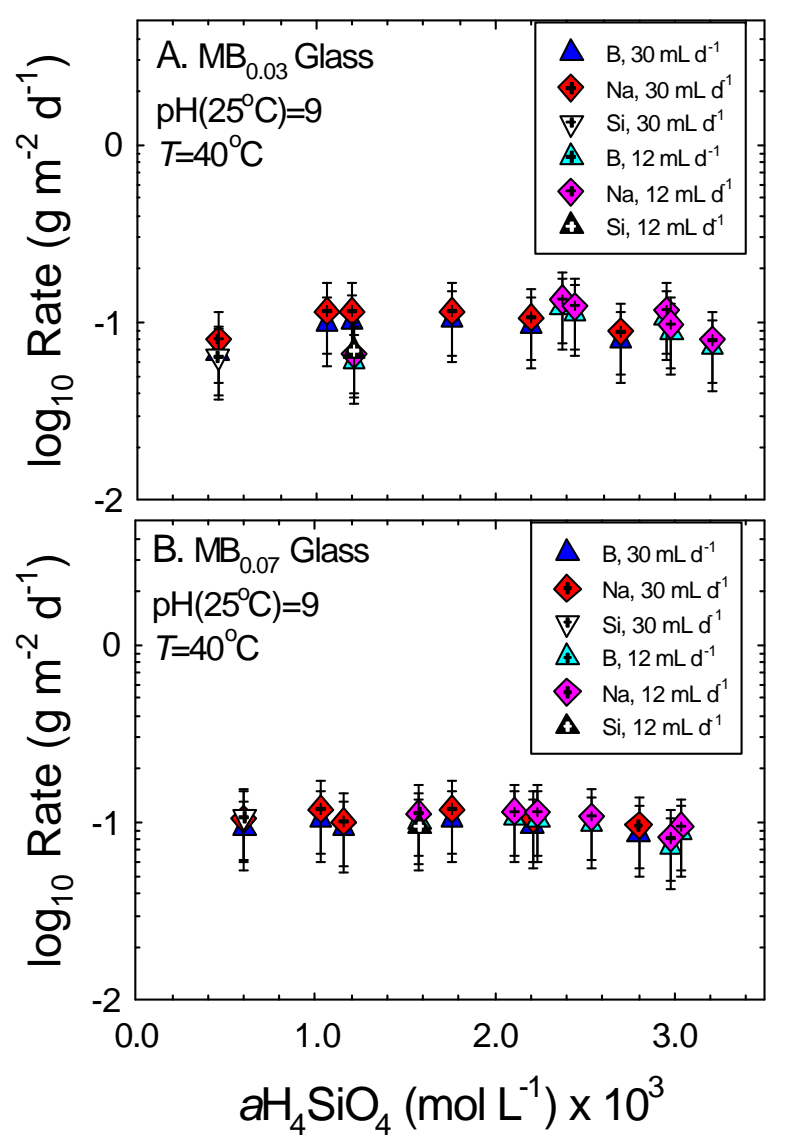

Figure 17. Plots of log element release rates versus the activity of silicic acid in solution for the $\mathrm{MB}_{0.03}$ and $\mathrm{MB}_{0.07}$ glass compositions, $\mathrm{pH}=9$, $\mathrm{T}=40^{\circ} \mathrm{C}$.

Series II glasses was calculated by solving the system of equations

$$
\left(\begin{array}{ccc}
\frac{1}{8} & \frac{1}{2} & \frac{1}{3} \\
\frac{1}{8} & \frac{1}{2} & 0 \\
\frac{3}{4} & 0 & \frac{2}{3}
\end{array}\right)\left(\begin{array}{l}
m_{\mathrm{RD}} \\
m_{\mathrm{MB}} \\
m_{\mathrm{DS}}
\end{array}\right)=\left(\begin{array}{l}
m_{\mathrm{Na}} \\
m_{\mathrm{B}} \\
m_{\mathrm{Si}}
\end{array}\right)
$$

where $m_{\mathrm{RD}}, m_{\mathrm{MB}}$, and $m_{\mathrm{DS}}$, are the unknown mol fractions of the MAM and $m_{\mathrm{Na}}, m_{\mathrm{B}}$, and $m_{\mathrm{Si}}$, are the mol fractions of $\mathrm{Na}_{2} \mathrm{O}, \mathrm{B}_{2} \mathrm{O}_{3}$, and $\mathrm{SiO}_{2}$ in the glass, respectively (see Table 1). Table 10 provides the calculated MAM distribution for each glass. 
Table 10. Calculated Distribution (mol fraction) of Mineral Analog Moieties in Series I, II, and II Glasses and Calculated ${ }^{29}$ Si NMR Chemical Shift Based on Rule of Mixtures Model. DS, sodium disilicate; MS, sodium metasilicate; $\mathrm{RD}$, reedmergnerite; $\mathrm{MB}$, sodium metaborate; $\mathrm{AB}$, albite; NE, nepheline; NA, sodium aluminate; Q, quartz.

\begin{tabular}{|c|c|c|c|c|c|c|c|c|c|}
\hline \multirow[b]{2}{*}{ Glass ID } & \multicolumn{8}{|c|}{ Mineral Analog Moiety } & \multirow{2}{*}{$\frac{\text { Shift }}{\mathrm{ppm}}$} \\
\hline & $\underline{\mathrm{DS}}$ & $\underline{\mathrm{MS}}$ & $\underline{\mathrm{RD}}$ & $\mathrm{MB}$ & $\underline{\mathrm{AB}}$ & $\mathrm{NE}$ & NA & $\underline{Q}$ & \\
\hline NaSiO-0Al & 1.00 & & & & & & & & -87 \\
\hline $\mathrm{NaSiO}-5 \mathrm{Al}$ & 0.60 & 0.20 & & & & 0.20 & & & -84 \\
\hline NaSiO-10Al & 0.18 & 0.42 & & & & 0.40 & & & -81 \\
\hline NaSiO-15Al & & 0.46 & & & & 0.48 & 0.06 & & -79 \\
\hline $\mathrm{NaBSi}-\mathrm{RD}_{40}$ & 0.60 & & 0.40 & & & & & & -94 \\
\hline NaBSi-RD 66 & 0.33 & & 0.67 & & & & & & -98 \\
\hline NaBSi-RD 100 & & & 1.00 & & & & & & -103 \\
\hline $\mathrm{NaBSi}-\mathrm{MB}_{0.03}$ & 0.30 & & 0.67 & 0.03 & & & & & -98 \\
\hline $\mathrm{NaBSi}-\mathrm{MB}_{0.07}$ & & & 0.93 & 0.07 & & & & & -102 \\
\hline $\mathrm{NaBSi}-\mathrm{MB}_{20}$ & & & 0.80 & 0.20 & & & & & -100 \\
\hline $\mathrm{NaBSi}-\mathrm{MB}_{33}$ & & & 0.67 & 0.33 & & & & & -98 \\
\hline BAS-1 & 0.51 & & 0.20 & & 0.20 & & & 0.09 & -94 \\
\hline BAS-2 & 0.51 & & 0.40 & & & & & 0.09 & -95 \\
\hline BAS-3 & 0.51 & & & & 0.40 & & & 0.09 & -93 \\
\hline BAS-4 & 0.67 & & & & & & & 0.33 & -94 \\
\hline BAS-5 & 0.60 & & 0.20 & & 0.20 & & & & -92 \\
\hline BAS-6 & 0.60 & & & & 0.40 & & & & -91 \\
\hline Chemical Shift & $-87^{(\mathrm{a})}$ & $-75^{(\mathrm{a})}$ & $-103^{(\mathrm{b})}$ & $-87^{(a)}$ & $-98^{(a)}$ & $-86^{(a)}$ & $-65^{(\mathrm{c})}$ & -108 & \\
\hline
\end{tabular}

${ }^{(\mathrm{a})}$ Ref. [92]. ${ }^{(\mathrm{b})}$ Ref. [81]. ${ }^{(\mathrm{c})}$ Extrapolated from data in Ref. [93].

\section{DISCUSSION}

One quantitative assessment of the MAM model is to compare ${ }^{29} \mathrm{Si} \mathrm{NMR} \mathrm{measurements}$ on these glasses with values that can be calculated from a rule of mixtures model. To do this calculation, chemical shift values for each MAM were obtained from the literature (see Table 10) and the total chemical shift calculated by a weighted molar sum. Figure 18 shows a comparison of the calculated and measured ${ }^{29} \mathrm{Si}$ chemical shift for each glass. The correlation is excellent indicating a reasonable assignment of MAM distribution in these glasses.

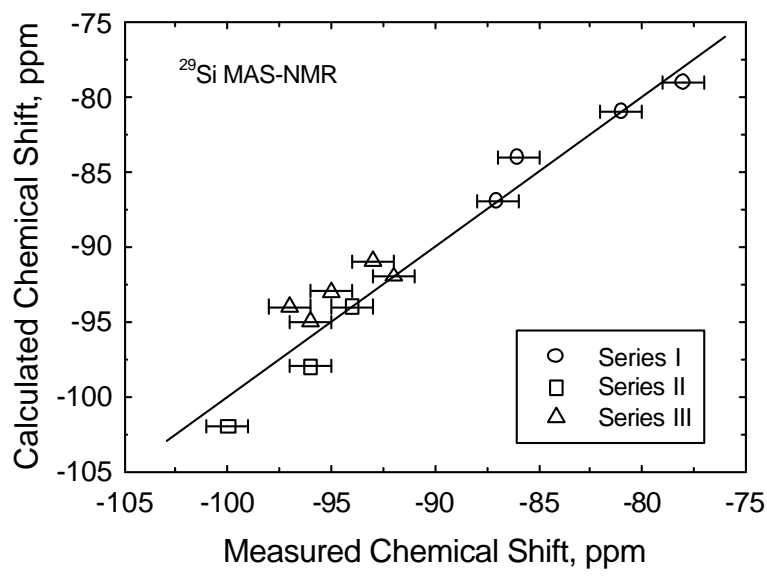

Figure 18. Plot of ${ }^{29} \mathrm{Si}$ Chemical Shift Measured by MAS-NMR and Calculated with a Rule of Mixtures for Mineral Analog Moieties 
The MAM model can also be used to explain the corrosion and $\mathrm{Na}$ IEX data observed for these glasses. With increasing amount of reedmergnerite, more sodium is tied up in sixmember $\mathrm{SiO}_{4}{ }^{4-}$ rings, and less as a chargebalancing cation for non-bridging oxygen (NBO) atoms in the disilicate moiety. As stated earlier, sodium atoms surrounded by silicate rings are less prone to ion exchange reactions than those associated with NBO's. Therefore, we expected that as the reedmergnerite content of the glass increased, the ion exchange (IEX) rate would decrease. This is indeed what is observed (Figure 16). However, unlike the Series I glasses where a significant percentage of metasilicate is present, even at $15 \mathrm{~mol} \% \mathrm{Al}_{2} \mathrm{O}_{3}$ added, the reedmergnerite glasses are more silica rich so at the addition of $10 \mathrm{~mol} \% \quad \mathrm{~B}_{2} \mathrm{O}_{3}$ the major MAM in the glass is reedmergnerite $(67 \%)$. Since the SPFT experiments measure a steady-state release rate, dissolution of the slower dissolving reedmergnerite MAM eventually controls the bulk dissolution rate of the glass. The model makes sense except that one would expect a further increase in the reedmergnerite component to continue to cause the glass dissolution rate to decrease. However the data in Figure 16 actually show a 10X increase in dissolution rate in going from 40 to $67 \% \mathrm{RD}$ and a further $2 \mathrm{X}$ increase in going from $67 \%$ to $93 \%$ RD.

The inverse correlation can be reconciled by noting that in both of these glasses a few mol\% of a sodium metaborate MAM is calculated to be present. However, when converted to a mass\% basis, the MB component accounts for 16 and $27 \%$ of the total boron in the $\mathrm{NaBSi}-\mathrm{MB}_{3}$ and $-\mathrm{MB}_{7}$ glasses. The presence of a sodium metaborate component is significant because it reacts very rapidly with water according to a reaction

$$
\begin{aligned}
& \mathrm{NaBO}_{2}+2 \mathrm{H}_{2} \mathrm{O} \rightarrow \\
& \mathrm{Na}^{+}+\mathrm{B}(\mathrm{OH})_{3}(\mathrm{aq})+\mathrm{OH}^{-} .
\end{aligned}
$$

Accordingly, for every mole of sodium metaborate that reacts with water, one mole of hydroxyl is produced. The hydroxyls produced catalyze the hydrolysis of the silicate matrix in an analogous way as the $\mathrm{Na}$ ion exchange reaction [Equation (9)], and so increases the net glass dissolution rate. We note that a $2 \mathrm{X}$ increase in $\mathrm{MB}$ content caused a $2 \mathrm{X}$ increase in glass dissolution rate for the $\mathrm{NaBSi}-\mathrm{MB}_{3}$ and $-\mathrm{MB}_{7}$ glasses. Finally, because reaction (21) does not depend on silicic acid activity, the rate of $\mathrm{Na}$ and $\mathrm{B}$ release will be independent of solution saturation state if the amount of metaborate moiety in glass exceeds a critical value. Again, this is precisely what is observed in our experiments (Figure 17). It is our contention, therefore, that a MAM hypothesis explains the complete dissolution behavior of the glasses we have studied along and slighted deviated from the $\mathrm{Na}_{2} \mathrm{O} \cdot 2 \mathrm{SiO}_{2}-$ $\mathrm{Na}_{2} \mathrm{O} \cdot \mathrm{B}_{2} \mathrm{O}_{3} \cdot 6 \mathrm{SiO}_{2}$ join. 


\section{RESULTS: SERIES III GLASSES}

The Series III glasses are all peralkaline glass compositions in the $\mathrm{Na}_{2} \mathrm{O} \cdot \mathrm{Al}_{2} \mathrm{O}_{3}$. $\mathrm{B}_{2} \mathrm{O}_{3} \cdot \mathrm{SiO}_{2}$ system (see Table 1). Dissolution experiments with BAS- 1 and BAS-2 glasses were conducted in silica-saturated $\mathrm{H}_{2} \mathrm{O}$ and $\mathrm{D}_{2} \mathrm{O}$ solutions with $\mathrm{pH}=\mathrm{pD}=8$.

As was the case for both the Series I and Series II set of glasses, the initial substitution of $\mathrm{B}_{2} \mathrm{O}_{3} / \mathrm{Al}_{2} \mathrm{O}_{3}$ into the glass causes a dramatic drop in the rate of glass matrix dissolution. Figure 2 shows that rates based on boron concentrations in effluent solution samples are, in fact, slower than $\mathrm{Na}$ rates by a factor of $\sim 20$ to $40 \mathrm{X}$. Consequently, Na ionexchange is the principal mechanism that controls $\mathrm{Na}$ release from the glasses, exactly as was observed in the $\mathrm{Na}_{2} \mathrm{O} \cdot \mathrm{B}_{2} \mathrm{O}_{3} \cdot \mathrm{SiO}_{2}$ system. Also, the rates of Na-release in $\mathrm{D}_{2} \mathrm{O}$-based solution are slower than those in $\mathrm{H}_{2} \mathrm{O}$-based solutions while the rate of matrix dissolution indicated by $\mathrm{B}$ release shows no isotope effect. These results are identical to what was observed for the Series I glasses, and to our knowledge, are the first instance in which this isotope effect has been documented in sodium borosilicate glasses. Therefore, our Na ionexchange model appears to apply to equally well to the $\mathrm{Na}_{2} \mathrm{O} \cdot \mathrm{Al}_{2} \mathrm{O}_{3} \cdot \mathrm{B}_{2} \mathrm{O}_{3} \cdot \mathrm{SiO}_{2}$ system.

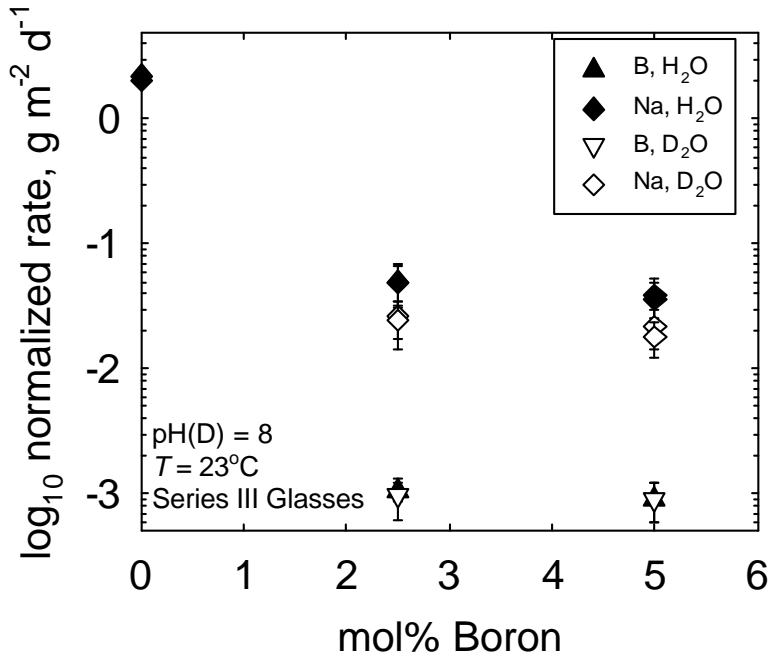

Figure 19: Plot of normalized log rate versus the boron concentration in the glass specimens. Solutions are silica saturated $\mathrm{H}_{2} \mathrm{O}$ - or $\mathrm{D}_{2} \mathrm{O}$-based and $\mathrm{pH}=\mathrm{pD}=8$. The figure shows that matrix dissolution rate (indexed by the boron rates) are unaffected by dissolution in $\mathrm{D}_{2} \mathrm{O}$, but the $\mathrm{Na}$ release rates are $\sim 30 \%$ slower in $\mathrm{D}_{2} \mathrm{O}$ - compared with $\mathrm{H}_{2} \mathrm{O}$-based solutions. These data are consistent with the rupture of the $(\mathrm{H}) \mathrm{D}-\mathrm{O}$ bond of the $\mathrm{D}(\mathrm{H})_{2} \mathrm{O}$ molecule as the rate limiting step in the $\mathrm{Na}^{+}-\mathrm{H}^{+}$exchange reaction. 



\section{RESULTS: SERIES IV GLASSES}

In this final series of glasses, hafnium dioxide was added at the expense of all other oxides in the glass. In other words, as $\mathrm{HfO}_{2}$ was added to glass, the concentrations of $\mathrm{Al}_{2} \mathrm{O}_{3}, \mathrm{~B}_{2} \mathrm{O}_{3}, \mathrm{Na}_{2} \mathrm{O}$, and $\mathrm{SiO}_{2}$ decreased proportionally (see Table 1). The choice of this particular series was guided by several factors. First, previous work [26] indicates that as $\mathrm{Hf}$ is added to glass, the ratio of three- to four-fold coordinate boron increases. There- fore, the molar ratio of $\mathrm{Na}$ to the sum of $\mathrm{Al}$ and ${ }^{\text {iv }} \mathrm{B}$ decreases and the glass becomes peralkaline. Thus, the compositions of the glass become more like those expected to serve as a matrix for low-activity waste $\left(\mathrm{Na} /\left(\mathrm{Al}+{ }^{\mathrm{iv}} \mathrm{B}\right)\right.$ $>1$ ). Second, hafnium is a tetravalent cation, and, as such, can be used to study the effects of incorporating high field strength elements (HFSE's) on glass durability and $\mathrm{Na}$ ion exchange rates.
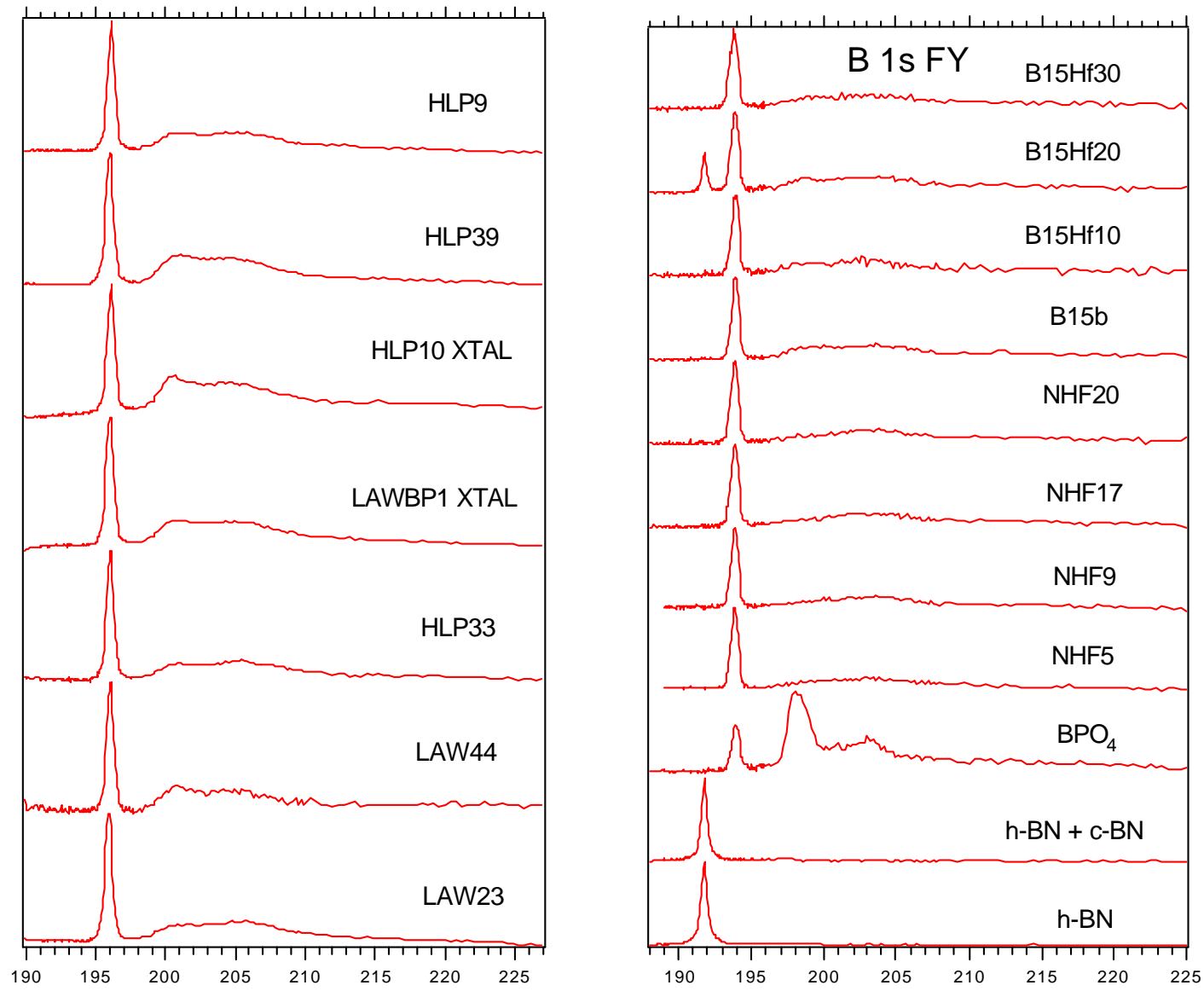

Figure 20. Boron K edge NEXAFS spectra collected in FY mode at Beamline 7.0 of the ALS for a series of non-ideal glasses. The left panel has spectra from several reference materials and glass formations containing hafnium. The spectra in the right panel are from actual waste glass formulations less radioactive constituents (HLP is a high-level; LAW is low activity waste glass). All of the spectra have been normalized to the amplitude of the largest respective feature. 
Table 11. Proportion of tetrahedral boron derived from peak-fitting of the $\mathrm{B} K$ edge fluorescence yield NEXAFS spectra from the BAS- $x$ Hf glass series with increasing Hf content using the method in Ref. [33] and normalization to a $72.5 \%{ }^{\text {iv }} \mathrm{B}$ content in glass BAS-0Hf

\begin{tabular}{lccccccc} 
Glass ID & \multicolumn{2}{c}{ Peak A } & \multicolumn{2}{c}{ Peak B } & \multicolumn{2}{c}{ Peak C } & ${ }^{\mathrm{iv}} \mathrm{B} /\left({ }^{\mathrm{iv}} \mathrm{B}+{ }^{\mathrm{iii}} \mathrm{B}\right)$ \\
\hline & $\underline{\text { Area }}$ & $\underline{\mathrm{eV}}$ & $\underline{\text { Area }}$ & $\underline{\mathrm{eV}}$ & $\underline{\text { Area }}$ & $\underline{\mathrm{eV}}$ & 0.72 \\
BAS-0Hf & 193.90 & 0.62 & 198.83 & 0.23 & 203.13 & 0.60 & 0.52 \\
BAS-10Hf & 193.90 & 0.61 & 198.45 & 0.15 & 202.76 & 0.64 & 0.54 \\
BAS-20Hf & 193.87 & 0.65 & 198.60 & 0.16 & 203.10 & 0.76 & 0.54 \\
\hline
\end{tabular}

\section{BORON NEXAFS}

To determine the utility of boron speciation using NEXAFS in actual waste form glasses, boron spectra were recorded from several glass formulations containing significant waste or paramagnetic constituents from both glass powders and coupons. The glass and reference material spectra were obtained at Beamline 7.0 in TEY and in the FY mode using a channeltron apparatus. The FY spectra obtained are shown in Figure 20 and the glasses were powders except for the two coupons denoted by XTAL following the glass sample identification. These spectra, some of which have yet to be deconvoluted, are from a range of simple glasses (left panel) and from actual waste glasses (right panel). The coordination information derived for the BAS- $x \mathrm{Hf}$ glasses (labeled B15Hfx in Figure 20) from the NEXAFS measurement are summarized in Table 11 based on the known coordination of the BAS-0Hf glass [86]. Similar to the B NEXAFS spectrum from the BG3 glass in Figure 14, the B15Hf20 glass spectrum also contains a feature at the energy usually associated with the boron coordination found in hexagonal boron nitride that may be a result of sample contamination. Variations in the ${ }^{\mathrm{iv}} \mathrm{B}$ fractions in the HLP and LAW glasses are evident even prior to spectral deconvolution. Furthermore, since the spectra were collected in both surface sensitive TEY and bulk sensitive FY modes, any differences between the near-surface and the bulk coordination can be discerned once the spectra are fully deconvoluted, provided that adequate signal to noise is obtained in the TEY mode spectra [94].

\section{DISSOLUTION BEHAVIOR}

The experiments conducted on the Series IV glasses can be subdivided into three categories: 1) experiments in which solutions were at silica-saturation, 2) experiments in dilute solution, and 3) experiments in solutions with a range of silicon concentrations.

Experiments in solutions saturated with respect to amorphous silica were carried out at $\mathrm{pH}=8$ and room temperatures. In all cases, concentrations of aluminum in solution were below the detection threshold and, for the $\mathrm{HfO}_{2}=20 \mathrm{~mol} \%$ composition, concentrations of $\mathrm{Na}$ and $\mathrm{B}$ were also below detection. Figure 21 illustrates the release rates of $\mathrm{Na}$ and $\mathrm{B}$ from the glass specimens plotted against the concentration of $\mathrm{HfO}_{2}$ in glass. Dissolution rates of the glass decrease by a factor of $\sim 100 \mathrm{X}$ over the series from 0 to 15 mol\%. As can be clearly seen, the rates decrease logarithmically with increasing $\mathrm{Hf}$ concentration in glass. This is important because the decrease in element release rates, therefore, is not due to simple dilution by addition of $\mathrm{HfO}_{2}$. Another important feature of this figure is that despite the increase in molar $\mathrm{Na} /\left(\mathrm{Al}+{ }^{\mathrm{iv}} \mathrm{B}\right)$ with addition of $\mathrm{Hf}$, the release rates of $\mathrm{Na}$ and $\mathrm{B}$ are the same within experimental uncertainty. The implications of this will be discussed below. 


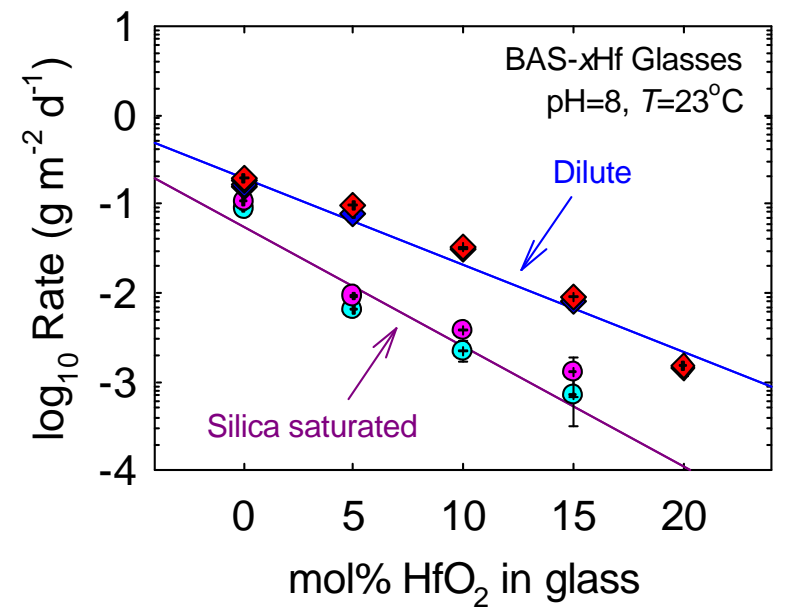

Figure 21. Plot of log release rate of $\mathrm{Na}$ and $\mathrm{B}$ versus concentration of hafnium in glass for experiments in dilute and in silica saturated solutions. Data for experiments at dilute solution conditions were adjusted to $\mathrm{pH}=8$.

Dissolution rates of the Hf-bearing glasses were also determined in dilute solutions. To compare the rates of dissolution in dilute and in silica saturated solutions, the data are plotted in Figure 21. Because the experiments in the dilute solutions were conducted at $\mathrm{pH}=9$, a small correction was applied to the rates in order to compare rates at the same $\mathrm{pH}$. Figure 21 shows that the amount of decrease in element release rates with increasing $\mathrm{Hf}$ concentration in glass is not as strong as in silica saturated solutions.

Dissolution rates of the Series IV glasses were also determined over a range of silicon concentrations by adding dissolved $\mathrm{SiO}_{2} \cdot 2 \mathrm{H}_{2} \mathrm{O}$ to input solutions. The experiments were conducted at $\mathrm{pH}=9$ and room temperature. Figure 22 illustrates the data obtained from these experiments with the BAS-0Hf and BAS-5Hf compositions. The hafnium-free composition shows an increase in rates with the addition of small amounts of dissolved silicon to solution followed by a linear decrease in rate as more silicon is added to the input solution. Abraitis et al. [72] noted similar dissolution behavior for the Magnox glass composition (a chemically complex boroaluminosilicate composition)

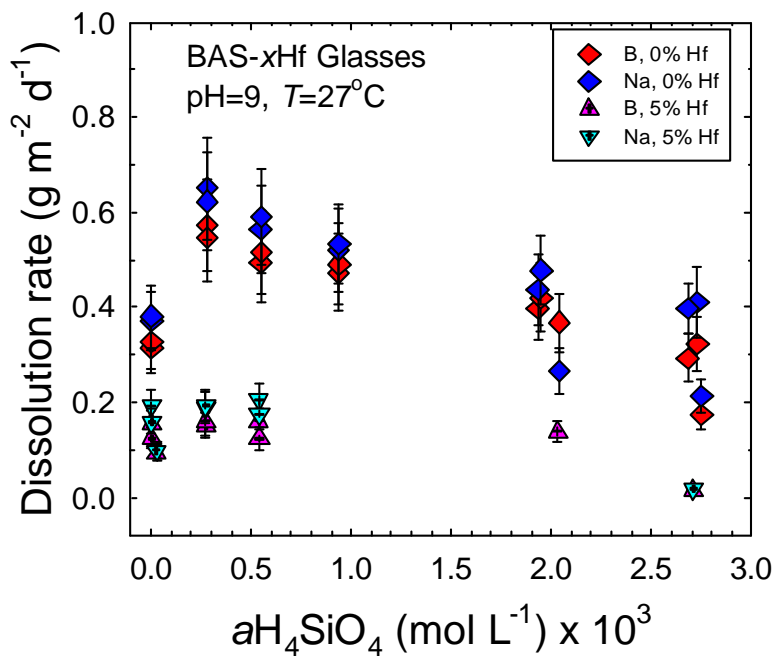

Figure 22. Plot of dissolution rate versus activity of silicic acid in solution for glass compositions BAS-0Hf and BAS-5Hf, $\mathrm{pH}=9, \mathrm{~T}=23^{\circ} \mathrm{C}$.

and attributed the initial rise in dissolution rate to the following phenomenon. They hypothesized that in dilute solutions, the release of elements includes aluminum, which suppresses the dissolution rate. As more dissolved silicon is added to the input solution, however, a low solubility aluminosilicate phase forms, effectively removing $\mathrm{Al}$ from solution and allowing the dissolution rate to increase. In the case of our experiments, the concentration of $\mathrm{Al}$ is below detection for all our experiments, so it is impossible to ascertain whether this model can be explain the dissolution behavior exhibited in Figure 22.

\section{DISCUSSION}

Within experimental uncertainty, the release rates of $\mathrm{Na}$ and $\mathrm{B}$ are identical over the range of silicic acid activities for the BAS$x \mathrm{Hf}$ glasses. This is expected, since the ratio of $\mathrm{Na} /\left(\mathrm{Al}+{ }^{\mathrm{iv}} \mathrm{B}\right)$ is near unity and so most of the sodium is associated with bridging oxygen (BO) atoms that are not vulnerable to ionexchange reactions.

A line projected through the dissolution rate data (Figure 22) for the $0 \%$ Hf glass extrapolates to a silicic acid activity $>3.5 \times 10^{-3}$ mol L $\mathrm{L}^{-1}$, which exceeds the solubility of silica 
polymorphs at room temperature [95]. This unusual behavior can be interpreted via the mineral analog moiety model discussed in the previous section. As much as $20 \%$ of the boron in this glass may be present as ${ }^{\text {iii }} \mathrm{B}$ [86], which would be manifest as a sodium diborate $\left(\mathrm{Na}_{2} \mathrm{~B}_{4} \mathrm{O}_{7}\right)$ MAM. This moiety is extremely reactive with water according to a reaction of the form

$$
\begin{gathered}
\mathrm{Na}_{2} \mathrm{~B}_{4} \mathrm{O}_{7}+7 \mathrm{H}_{2} \mathrm{O} \rightarrow 2 \mathrm{Na}^{+}+ \\
4 \mathrm{~B}(\mathrm{OH})_{3}(\mathrm{aq})+2 \mathrm{OH}^{-} .
\end{gathered}
$$

Now, every mol of $\mathrm{Na}_{2} \mathrm{~B}_{4} \mathrm{O}_{7}$ produces $2 \mathrm{~mol}$ $\mathrm{OH}^{-}$. As we discussed previously, reactions such as (22) catalyze the irreversible hydrolysis reaction<smiles>C[Si](O)(O)O[18OH]</smiles>

and so increase the rate of glass matrix dissolution. Since the reactivity of (22) does not depend on the saturation state of the aqueous phase, the effect is to cause enhanced rates of glass dissolution, even in silica-saturated solutions.

Based on the B NEXAFS data shown in Table 11, a $25 \%$ increase in proportion of ${ }^{\mathrm{iii}} \mathrm{B}$ in the glass occurs as the $\mathrm{HfO}_{2}$ content increases to $20 \mathrm{~mol} \%$. However, the total amount of $\mathrm{Na}$ and $\mathrm{B}$ decreases by nearly the same amount (20\%) in this series of glasses. Consequently, the relative amount of the $\mathrm{Na}_{2} \mathrm{~B}_{4} \mathrm{O}_{7}$ moiety remains approximately constant across the series and the dramatic decrease in glass dissolution rate with increasing substitution of $\mathrm{HfO}_{2}$ cannot be explained by the reaction scheme involving sodium diborate enhanced silicate hydrolysis.

Base catalyzed hydrolysis of $\mathrm{SiO}_{2}$ proceeds readily at $\mathrm{pH}>9$, since the $\mathrm{pK}_{\mathrm{a}}$ for the reaction

$$
\mathrm{SiO}_{2}+\mathrm{OH}^{-}=\mathrm{HSiO}_{3}^{-} \quad \mathrm{pK}_{\mathrm{a}}=9.5
$$

is about 9.5. In contrast, the $\mathrm{pK}_{\mathrm{a}}$ for the equivalent reaction with hafnium dioxide

$$
\mathrm{HfO}_{2}+\mathrm{OH}^{-}=\mathrm{HHfO}_{3}^{-} \quad \mathrm{pK}_{\mathrm{a}}>14
$$

is estimated to exceed 14 based on a chemical analog model for $\mathrm{Zr}$ [25]. Consequently, as $\mathrm{HfO}_{2}$ is incorporated into the glass, the $\mathrm{SiO}_{2}$ $\mathrm{HfO}_{2}$ backbone becomes increasingly resistant to attack by $\mathrm{OH}^{-}$produced via reaction (22).

\section{Chemical Kinetics Model}

To illustrate how incorporation of $\mathrm{HfO}_{2}$ could affect dissolution kine tics, we construct a simple chemical kinetics model using the following set of hypothetical reactions

$$
\begin{aligned}
& \mathrm{Na}_{2} \mathrm{~B}_{4} \mathrm{O}_{7}+7 \mathrm{H}_{2} \mathrm{O} \stackrel{k_{1}}{\rightarrow} 2 \mathrm{OH}^{-}+\mathrm{P} \\
& -\underset{\mathrm{Si}}{\mathrm{OH}}-\mathrm{OH}+\mathrm{OH}^{-} \stackrel{k_{2}}{\rightarrow} \mathrm{SiO}_{2}(\mathrm{aq})+2 \mathrm{H}_{2} \mathrm{O} \\
& -\underset{\mathrm{OH}}{\mathrm{OH}}-\mathrm{OH}+\mathrm{OH}^{-} \stackrel{k_{3}}{\rightarrow} \mathrm{HfO}_{2}(\mathrm{aq})+2 \mathrm{H}_{2} \mathrm{O} \\
& \mathrm{OH}
\end{aligned}
$$

where $\mathrm{P}$ is reaction products, and $k_{1}, k_{2}$, and $k_{3}$ are kinetic rate constants. Equations (25) to (27) can be rewritten in terms of a set of general kinetic equations

$$
\begin{gathered}
\mathrm{A}+7 \mathrm{~B} \stackrel{k_{1}}{\rightarrow} 2 \mathrm{C}+\mathrm{P} \\
x \mathrm{G}+\mathrm{C} \stackrel{k_{2}}{\rightarrow} \mathrm{P}+2 \mathrm{~B} \\
(1-x) \mathrm{G}+\mathrm{C} \stackrel{k_{3}}{\rightarrow} \mathrm{P}+2 \mathrm{~B}
\end{gathered}
$$

where $x$ is the mol fraction $\mathrm{Si}$ in a mixture $\mathrm{G}$ of the form $x \mathrm{SiO}_{2} \cdot(1-x) \mathrm{HfO}_{2}$ normalized such that $0 \leq \mathrm{x} \leq 1$.

From simple first order chemical kinetics methods [96], kinetic rate equations for this reaction system are 


$$
\begin{gathered}
\frac{d C}{d t}=k_{1}[A][B] \\
\frac{d B}{d t}=[G][C]\left(x k_{2}+(1-x) k_{3}\right)
\end{gathered}
$$

Since the concentration of sodium diborate (A) is approximately constant as $x$ is varied, and $[\mathrm{G}]$ is assumed a known constant, Equations (31) and (32) reduce to two equations in the two unknowns [C] and [B]. Using the initial conditions $C[0]=0$ and $B[0]=B_{o}$, the solution for $\mathrm{C}[t]$ is

$$
C[t]=\frac{[A] B_{\mathrm{o}} k_{1} \sinh \left(t \sqrt{[A][G] k_{1}\left(x k_{2}+(1-x) k_{3}\right)}\right)}{\sqrt{[A][G] k_{1}\left(x k_{2}+(1-x) k_{3}\right)}}
$$

The rate of metaborate consumption $\left(r_{\mathrm{mb}}\right)$ is then given by $d C / d t$, which after some manipulation is

$$
r_{\mathrm{mb}}=[A] B_{o} k_{1} \cosh \left(t \sqrt{[A][G] k_{1}\left(x k_{2}+(1-x) k_{3}\right.}\right)
$$

Our principal interest here is to see how the rate of metaborate consumption varies in response to increasing the amount of $\mathrm{Hf}$ in the system. To illustrate, we assign values of $k_{1}=$ $300, k_{2}=0.1$, and vary the value of $k_{3}$ between 0.001 and 0.05 . These values are assigned such that the metaborate reaction proceeds very rapidly relative to the other reactions, and the rate of $\mathrm{HfO}_{2}$ hydrolysis is the slowest reaction relative to the rate of silica hydrolysis. We assign arbitrary values for the other constants in Equation (34) and normalize the rate at $x=1$ to a value of 1 . Figure 23 shows the predicted change in the reaction rate as a function of the mol fraction of $\mathrm{HfO}_{2}$. The model predicts a logarithmic dependence of the rate on the $\mathrm{HfO}_{2}$ mol fraction, which is in accord with the results from our dissolution measurements (see Figure 21). Note that as the $\mathrm{HfO}_{2}$ hydrolysis rate gets very small relative to the rate of $\mathrm{SiO}_{2}$ hydrolysis, a limiting rate of change in the normalized rate is predicted, i.e. additional reductions in $\mathrm{Hf}$ rate do not affect the magnitude of the over all change. Consequently, our simple chemical kinetics model shows that substitution of the highly hydrolysis resistant $\mathrm{HfO}_{2}$ for $\mathrm{SiO}_{2}$ produces an exponential change in the overall dissolution rate of the glass.

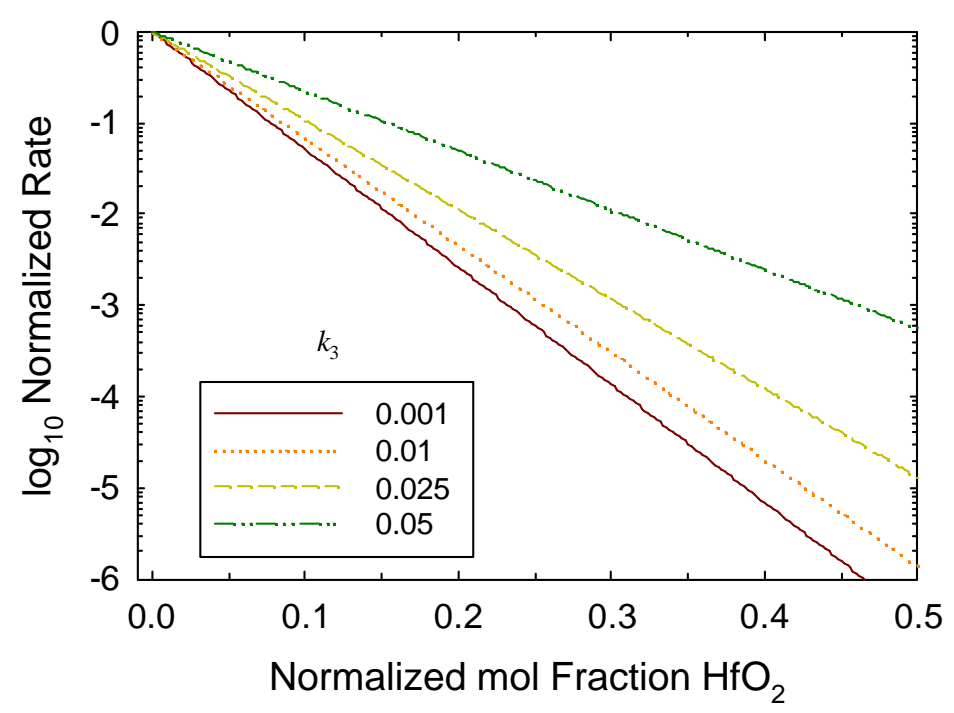

Figure 23. Calculated Normalized Rate of Metaborate Reaction as a Function of Mol Fraction of $\mathrm{HfO}_{2}$ in the BAS- $x \mathrm{Hf}$ Series of Glasses. Lines are values of the $\mathrm{HfO}_{2}$ hydrolysis rate constant $\left(k_{3}\right)$. 


\section{CONCLUSION}

Sodium ion exchange rates were measured on a series of glasses in the $\mathrm{Na}_{2} \mathrm{O}-\mathrm{Al}_{2} \mathrm{O}_{3}-\mathrm{SiO}_{2}$ system. In silica-saturated solutions, and slightly alkaline conditions $(\mathrm{pH}=8)$, sodium release rates are 10 to $50 \mathrm{X}$ faster than rates of matrix hydrolysis and dissolution. Alkali-H exchange reactions are shown to persist indefinitely and determine the "residual" rate of glass dissolution observed under silicasaturated conditions. Ion exchange is not considered in conventional kinetic rate laws based on transition state theory for silicate glass (and mineral) dissolution, raising serious questions about the validity of the theory for modeling systems near saturation, where the chemical affinity term approaches zero. Experiments with silica-saturated $\mathrm{D}_{2} \mathrm{O}$ solutions show that Na-release rates are slowed by $\sim 30 \%$, but matrix dissolution rates are unaffected. These data indicate the rate-limiting step in the $\mathrm{Na}^{+}-\mathrm{H}^{+}$exchange reaction is rupture of the $\mathrm{O}-\mathrm{H}$ bond in water or the hydronium ion, not diffusion of $\mathrm{H}_{2} \mathrm{O}$ or $\mathrm{H}_{3} \mathrm{O}^{+}$ species.

Bond length and coordination as determined by Na K-edge XAFS spectroscopy and XPS measurements of binding energy shifts for $\mathrm{Si}-\mathrm{O}^{-} \mathrm{Na}^{+}$sites were used in a simple model to estimate a structural energy barrier for alkali ion exchange. The energy barrier was calculated to increase from $34 \mathrm{~kJ} / \mathrm{mol}$ for $0 \% \mathrm{Al}_{2} \mathrm{O}_{3}\left(\mathrm{Na}_{2} \mathrm{O} \cdot 2 \mathrm{SiO}_{2}\right)$ glass to $50 \mathrm{~kJ} / \mathrm{mol}$ for $15 \mathrm{Al}_{2} \mathrm{O}_{3} \cdot 38 \mathrm{Na}_{2} \mathrm{O} \cdot 47 \mathrm{SiO}_{2}$ glass, consistent with stronger bonding of $\mathrm{Na}$ on $\mathrm{NBO}$ sites and increasing mechanical stiffness of the glass network with increasing $\mathrm{Al}$ content. The calculated ion-exchange enthalpies were then used in a simple model to calculate $\mathrm{Na}$ ion exchange rates as a function of glass composition. Agreement between the calculated and measured $\mathrm{Na}$ ion exchange rates was excellent.
The information presented in this report requires significant extension before waste glasses can be formulated with reduced $\mathrm{Na}$ ion-exchange rate. While increasing the $\mathrm{Al}_{2} \mathrm{O}_{3}$ content is effective, processing constraints (melt viscosity, crystallinity, etc.) limit the amount of $\mathrm{Al}_{2} \mathrm{O}_{3}$ that can be added to a glass waste form. Also, addition of $\mathrm{Al}_{2} \mathrm{O}_{3}$ can have severe negative impacts on the longterm performance of waste glasses. Formation of aluminosilicate zeolite alteration phases has been shown to dramatically accelerate the corrosion rate of some waste glasses $[10,11,97]$. Studies of $\mathrm{Na}$ ion-exchange in the $\mathrm{Na}_{2} \mathrm{O}-\mathrm{B}_{2} \mathrm{O}_{3}-\mathrm{SiO}_{2}$ system showed that addition of $\mathrm{B}_{2} \mathrm{O}_{3}$ suppresses the $\mathrm{Na}$ ion-exchange rate in a manner analogous to $\mathrm{Al}_{2} \mathrm{O}_{3}$. However, increasing additions of boron enter the glass as trigonal ${ }^{\mathrm{iii}} \mathrm{B}$ that separate into macromolecular clusters or moieties of sodium borate. Development of these moieties was shown to cause increased rates of glass degradation.

The effects of other additives, such as $\mathrm{B}_{2} \mathrm{O}_{3}, \mathrm{La}_{2} \mathrm{O}_{3}, \mathrm{CaO}, \mathrm{ZrO}_{2}$ etc. need to be evaluated and understood before low ionexchange rate waste glasses can be intelligently formulated. In this study, we examined the effect of incorporation of $\mathrm{Hf}$, a chemical analog of $\mathrm{Zr}$, on $\mathrm{Na}$ ion-exchange and glass durability. It was found that incorporation of $\mathrm{Hf}$ in a boroaluminosilicate glass reduced the glass corrosion rate logarithmically as a function of mol\% $\mathrm{HfO}_{2} . \mathrm{HfO}_{2}$ is much more resistant than $\mathrm{SiO}_{2}$ to nucleophilic attack by $\mathrm{OH}^{-}$and a simple kinetics model showed that incorporation $\mathrm{HfO}_{2}$ reduces the rate that water can attack the glass matrix in a logarithmic fashion.

Soft x-ray XAFS spectroscopy was employed in this study to investigate the local structural environments around sodium, boron, and oxygen in glasses. This is the first time that a diffraction grating-based beamline 
has been used to perform EXAFS at the $\mathrm{Na} \mathrm{K}$ edge. A fluorescence detector has been installed on Beamline 6.3.1 at the ALS and in combination with the beamline improvements, significantly improved $\mathrm{Na}$ spectra can be routinely collected with higher quality in the near future from glasses. The methodologies for successfully processing the $\mathrm{Na}$ EXAFS data have been developed, implemented, and will make future studies much less complex. The fluorescence detector has and will be used to compare near-surface and bulk sodium environments. Utilizing other beamlines at the ALS, the speciation of boron in the glasses of interest has been determined by NEXAFS spectroscopy and the ability to successfully obtain this information from real waste glasses demonstrated. NEXAFS spectra were also acquired at the $\mathrm{O} \mathrm{K}$ edge from the first glass series and trends in the near edge spectra were evident as a function of glass composition.

\section{ACKNOWLEDGEMENTS}

We acknowledge Jackie Steele and Toni Owen for invaluable laboratory assistance and John Linehan for conducting the NMR measurements. We especially thank Elsa Rodriguez for helping to run the flow experiments.
We also express gratitude to Todd Schaef, Matthew O'Hara, and Christopher F. Brown for help in chemical analyses of numerous effluent samples. The authors would also like to thank T. van Buuren (Lawrence Livermore National Laboratory) and R. C. C. Perera [Lawrence Berkeley National Laboratory (LBNL)] for their assistance at Beamline 8.0 and Beamline 6.3.1, respectively. This work is supported by the Office of Science and Technology, within the U.S. Department of Energy (DOE), under the Environmental Management Science Program. Parts of the work were conducted in the Environmental Molecular Sciences Laboratory, a DOE User facility operated for the DOE by Pacific Northwest National Laboratory (PNNL). The Advanced Light Source is operated by the Director, Office of Science, Office of Basic Energy Sciences, Division of Materials Science of U.S. Department of Energy under Contract No. DE-AC03-76SF00098 at LBNL. Financial support from the National Science Foundation under contract Nevada-NSF-EPSCoR is gratefully acknowledged. PNNL and LBNL are operated for the U.S. DOE under Contract No.'s DE-AC06-76RLO-1830 and DE-AC03-76SF00098, respectively. 


\section{REFERENCES}

[1] Douglas, R. W. and T. M. M. El-Shamy. 1967. "Reactions of Glasses with Aqueous Solutions." $J$. Am. Ceram. Soc. 50:1-8.

[2] Rana, M. A. and R. W. Douglas. 1961. "The Reaction Between Glass and Water. Part 1. Experimental Methods and Observations." Phys. Chem. Glasses 2(6):179-195.

[3] Rana, M. A. and R. W. Douglas. 1961. "The Reaction Between Glass and Water. Part 2. Discussion of the Results." Phys. Chem. Glasses 2(6):196-204.

[4] Doremus, R. H. 1975. "Interdiffusion of Hydrogen and Alkali Ions in a Glass Surface." J. NonCryst. Solids 19(2):137-144.

[5] Doremus, R. H. 1977. "Diffusion in Glasses and Melts." J. Non-Cryst. Solids 25:261-292.

[6] Lanford, W. A., K. Davis, P. Lamarche, T. Laursen, R. Groleau, and R. H. Doremus. 1979. "Hydration of Soda-Lime Glass." J. Non-Cryst. Solids 33(2):249-266.

[7] Doremus, R. H., Y. Mehrotra, and W. A. Lanford. 1983. "Reaction of Water with Glass: Influence of a Transformed Surface Layer." Journal of Materials Science 18:612-622.

[8] Dran, J.-C., G. Della Mea, A. Paccengella, J.-C. Petit, and L. Trotignon. 1988. "The Aqueous Dissolution of Alkali Silicate Glasses: Reappraisal of Mechanisms by $\mathrm{H}$ and $\mathrm{Na}$ Depth Profiling with High Energy Ion Beams." Phys. Chem. Glasses 29(6):249-255.

[9] Grambow, B. E. 1985. "A General Rate Equation for Nuclear Waste Glass Corrosion." Mat. Res. Soc. Symp. Proc. 44:15-27.

[10] Van Isegham, P. and B. Grambow. 1988. "The Long-Term Corrosion and Modelling of Two Simulated Belgian Reference High-Level Waste Glasses." Mat. Res. Soc. Symp. Proc. 112:631639.

[11] Ebert, W. L. and J. K. Bates. 1993. "A Comparison of Glass Reaction at High and Low Glass Surface/Solution Volume." Nuc. Tech. 104:372-384.
[12] Bates, J. K., C. R. Bradley, E. C. Buck, J. C. Cunnane, W. L. Ebert, X. Feng, J. J. Mazer, D. J. Wronkiewicz, J. Sproull, W. L. Bourcier, B. P. McGrail, and M. K. Altenhofen. 1994. HighLevel Waste Borosilicate Glass: A Compendium of Corrosion Characteristics. DOE-EM-0177, U.S. Department of Energy, Washington D.C.

[13] Vernaz, E. Y. and J. L. Dussossoy. 1992. "Current State of Knowledge of Nuclear Waste Glass Corrosion Mechanisms: The Case of R7T7 Glass." Appl. Geochem. Suppl. 1:13-22.

[14] Strachan, D. M., B. P. McGrail, M. J. Apted, D. W. Engel, and P. W. Eslinger. 1990. Preliminary Assessment of the Controlled Release of Radionuclides from Waste Packages Containing Borosilicate Waste Glass. PNL-7591, Pacific Northwest Laboratory, Richland, Washington.

[15] Bourcier, W. L., W. L. Ebert, and X. Feng. 1993. "Modeling Surface Area to Volume Effects on Borosilicate Glass Dissolution." Mat. Res. Soc. Symp. Proc. 294:577-582.

[16] DOE. (1997) Record of Decision for the Tank Waste Remediation System, Hanford Site, Richland, Washington, Vol. 62, pp. 8693.

[17] Sheng, J. W., S. G. Luo, and B. L. Tang. 1998. "Temperature Effects on the Leaching Behavior of a High-level Waste Glass Form." Nuc. Tech. 123(3):296-303.

[18] Chen, Y., B. P. McGrail, and D. W. Engel. 1997. "Source-Term Analysis for Hanford Low-Activity Tank Waste Using the Reaction-Transport Code AREST-CT." Mat. Res. Soc. Symp. Proc. 465:1051-1058.

[19] Bunker, B. C., G. W. Arnold, E. K. Beauchamp, and D. E. Day. 1983. "Mechanisms for Alkali Leaching in Mixed Na-K Silicate Glasses." $J$. Non-Cryst. Solids 58:295-322.

[20] Harvey, K. B., C. D. Litke, and C. A. Boase. 1986. "The Dissolution of a Simple Glass .1. Initial Model and Application to an Open Glass Water-System." Phys. Chem. Glasses 27(1):15-21. 
[21] Pederson, L. R. 1987. "Comparison of Sodium Leaching Rates From a $\mathrm{Na}_{2} \mathrm{O} \cdot 3 \mathrm{SiO}_{2}$ Glass in $\mathrm{H}_{2} \mathrm{O}$ and $\mathrm{D}_{2} \mathrm{O}$." Phys. Chem. Glasses 28(1):17-21.

[22] Pederson, L. R., D. R. Baer, G. L. McVay, and M. H. Engelhard. 1986. "Reaction of Soda Lime Silicate Glass in Isotopically Labeled Water." J. NonCryst. Solids 86(369-380).

[23] Pederson, L. R., D. R. Baer, G. L. McVay, K. F. Ferris, and M. H. Engelhard. 1990. "Reaction of Silicate Glasses in Water Labelled With D and ${ }^{18}$ O." Phys. Chem. Glasses 31:177-182.

[24] Sokolova, E. V., F. C. Hawthorne, and A. P. Khomyakov. 2001. "The Crystal Chemistry of Malinkoite, $\mathrm{NaBSiO}_{4}$, and Lisitsynite, $\mathrm{KBSi}_{2} \mathrm{O}_{6}$, from the Khibina-Lovozero complex, Kola Peninsula, Russia." Can. Mineral.39:159-169.

[25] Pourbaix, M. (1997) Atlas of Chemical \& Electrochemical Equilibria in the Presence of a Gaseous Phase. NACE International.

[26] Davis, L. L., L. Li, J. G. Darab, H. Li, and D. M. Strachan. 1999. "The Effects of $\mathrm{Na}_{2} \mathrm{O}, \mathrm{Al}_{2} \mathrm{O}_{3}$, and $\mathrm{B}_{2} \mathrm{O}_{3}$ on $\mathrm{HfO}_{2}$ Solubility in Borosilicate Glass." Mat. Res. Soc. Symp. Proc. 556:313-320.

[27] McGrail, B. P., W. L. Ebert, A. J. Bakel, and D. K. Peeler. 1997. "Measurement of Kinetic Rate Law Parameters on a Na-Ca-Al Borosilicate Glass for Low-Activity Waste." J. Nuc. Mat. 249:175189.

[28] McGrail, B. P., J. P. Icenhower, P. F. Martin, H. T. Schaef, M. J. O'Hara, E. A. Rodriguez, and J. L. Steele. 2001. Waste Form Release Data Package for the 2001 Immobilized Low-Activity Waste Performance Assessment. PNNL-13043 Rev. 2, Pacific Northwest National Laboratory, Richland, Washington.

[29] Sen, S., Z. Xu, and J. F. Stebbins. 1998. "Temperature Dependent Structural Changes in Borate, Borosilicate and Boroaluminate Liquids: HighResolution B-11, Si-29 And Al-27 NMR Studies." J. Non-Cryst. Solids 226(1-2):29-40.

[30] Bray, P. J., S. A. Feller, G. E. Jellison, and Y. H. Yun. 1980. "B-10 NMR Studies of the Structure of Borate Glasses." J. Non-Cryst. Solids 3839(MAY-):93-98.
[31] Garvie, L. A. J., A. J. Craven, and R. Brydson. 1995. "Parallel Electron Energy-Loss Spectroscopy (PEELS) Study of B in Minerals: The Electron Energy-Loss Near-Edge Structure (ELNES) of the B K-Edge." Am. Mineral. 80(11-12):11321144.

[32] Fleet, M. E. and S. Muthupari. 2000. "Boron Kedge XANES of borate and borosilicate minerals." Am. Mineral. 85(7-8):1009-1021.

[33] Fleet, M. E. and S. Muthupari. 1999. "Coordination of Boron in Alkali Borosilicate Glasses Using XANES." J. Non-Cryst. Solids 255(2-3):233-241.

[34] Kasrai, M., M. E. Fleet, S. Muthupari, D. Li, and G. M. Bancroft. 1998. "Surface Modification Study of Borate Materials From B K-edge X-ray Absorption Spectroscopy." Phys. Chem. Miner. 25(4):268-272.

[35] Fleet, M. E., S. Muthupari, M. Kasrai, and S. Prabakar. 1997. "Sixfold Coordinated Si in Alkali and Alkali-CaO Silicophosphate Glasses by Si Kedge XANES Spectroscopy." J. Non-Cryst. Solids 220(1):85-92.

[36] Li, D., G. M. Bancroft, M. E. Fleet, P. C. Hess, and Z. F. Yin. 1995. "Coordination of B in $\mathrm{K}_{2} \mathrm{O}$ $\mathrm{SiO}_{2}-\mathrm{B}_{2} \mathrm{O}_{3}-\mathrm{P}_{2} \mathrm{O}_{5}$ Glasses Using B K-Edge XANES." Am. Mineral. 80(9-10):873-877.

[37] Baker, G. J., G. N. Greaves, M. Surman, and M. Oversluizen. 1995. "An Oxygen XAFS Study of Sodium Disilicate Glass Surfaces." Nucl Instrum Meth Phys Res B 97(1-4):375-382.

[38] Terminello, L. J., A. Chaiken, D. A. Lapianosmith, G. L. Doll, and T. Sato. 1994. "Morphology and Bonding Measured from Boron-Nitride Powders and Films Using Near-Edge X-Ray Absorption Fine Structure." J Vac Sci Technol A 12(4):2462-2466.

[39] Greaves, G. N. 1990. "EXAFS for Studying Corrosion of Glass Surfaces." J. Non-Cryst. Solids 120(1-3):108-116.

[40] McKeown, D. A., G. A. Waychunas, and G. E. Brown. 1985. "EXAFS and XANES Study of the Local Coordination Environment of Sodium in a Series of Silica-Rich Glasses and Selected Minerals Within the $\mathrm{Na}_{2} \mathrm{O}-\mathrm{Al}_{2} \mathrm{O}_{3}-\mathrm{SiO}_{2}$ System." J. NonCryst. Solids 74(2-3):325-348. 
[41] McKeown, D. A., G. A. Waychunas, and G. E. Brown. 1985. "EXAFS Study of the Coordination Environment of Aluminum in a Series of SilicaRich Glasses and Selected Minerals Within the $\mathrm{Na}_{2} \mathrm{O}-\mathrm{Al}_{2} \mathrm{O}_{3}-\mathrm{SiO}_{2}$ System." J. Non-Cryst. Solids 74(2-3):349-371.

[42] Greaves, G. N., A. Fontaine, P. Lagarde, D. Raoux, and S. J. Gurman. 1981. "Local-Structure of Silicate-Glasses." Nature 293:611-616.

[43] Jia, J. J., T. A. Callcott, J. Yurkas, A. W. Ellis, F. J. Himpsel, M. G. Samant, J. Stohr, D. L. Ederer, J. A. Carlisle, E. A. Hudson, L. J. Terminello, D. K. Shuh, and R. C. C. Perera. 1995. "First Experimental Results From IBM/Tenn/Tulane/LLNL/LBL Undulator Beamline at the Advanced Light Source." Rev. Sci. Instrum. 66(2):1394-1397.

[44] Denlinger, J. D., E. Rotenberg, T. Warwick, G. Visser, J. Nordgren, J. H. Guo, P. Skytt, S. D. Kevan, K. S. McCutcheon, D. Shuh, J. Bucher, N. Edelstein, J. G. Tobin, and B. P. Tonner. 1995. "First Results from the Spectromicroscopy Beamline at the Advanced Light Source." Rev. Sci. Instrum. 66(2):1342-1345.

[45] Underwood, J. H. and E. M. Gullikson. 1998. "High-Resolution, High-Flux, User Friendly VLS Beamline at the ALS for the 50-1300 eV Energy Region." J. Electron Spectrosc. 92(1-3):265-272.

[46] Greaves, G. N. 1981. "Sodium Environments in Glass." Journal de Physique 42(NC4):225-228.

[47] Hsieh, C. H. and H. Jain. 1995. "Influence of Network-Forming Cations on Ionic Conduction in Sodium Silicate Glass." J. Non-Cryst. Solids 183:1-11.

[48] Shutthanandan, V., D. R. Baer, S. Thevuthasan, E. M. Adams, S. Maheswaran, M. H. Engelhard, J. P. Icenhower, and B. P. McGrail. 2001. "High Energy Ion Beam Studies of Ion Exchange in a $\mathrm{Na}_{2} \mathrm{O}-\mathrm{Al}_{2} \mathrm{O}_{3}-\mathrm{SiO}_{2}$ Glass." J. Appl. Phys. (in press).

[49] Westcott, C. C. (1978) pH Measurements. Academic Press.

[50] Westerterp, K. R., W. P. M. van Swaaij, and A. A. C. M. Beenackers. (1983) Chemical Reactor Design and Operation. John Wiley and Sons.
[51] Fogler, H. S. (1986) Elements of Chemical Reaction Engineering. Prentice Hall.

[52] Darab, J. G., X. Feng, J. C. Linehan, P. A. Smith, and I. Roth. 1997. "Composition-Structure Relationships in Model Hanford Low-Level Waste Glasses." Ceram. Trans. 72:103-110.

[53] Kirkpatrick, R. J. 1988. "MAS NMRSpectroscopy of Minerals and Glasses." Reviews in Mineralogy 18:341-403.

[54] Eckert, H. 1992. "Structural Characterization of Noncrystalline Solids and Glasses Using SolidState NMR." Progress in Nuclear Magnetic Resonance Spectroscopy 24:159-293.

[55] Hayes, T. M. and J. B. Boyce. (1982) Solid State Physics. Academic Press.

[56] Li, G. G., F. Bridges, and C. H. Booth. 1995. "XRay-Absorption Fine-Structure Standards - A Comparison of Experiment and Theory." Physical Review B 52(9):6332-6348.

[57] Erbil, A., G. S. Cargill, R. Frahm, and R. F. Boehme. 1988. "Total-Electron-Yield Current Measurements for Near-Surface Extended X-RayAbsorption Fine-Structure." Physical Review B 37(5):2450-2464.

[58] Stohr, J., C. Noguera, and T. Kendelewicz. 1984. "Auger and Photoelectron Contributions to the Electron-Yield Surface Extended X-RayAbsorption Fine-Structure Signal." Physical Review B 30(10):5571-5579.

[59] Zabinsky, S. I., J. J. Rehr, A. Ankudinov, R. C. Albers, and M. J. Eller. 1995. "MultipleScattering Calculations of X-Ray-Absorption Spectra." Physical Review B 52(4):2995-3009.

[60] Roy, M., S. J. Gurman, and G. vanDorssen. 1997. "The Amplitude Reduction Factor in EXAFS." Journal de Physique IV 7(C2):151-152.

[61] Angeli, F., J.-M. Delaye, T. Carpentier, J.-C. Petit, D. Ghaleb, and P. Faucon. 2000. "Influence of Glass Chemical Composition on the $\mathrm{Na}-\mathrm{O}$ Bond Distance: A ${ }^{23} \mathrm{Na}$ 3Q-MAS NMR and Molecular Dynamics Study." J. Non-Cryst. Solids 276:132-144. 
[62] Yuan, X. and A. N. Cormack. 2001. "Local Structures of MD-modeled Vitreous Silica and Sodium Silicate Glass." J. Non-Cryst. Solids 283:69-87.

[63] Doweidar, H. 1998. "Density-Structure Correlations in $\mathrm{Na}_{2} \mathrm{O}-\mathrm{Al}_{2} \mathrm{O}_{3}-\mathrm{SiO}_{2}$ Glasses." J. Non-Cryst. Solids 240(1-3):55-65.

[64] Brown, I. D. and D. Altermatt. 1985. "BondValence Parameters Obtained From a Systematic Analysis of the Inorganic Crystal-Structure Database." Acta Crystallographica B41:244-247.

[65] Araujo, R. 1997. "Influence of Boron-Oxygen Bonding on Glass Properties." J. Non-Cryst. Solids 222:25-32.

[66] Kivimaki, A., B. Kempgens, M. N. Piancastelli, M. Neeb, K. Maier, A. Rudel, U. Hergenhahn, and A. M. Bradshaw. 1998. "Angle-Resolved Electronic Decay of the Pi*, Sigma* and Rydberg Resonances Below the O K-Edge in O-2." J. Electron Spectrosc. Relat. Phenom. 93(1-3):81-88.

[67] Hitchcock, A. P. and C. E. Brion. 1980. "K-Shell Excitation-Spectra of $\mathrm{CO}, \mathrm{N}_{2}$ and $\mathrm{O}_{2}$." J. Electron Spectrosc. Relat. Phenom. 18(1-2):1-21.

[68] Hsieh, C. H., H. Jain, A. C. Miller, and E. I. Kamitsos. 1994. "X-Ray Photoelectron Spectroscopy of Al-Substituted and B-Substituted Sodium Trisilicate Glasses." J. Non-Cryst. Solids 168(3):247-257.

[69] Moulder, J. F., W. F. Stickle, P. E. Sobol, and K. D. Bomben. (1995) Handbook of X-ray Photoelectron Spectroscopy: A Reference Book of Standard Spectra for Identification and Interpretation of XPS Data. Physical Electronics.

[70] Lasaga, A. C. (1995) Fundamental Approaches in Describing Mineral Dissolution and Precipitation Rates. In Chemical Weathering Rates of Silicate Minerals, Reviews in Mineralogy, Vol. 31 (ed. A. F. White and S. L. Brantley), pp. 23-86. Mineralogical Society of America.

[71] Aagaard, P. and H. C. Helgeson. 1982. "Thermodynamic and Kinetic Constraints on Reaction Rates Among Minerals and Aqueous Solutions. I. Theoretical Considerations." Am. J. Sci. 282:237285.
[72] Abraitis, P. K., B. P. McGrail, D. P. Trivedi, F. R. Livens, and D. J. Vaughan. 2000. "Single-pass Flow-through Experiments on a Simulated Waste Glass in Alkaline Media at $40{ }^{\circ} \mathrm{C}$. Part 2: Experiments Conducted With Buffer Solutions Containing Controlled Quantities of Si and Al." $J$. Nuc. Mat. 280(2):206-215.

[73] Jégou, C., S. Gin, and F. Larché. 2000. "Alteration Kinetics of a Simplified Nuclear Glass in an Aqueous Medium: Effects of Solution Chemistry and of Protective Gel Properties on Diminishing the Alteration Rate." J. Nuc. Mat. 280:216-229.

[74] Grambow, B. E., H. P. Hermansson, I. K. Björner, H. Christensen, and L. Werme. (1986) Reaction of Nuclear Waste Glass with Slowly Flowing Solutions. In Advances in Ceramics, Vol. 20 (ed. D. E. Clark, W. B. White, and A. J. Machiels), pp. 465-474. American Ceramic Society.

[75] Hamilton, J. P. and C. G. Pantano. 1997. "Effects of Glass Structure on the Corrosion Behavior of Sodium-Aluminosilicate Glasses." J. Non-Cryst. Solids 222:167-174.

[76] Shelby, J. E. 1978. J. Appl. Phys. 49:5885.

[77] Pauling, L. 1929. J. Am. Chem. Soc. 51:10101026.

[78] Tomozawa, M. 1996. "Structure of Mixed Alkali Glasses." J. Non-Cryst. Solids 196:280-284.

[79] Rocherulle, J., C. Ecolivet, M. Poulain, P. Verdier, and Y. Laurent. 1989. "Elastic-Moduli of Oxynitride Glasses - Extension of Makishima and Mackenzie's Theory." J. Non-Cryst. Solids 108:187-193.

[80] McGrail, B. P., J. P. Icenhower, P. F. Martin, D. R. Rector, H. T. Schaef, E. A. Rodriguez, and J. L. Steele. 2000. Low-Activity Waste Glass Studies: FY2000 Summary Report. Pacific Northwest National Laboratory, Richland, Washington.

[81] Geisinger, K. L., R. Oestrike, A. Navrotsky, G. L. Turner, and R. J. Kirkpatrick. 1988. "Thermochemistry and Structure of Glasses Along the Join $\mathrm{NaAlSi}_{3} \mathrm{O}_{8}-\mathrm{NaBSi}_{3} \mathrm{O}_{8}$." Geochim. Cosmochim. Acta 52(10):2405-2414. 
[82] Troger, L., D. Arvanitis, K. Baberschke, H. Michaelis, U. Grimm, and E. Zschech. 1992. "Full Correction of the Self-Absorption in SoftFluorescence Extended X-Ray-Absorption Fine Structure." Phys Rev B-Condensed Matter 46(6):3283-3289.

[83] Jimenez, I., A. Jankowski, L. J. Terminello, J. A. Carlisle, D. G. J. Sutherland, G. L. Doll, J. V. Mantese, W. M. Tong, D. K. Shuh, and F. J. Himpsel. 1996. "Near-Edge X-Ray Absorption Fine Structure Study of Bonding Modifications in BN Thin Films by Ion Implantation." Appl Phys Lett 68(20):2816-2818.

[84] Jimenez, I., A. F. Jankowski, L. J. Terminello, D. G. J. Sutherland, J. A. Carlisle, G. L. Doll, W. M. Tong, D. K. Shuh, and F. J. Himpsel. 1997. "Core-level Photoabsorption Study of Defects and Metastable Bonding Configurations in Boron Nitride." Phys Rev B-Condensed Matter 55(18):12025-12037.

[85] Chaiken, A., L. J. Terminello, J. Wong, G. L. Doll, and C. A. Taylor. 1993. "Electronic and Atomic Structure of Metastable Phases of Boron Nitride Using Core-Level Photoabsorption." Appl Phys Lett 63(15):2112-2114.

[86] Dell, W. J., P. J. Bray, and S. Z. Xiao. 1983. "B 11 NMR-Studies and Structural Modeling of $\mathrm{Na}_{2} \mathrm{O}-\mathrm{B}_{2} \mathrm{O}_{3}-\mathrm{SiO}_{2}$ Glasses of High Soda Content." J. Non-Cryst. Solids 58(1):1-16.

[87] Taylor, M. and G. E. Brown, Jr. 1979. "Structure of Mineral Glasses-I. The Feldspar Glasses $\mathrm{NaAlSi}_{3} \mathrm{O}_{8}, \mathrm{KAlSi}_{3} \mathrm{O}_{8}, \mathrm{CaAl}_{2} \mathrm{Si}_{2} \mathrm{O}_{8}$." Geochim. Cosmochim. Acta 43:61-75.

[88] Tomozawa, M. 1999. "A Source of the Immiscibility Controversy of Borate and Borosilicate Glass Systems." J. Am. Ceram. Soc. 82(11):206208.

[89] Polyakova, I. G. 2000. "Alkali Borosilicate Systems: Phase Diagrams and Properties of Glasses." Phys. Chem. Glasses 41(5):247-258.

[90] Yazawa, T., K. Kuraoka, T. Akai, N. Umesaki, and W.-F. Du. 2000. "Clarification of Phase Separation Mechanism of Sodium Borosilicate Glasses in Early Stage by Nuclear Magnetic Resonance." J. Phys. Chem. B 104(9):2109-2116.
[91] Haller, W., D. H. Blackburn, F. E. Wagstaff, and R. J. Charles. 1970. "Metastable Immiscibility Surface in the System $\mathrm{Na}_{2} \mathrm{O}-\mathrm{B}_{2} \mathrm{O}_{3}-\mathrm{SiO}_{2}$." J. Am. Ceram. Soc. 53:34-38.

[92] Maekawa, H., T. Maekawa, K. Kawamura, and T. Yokokawa. 1991. "Si-29 MAS NMR Investigation of the $\mathrm{Na}_{2} \mathrm{O}-\mathrm{Al}_{2} \mathrm{O}_{3}-\mathrm{SiO}_{2}$ Glasses." J. Physical Chem. 95(18):6822-6827.

[93] Lee, S. K. and J. F. Stebbins. 1999. "The Degree of Aluminum Avoidance in Aluminosilicate Glasses." Am. Mineral. 84(5-6):937-945.

[94] Stohr, J. (1996) NEXAFS Spectroscopy. SpringerVerlag, Inc.

[95] Rimstidt, J. D. and H. L. Barnes. 1980. "The Kinetics of Silica Water Reactions." Geochim. Cosmochim. Acta 44:1683-1699.

[96] Atkins, P. W. (1982) Physical Chemistry. W. H. Freeman and Co.

[97] McGrail, B. P., P. F. Martin, C. W. Lindenmeier, and H. T. Schaef. (2001) Application of the Pressurised Unsaturated Flow (PUF) Test for Accelerated Ageing of Waste Forms. In Ageing Studies \& Lifetime Extension of Materials (ed. L. G. Mallinson), pp. 313-320. Kluwer Academic/Plenum Publishers. 
Appendix A. Experimental Conditions, Effluent Solution Compositions, and Element Release Rates from Series II, III, and IV Glass Compositions

\section{Series II Glasses}

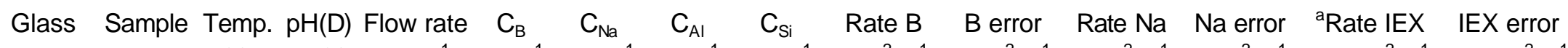

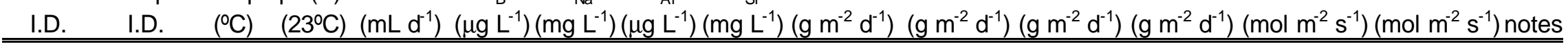

\begin{tabular}{|c|c|c|c|c|c|c|c|c|c|c|}
\hline $\mathrm{RD}_{40}$ & 1 & 23 & 9 & 36.94 & $<11$ & 0.94 & 85.64 & $<1.49 \mathrm{E}-02$ & 1.17E-01 (3.30E-02) & 1,3 \\
\hline $\mathrm{RD}_{40}$ & 2 & 23 & 9 & 37.1 & $<12$ & 0.92 & 89.11 & $<1.60 \mathrm{E}-02$ & 1.20E-01 (3.38E-02) & 1,3 \\
\hline $\mathrm{MB}_{3}$ & 13 & 23 & 9 & 18.81 & 32 & 0.17 & 90.76 & 1.10E-02 (4.03E-03) & 1.40E-02 (5.83E-03) & 1,3 \\
\hline $\mathrm{MB}_{3}$ & 14 & 23 & 9 & 18.97 & 26 & 0.17 & 91.03 & $9.28 \mathrm{E}-03(3.52 \mathrm{E}-03)$ & 1.46E-02 (6.07E-03) & 1,3 \\
\hline $\mathrm{MB}_{7}$ & 13 & 23 & 9 & 18.82 & 102 & 0.23 & 92.42 & $2.18 \mathrm{E}-02$ (7.19E-03) & 2.34E-02 (9.05E-03) & 1,3 \\
\hline $\mathrm{MB}_{7}$ & 14 & 23 & 9 & 19.09 & 74 & 0.16 & 95.06 & $1.58 \mathrm{E}-02(5.31 \mathrm{E}-03)$ & $1.65 \mathrm{E}-02(7.00 \mathrm{E}-03)$ & 1,3 \\
\hline $\mathrm{MB}_{3}$ & 1 & 40 & 9 & 11.6 & 3675 & 17.19 & 39.06 & 6.05E-02 (2.30E-02) & 6.66E-02 (2.84E-02) & 1 \\
\hline $\mathrm{MB}_{3}$ & 2 & 40 & 9 & 11.67 & 7460 & 34.74 & 76.70 & 1.24E-01 (4.69E-02) & 1.35E-01 (5.77E-02) & 1 \\
\hline $\mathrm{MB}_{3}$ & 3 & 40 & 9 & 11.02 & 7312 & 34.06 & 78.91 & 1.14E-01 (4.33E-02) & 1.25E-01 (5.32E-02) & 1 \\
\hline $\mathrm{MB}_{3}$ & 4 & 40 & 9 & 12.01 & 6236 & 29.39 & 95.46 & 1.06E-01 (4.04E-02) & $1.18 \mathrm{E}-01$ (5.02E-02) & 1 \\
\hline $\mathrm{MB}_{3}$ & 5 & 40 & 9 & 11.67 & 5371 & 24.97 & 96.37 & 8.90E-02 (3.38E-02) & 9.73E-02 (4.15E-02) & 1 \\
\hline $\mathrm{MB}_{3}$ & 6 & 40 & 9 & 11.89 & 4306 & 20.20 & 103.94 & 7.27E-02 (2.76E-02) & 8.02E-02 (3.43E-02) & 1 \\
\hline $\mathrm{MB}_{3}$ & 7 & 40 & 9 & 35.45 & 1109 & 5.73 & 12.08 & $5.58 \mathrm{E}-02(2.13 \mathrm{E}-02)$ & 6.78E-02 (2.94E-02) & 1 \\
\hline $\mathrm{MB}_{3}$ & 8 & 40 & 9 & 35.99 & 1921 & 9.64 & 34.44 & $9.81 \mathrm{E}-02$ (3.73E-02) & 1.16E-01 (4.98E-02) & 1 \\
\hline $\mathrm{MB}_{3}$ & 9 & 40 & 9 & 34.93 & 2044 & 9.96 & 38.89 & $1.01 \mathrm{E}-01 \quad(3.85 \mathrm{E}-02)$ & 1.16E-01 (4.98E-02) & 1 \\
\hline $\mathrm{MB}_{3}$ & 10 & 40 & 9 & 36.16 & 2038 & 9.65 & 56.90 & 1.05E-01 (3.99E-02) & 1.17E-01 (5.01E-02) & 1 \\
\hline $\mathrm{MB}_{3}$ & 11 & 40 & 9 & 35.94 & 1884 & 8.90 & 71.22 & $9.61 \mathrm{E}-02(3.65 \mathrm{E}-02)$ & 1.07E-01 (4.59E-02) & 1 \\
\hline $\mathrm{MB}_{3}$ & 12 & 40 & 9 & 35.72 & 1575 & 7.47 & 87.24 & 7.99E-02 (3.04E-02) & 8.91E-02 (3.84E-02) & 1 \\
\hline
\end{tabular}


Appendix A. Experimental Conditions, Effluent Solution Compositions, and Element Release Rates from Series II, III, and IV Glass Compositions

\section{Series II Glasses}

Glass Sample Temp. $\mathrm{pH}(\mathrm{D})$ Flow rate $\quad \mathrm{C}_{\mathrm{B}} \quad \mathrm{C}_{\mathrm{Na}} \quad \mathrm{C}_{\mathrm{Al}} \quad \mathrm{C}_{\mathrm{Si}} \quad$ Rate $\mathrm{B} \quad \mathrm{B}$ error Rate Na Na error ${ }^{a}$ Rate IEX IEX error I.D. I.D. (으 $\left(23^{\circ} \mathrm{C}\right)\left(\mathrm{mL} \mathrm{d}^{-1}\right)\left(\mu \mathrm{g} \mathrm{L}^{-1}\right)\left(\mathrm{mg} \mathrm{L}^{-1}\right)\left(\mu \mathrm{g} \mathrm{L}^{-1}\right)\left(\mathrm{mg} \mathrm{L}^{-1}\right)\left(\mathrm{g} \mathrm{m}^{-2} \mathrm{~d}-1\right)\left(\mathrm{g} \mathrm{m}^{-2} \mathrm{~d}^{-1}\right)\left(\mathrm{g} \mathrm{m}^{-2} \mathrm{~d}^{-1}\right)\left(\mathrm{g} \mathrm{m}^{-2} \mathrm{~d}^{-1}\right)\left(\mathrm{mol} \mathrm{m}^{-2} \mathrm{~s}^{-1}\right)\left(\mathrm{mol} \mathrm{m}^{-2} \mathrm{~s}^{-1}\right) \mathrm{notes}$

$\begin{array}{lcccccccc}\mathrm{MB}_{7} & 1 & 40 & 9 & 11.93 & 9024 & 21.26 & 51.05 & 1.03 \mathrm{E}-01(3.89 \mathrm{E}-02) 1.14 \mathrm{E}-01(4.34 \mathrm{E}-02) \\ \mathrm{MB}_{7} & 2 & 40 & 9 & 11.82 & 9362 & 21.79 & 68.17 & 1.05 \mathrm{E}-01(4.01 \mathrm{E}-02) 1.15 \mathrm{E}-01(4.41 \mathrm{E}-02) \\ \mathrm{MB}_{7} & 3 & 40 & 9 & 12.02 & 9086 & 21.21 & 72.40 & 1.04 \mathrm{E}-01(3.95 \mathrm{E}-02) 1.14 \mathrm{E}-01(4.36 \mathrm{E}-02) \\ \mathrm{MB}_{7} & 4 & 40 & 9 & 11.79 & 8688 & 20.50 & 82.08 & 9.76 \mathrm{E}-02(3.70 \mathrm{E}-02) 1.08 \mathrm{E}-01(4.14 \mathrm{E}-02) \\ \mathrm{MB}_{7} & 5 & 40 & 9 & 11.77 & 7822 & 18.16 & 98.45 & 8.77 \mathrm{E}-02(3.33 \mathrm{E}-02) 9.58 \mathrm{E}-02(3.66 \mathrm{E}-02) \\ \mathrm{MB}_{7} & 6 & 40 & 9 & 11.98 & 6489 & 15.26 & 96.49 & 7.41 \mathrm{E}-02(2.81 \mathrm{E}-02) 8.19 \mathrm{E}-02(3.14 \mathrm{E}-02) \\ \mathrm{MB}_{7} & & & & & & & & \\ \mathrm{MB}_{7} & 7 & 40 & 9 & 35.83 & 2713 & 6.52 & 19.56 & 9.26 \mathrm{E}-02(3.52 \mathrm{E}-02) 1.05 \mathrm{E}-01(4.06 \mathrm{E}-02) \\ \mathrm{MB}_{7} & 8 & 40 & 9 & 35.7 & 3069 & 7.46 & 33.37 & 1.04 \mathrm{E}-01(3.97 \mathrm{E}-02) 1.19 \mathrm{E}-01(4.61 \mathrm{E}-02) \\ \mathrm{MB}_{7} & 9 & 40 & 9 & 35.63 & 2724 & 6.32 & 37.65 & 9.25 \mathrm{E}-02(3.52 \mathrm{E}-02) 1.01 \mathrm{E}-01(3.92 \mathrm{E}-02) \\ \mathrm{MB}_{7} & 10 & 40 & 9 & 36.24 & 3033 & 7.38 & 56.27 & 1.05 \mathrm{E}-01(3.98 \mathrm{E}-02) 1.20 \mathrm{E}-01(4.63 \mathrm{E}-02) \\ \mathrm{MB}_{7} & 11 & 40 & 9 & 35.77 & 2808 & 6.57 & 71.58 & 9.57 \mathrm{E}-02(3.64 \mathrm{E}-02) 1.05 \mathrm{E}-01(4.09 \mathrm{E}-02) \\ \mathrm{MB}_{7} & 12 & 40 & 9 & 35.21 & 2593 & 6.12 & 90.65 & 8.70 \mathrm{E}-02(3.30 \mathrm{E}-02) 9.66 \mathrm{E}-02(3.75 \mathrm{E}-02)\end{array}$


Appendix A. Experimental Conditions, Effluent Solution Compositions, and Element Release Rates from Series II, III, and IV Glass Compositions

\section{Series III Glasses}

Glass Sample Temp. pH(D) Flow rate $\quad C_{B} \quad C_{N a} \quad C_{A l} \quad C_{S i}$ Rate $B \quad B$ error Rate $\mathrm{Na} \quad N a$ error ${ }^{a}$ Rate IEX IEX error

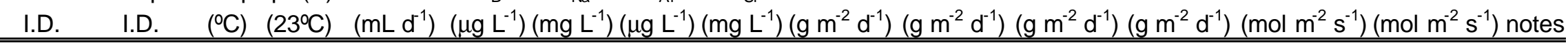

\begin{tabular}{|c|c|c|c|c|c|c|c|c|c|c|c|c|}
\hline BAS-1 & 47 & 23 & 8 & 10 & 18.8 & 16.00 & & 63.54 & 1.06E-03 (1.83E-04) & 4.88E-02 (1.71E-02) & 3.93E-09 & (2.86E-09) \\
\hline BAS-2 & 48 & 23 & 8 & 10 & 32.3 & 13.00 & & 62.85 & 9.04E-04 (3.13E-04) & 3.90E-02 (1.34E-02) & 3.18E-09 & $(2.24 \mathrm{E}-09)$ \\
\hline BAS-1 & 45 & 23 & 8 & 10 & 17.1 & 8.54 & & 55.76 & 9.73E-04 (3.53E-04) & 2.62E-02 (9.13E-03) & 2.08E-09 & (1.53E-09) \\
\hline BAS-2 & 46 & 23 & 8 & 10 & 32.1 & 7.30 & & 55.25 & $9.00 \mathrm{E}-04(3.12 \mathrm{E}-04)$ & 2.19E-02 (7.65E-03) & 1.76E-09 & $(1.28 \mathrm{E}-09)$ \\
\hline BAS-1 & 26 & 23 & 8 & 4.87 & & 34.00 & & 86.22 & & 5.05E-02 (1.93E-02) & 4.16E-09 & (3.22E-09) \\
\hline BAS-2 & 27 & 23 & 8 & 4.88 & & 24.30 & & 86.04 & & 3.56E-02 (1.40E-02) & 2.97E-09 & (2.34E-09) \\
\hline BAS-1 & 28 & 23 & 8 & 5.42 & & 15.00 & & 64.35 & & 2.48E-02 (1.63E-02) & 2.04E-09 & $(2.72 E-09)$ \\
\hline BAS-2 & 29 & 23 & 8 & 5.42 & & 11.06 & & 59.25 & & 1.80E-02 (1.18E-02) & $1.50 \mathrm{E}-09$ & (1.97E-09) \\
\hline BAS-2 & 1 & 40 & 10 & 30 & 244 & 8.10 & & 5.63 & 4.14E-02 (4.48E-03) & 1.47E-01 (1.60E-02) & 8.83E-09 & (2.78E-09) \\
\hline BAS-2 & 2 & 40 & 10 & 30 & 112 & 6.80 & 466 & 2.90 & 1.90E-02 (2.12E-03) & 1.23E-01 (1.34E-02) & 8.73E-09 & (2.27E-09) \\
\hline BAS-2 & 3 & 40 & 10 & 30 & 129 & 6.40 & 952 & 3.07 & 2.19E-02 (2.43E-03) & 1.16E-01 (1.28E-02) & 7.88E-09 & (2.18E-09) \\
\hline BAS-2 & 4 & 40 & 10 & 30 & 116 & 6.10 & 1388 & 2.80 & 1.97E-02 (2.20E-03) & 1.11E-01 (1.21E-02) & 7.61E-09 & (2.05E-09) \\
\hline BAS-2 & 5 & 40 & 10 & 30 & 120 & 6.00 & 1919 & 2.76 & 2.03E-02 (2.26E-03) & 1.09E-01 (1.21E-02) & 7.40E-09 & (2.06E-09) \\
\hline BAS-2 & 6 & 40 & 10 & 30 & 129 & 6.40 & 2396 & 3.07 & 2.19E-02 (2.44E-03) & 1.16E-01 (1.27E-02) & 7.88E-09 & (2.16E-09) \\
\hline BAS-2 & & & & & & & & & & & & \\
\hline BAS-2 & 7 & 40 & 10 & 30 & 245 & 6.90 & & 5.70 & 4.15E-02 (4.50E-03) & 1.25E-01 (1.37E-02) & 7.00E-09 & (2.41E-09) \\
\hline BAS-2 & 8 & 40 & 10 & 30 & 120 & 6.30 & 470 & 2.94 & 2.03E-02 (2.27E-03) & 1.14E-01 (1.25E-02) & 7.86E-09 & (2.12E-09) \\
\hline BAS-2 & 9 & 40 & 10 & 30 & 93 & 5.80 & 931 & 2.25 & 1.58E-02 (5.43E-03) & 1.05E-01 (1.17E-02) & 7.48E-09 & (2.15E-09) \\
\hline BAS-2 & 10 & 40 & 10 & 30 & 113 & 6.10 & 1430 & 2.70 & 1.92E-02 (6.57E-03) & $1.11 \mathrm{E}-01$ (1.23E-02) & 7.65E-09 & (2.33E-09) \\
\hline BAS-2 & 11 & 40 & 10 & 30 & 137 & 6.60 & 1947 & 3.19 & 2.32E-02 (7.91E-03) & 1.20E-01 (1.31E-02) & 8.07E-09 & (2.56E-09) \\
\hline BAS-2 & 12 & 40 & 10 & 30 & 122 & 6.00 & 2436 & 3.01 & 2.07E-02 (7.09E-03) & 1.09E-01 (1.19E-02) & 7.37E-09 & (2.31E-09) \\
\hline
\end{tabular}


Appendix A. Experimental Conditions, Effluent Solution Compositions, and Element Release Rates from Series II, III, and IV Glass Compositions

\section{Series III Glasses}

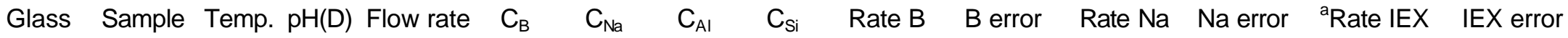

\begin{tabular}{|c|c|c|c|c|c|c|c|c|c|c|c|c|c|}
\hline I.D. & I.D. & $(\stackrel{\circ}{\circ})$ & $\left(23^{\circ} \mathrm{C}\right)$ & $\left(m L d^{-1}\right)$ & $g \mathrm{~L}$ & $y$ & 1 & $\mathrm{ng}$ & $\left(g^{-2} d^{-1}\right)\left(g^{-2} d\right.$ & $\left(g^{-2} d^{-1}\right)\left(g^{-2} d\right.$ & $\left(\mathrm{mol} \mathrm{m}^{-2} \mathrm{~s}\right.$ & $\left(\mathrm{mol} \mathrm{m}^{-2}\right.$ & lotes \\
\hline BAS-2 & 14 & 40 & 10 & 40 & 175 & 6.20 & & 3.95 & 3.95E-02 (1.34E-02) & $1.50 \mathrm{E}-01$ (1.64E-02) & 9.23E-09 & (3.54E-09) & 1 \\
\hline BAS-2 & 45 & 40 & 10 & 40 & 41 & 4.50 & 462 & 1.37 & 9.27E-03 (3.34E-03) & $1.09 \mathrm{E}-01(1.28 \mathrm{E}-02)$ & 8.33E-09 & (2.21E-09) & 1 \\
\hline BAS-2 & 16 & 40 & 10 & 40 & 96 & 6.40 & 1013 & 2.52 & $2.17 \mathrm{E}-02$ (7.46E-03) & $1.55 \mathrm{E}-01(1.91 \mathrm{E}-02)$ & $1.11 \mathrm{E}-08$ & (3.42E-09) & 1 \\
\hline BAS-2 & 17 & 40 & 10 & 40 & 60 & 5.20 & 1497 & 1.82 & 1.36E-02 (4.80E-03) & 1.26E-01 (1.48E-02) & 9.38E-09 & (2.60E-09) & 1 \\
\hline BAS-2 & 18 & 40 & 10 & 40 & 48 & 4.60 & 1884 & 1.43 & $1.08 \mathrm{E}-02(3.88 \mathrm{E}-03)$ & $1.11 \mathrm{E}-01(1.30 \mathrm{E}-02)$ & $8.40 \mathrm{E}-09$ & (2.27E-09) & 1 \\
\hline BAS-2 & 19 & 40 & 10 & 40 & 66 & 5.00 & 2444 & 1.75 & 1.49E-02 (5.19E-03) & $1.21 \mathrm{E}-01(1.40 \mathrm{E}-02)$ & 8.86E-09 & (2.49E-09) & 1 \\
\hline BAS-2 & 20 & 40 & 10 & 50 & 135 & 4.50 & & 3.17 & $3.81 \mathrm{E}-02(1.30 \mathrm{E}-02)$ & 1.36E-01 (1.51E-02) & 8.19E-09 & (3.33E-09) & 1 \\
\hline BAS-2 & 21 & 40 & 10 & 50 & 21 & 3.60 & 479 & 0.86 & 5.93E-03 (2.36E-03) & 1.09E-01 (1.26E-02) & 8.60E-09 & (2.14E-09) & 1 \\
\hline BAS-2 & 22 & 40 & 10 & 50 & 36 & 3.80 & 925 & 1.05 & $1.02 \mathrm{E}-02(3.72 \mathrm{E}-03)$ & $1.15 \mathrm{E}-01(1.35 \mathrm{E}-02)$ & 8.76E-09 & (2.34E-09) & 1 \\
\hline BAS-2 & 23 & 40 & 10 & 50 & 68 & 3.90 & 1475 & 1.78 & 1.92E-02 (6.69E-03) & $1.18 \mathrm{E}-01$ (1.42E-02) & 8.25E-09 & (2.62E-09) & 1 \\
\hline BAS-2 & 24 & 40 & 10 & 50 & 24 & 3.30 & 1834 & 0.94 & 6.78E-03 (2.69E-03) & 9.99E-02 (1.18E-02) & 7.77E-09 & (2.02E-09) & 1 \\
\hline BAS-2 & 25 & 40 & 10 & 50 & 49 & 3.50 & 2349 & 1.21 & $1.38 \mathrm{E}-02(4.95 \mathrm{E}-03)$ & 1.06E-01 (1.26E-02) & 7.69E-09 & (2.26E-09) & 1 \\
\hline BAS-4 & 1 & 23 & 9 & 49.69 & & 9.84 & & 90.03 & & $2.33 \mathrm{E}+00(7.41 \mathrm{E}-01)$ & & & 1,3 \\
\hline BAS-4 & 2 & 23 & 9 & 51.53 & & 8.82 & & 91.40 & & $2.08 \mathrm{E}+00(6.75 \mathrm{E}-01)$ & & & 1,3 \\
\hline
\end{tabular}


Appendix A. Experimental Conditions, Effluent Solution Compositions, and Element Release Rates from Series II, III, and IV Glass Compositions

\section{Series IV Glasses}

Glass Sample Temp. pH Flow rate ${ }^{b} S . A . \quad C_{B} \quad C_{N a} \quad C_{S i} \quad$ Rate B $\quad$ B error Rate Na Na error ${ }^{c}$ Rate $q / S$ error $q / S$

$\begin{array}{llllllllllll}\text { I.D. } \quad \text { I.D. } \quad\left({ }^{\circ} \mathrm{C}\right) \quad\left(23^{\circ} \mathrm{C}\right) & \left(\mathrm{mL} \mathrm{d}^{-1}\right) & \left(\mathrm{m}^{2}\right) \quad\left(\mu \mathrm{g} \mathrm{L}^{-1}\right)\left(\mathrm{mg} \mathrm{L}^{-1}\right)\left(\mathrm{mg} \mathrm{L}^{-1}\right)\left(\mathrm{g} \mathrm{m}^{-2} \mathrm{~d}^{-1}\right)\left(\mathrm{g} \mathrm{m}^{-2} \mathrm{~d}^{-1}\right)\left(\mathrm{g} \mathrm{m}^{-2} \mathrm{~d}^{-1}\right)\left(\mathrm{g} \mathrm{m}^{-2} \mathrm{~d}^{-1}\right) & \left(\mathrm{m} \mathrm{s}^{-1}\right) & \left(\mathrm{m} \mathrm{s}^{-1}\right) & \text { notes }\end{array}$

\begin{tabular}{|c|c|c|c|c|c|c|c|c|c|c|}
\hline BAS-OHf & 58 & 23 & 8 & 2 & $1.21 \mathrm{E}-03$ & 2672 & 9.33 & 88.59 & 8.72E-02 (2.20E-02) 1.07E-01 (2.73E-02) 1.92E-08 (2.71E-09) & 1,3 \\
\hline BAS-5Hf & 59 & 23 & 8 & 2 & $1.34 \mathrm{E}-03$ & 188 & 0.75 & 89.49 & 6.48E-03 (1.69E-03) 9.12E-03 (2.51E-03) 1.73E-08 (2.44E-09) & 1,3 \\
\hline BAS-10Hf & 60 & 23 & 8 & 2 & $1.25 \mathrm{E}-03$ & 51 & 0.25 & 90.32 & 2.20E-03 (8.57E-04) 3.73E-03 (1.47E-03) 1.86E-08 (2.63E-09) & 1,3 \\
\hline BAS-15Hf & 61 & 23 & 8 & 2 & 1.39E-03 & 16 & 0.08 & 88.19 & 7.17E-04 (3.62E-04) 1.28E-03 (7.37E-04) 1.67E-08 (2.36E-09) & 1,3 \\
\hline BAS-OHf & 72 & 23 & 9 & 18.33 & 2.59E-04 & 229 & 0.76 & $<1$ & 3.20E-01 (4.66E-02) 3.72E-01 (5.12E-02) 8.21E-07 (1.16E-07) & 1,3 \\
\hline BAS-OHf & 73 & 23 & 9 & 19.05 & 2.34E-04 & 208 & 0.68 & $<1$ & 3.34E-01 (4.93E-02) 3.82E-01 (5.32E-02) 9.44E-07 (1.34E-07) & 1,3 \\
\hline BAS-5Hf & 74 & 23 & 9 & 18.75 & 2.76E-04 & 101 & 0.35 & $<1$ & 1.59E-01 (2.78E-02) 1.96E-01 (2.98E-02) 7.88E-07 (1.11E-07) & 1,3 \\
\hline BAS-5Hf & 82 & 23 & 9 & 1.91 & $1.22 \mathrm{E}-03$ & 2433 & 7.01 & $<1$ & 8.82E-02 (1.12E-02) 8.96E-02 (1.15E-02) 1.82E-08 (2.57E-09) & 1,3 \\
\hline BAS-10Hf & 83 & 23 & 9 & 1.93 & $1.18 \mathrm{E}-03$ & 1381 & 4.14 & $<1$ & 6.09E-02 (7.78E-03) 6.42E-02 (8.24E-03) 1.90E-08 (2.68E-09) & 1,3 \\
\hline BAS-15Hf & 84 & 23 & , & 1.88 & 1.27E-03 & 354 & 1.06 & $<1$ & 1.63E-02 (2.15E-03) 1.72E-02 (2.30E-03) 1.72E-08 (2.43E-09) & 1,3 \\
\hline BAS-20Hf & 85 & 23 & 9 & 1.85 & $9.75 \mathrm{E}-04$ & 42 & 0.13 & $<1$ & 2.87E-03 (5.35E-04) 3.08E-03 (6.40E-04) 2.20E-08 (3.11E-09) & 1,3 \\
\hline BAS-OHf & 64 & 23 & 9 & 18.81 & 2.42E-04 & 365 & 1.18 & 9.20 & 5.60E-01 (7.72E-02) 6.37E-01 (8.49E-02) 9.02E-07 (1.28E-07) & 1,3 \\
\hline BAS-OHf & 65 & 23 & 9 & 19.07 & $2.42 \mathrm{E}-04$ & 346 & 1.10 & 9.08 & 5.38E-01 (7.46E-02) 6.04E-01 (8.08E-02) 9.14E-07 (1.29E-07) & 1,3 \\
\hline BAS-OHf & 68 & 23 & 9 & 18.86 & 2.69E-04 & 353 & 1.12 & 17.20 & 4.88E-01 (6.75E-02) 5.48E-01 (7.32E-02) 8.13E-07 (1.15E-07) & 1,3 \\
\hline BAS-OHf & 69 & 23 & 9 & 19.09 & $2.51 \mathrm{E}-04$ & 347 & 1.12 & 17.34 & 5.21E-01 (7.22E-02) 5.93E-01 (7.93E-02) 8.82E-07 (1.25E-07) & 1,3 \\
\hline BAS-OHf & 76 & 23 & 9 & 19.31 & 2.34E-04 & 291 & 0.90 & 30.31 & 4.74E-01 (6.68E-02) 5.19E-01 (7.03E-02) 9.57E-07 (1.35E-07) & 1,3 \\
\hline BAS-OHf & 77 & 23 & 9 & 19.35 & 2.37E-04 & 247 & 0.77 & 62.57 & 3.98E-01 (5.74E-02) 4.38E-01 (6.01E-02) 9.47E-07 (1.34E-07) & 1,3 \\
\hline BAS-OHf & 78 & 23 & 9 & 19.25 & 2.58E-04 & 219 & 0.79 & 88.37 & 3.22E-01 (4.72E-02) 4.11E-01 (5.62E-02) 8.66E-07 (1.22E-07) & 1,3 \\
\hline BAS-OHf & 79 & 23 & 9 & 19.35 & 2.43E-04 & 313 & 0.96 & 30.39 & 4.92E-01 (6.88E-02) 5.33E-01 (7.19E-02) 9.24E-07 (1.31E-07) & 1,3 \\
\hline BAS-OHf & 80 & 23 & 9 & 19.45 & $2.49 \mathrm{E}-04$ & 273 & 0.88 & 63.19 & 4.21E-01 (5.98E-02) 4.78E-01 (6.49E-02) 9.06E-07 (1.28E-07) & 1,3 \\
\hline BAS-OHf & 81 & 23 & 9 & 19.22 & 2.36E-04 & 182 & 0.70 & 87.54 & 2.92E-01 (4.43E-02) 3.97E-01 (5.49E-02) 9.45E-07 (1.34E-07) & 1,3 \\
\hline
\end{tabular}


Appendix A. Experimental Conditions, Effluent Solution Compositions, and Element Release Rates from Series II, III, and IV Glass Compositions

\section{Series IV Glasses}

Glass Sample Temp. $\mathrm{pH}$ Flow rate ${ }^{\mathrm{b}} \mathrm{S} . \mathrm{A} . \quad \mathrm{C}_{\mathrm{B}} \quad \mathrm{C}_{\mathrm{Na}} \quad \mathrm{C}_{\mathrm{Si}} \quad$ Rate B $\mathrm{B}$ error Rate Na Na error ${ }^{\mathrm{c}}$ Rate $\mathrm{q} / \mathrm{S}$ error q/S

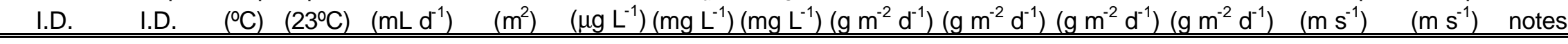

\begin{tabular}{|c|c|c|c|c|c|c|c|c|c|c|}
\hline $\mathrm{BAS}-\mathrm{OHf}$ & 88 & 23 & 7 & 2.04 & 2.18E-04 & 4845 & 15.88 & 81.47 & 8.94E-01 (1.13E-01) 1.03E+00 (1.31E-01) 1.09E-07 (1.54E-08) & 1,3 \\
\hline BAS-OHf & 89 & 23 & 7 & 9.87 & 2.12E-04 & 1858 & 5.33 & 83.63 & $1.71 \mathrm{E}+00(2.23 \mathrm{E}-01) 1.73 \mathrm{E}+00(2.39 \mathrm{E}-01) 5.40 \mathrm{E}-07$ (7.64E-08) & 1,3 \\
\hline AS-5Hf & 66 & 23 & 9 & 19.03 & 2.67E-04 & 93 & 0.33 & 8.97 & 1.53E-01 (2.77E-02) 1.89E-01 (2.92E-02) 8.27E-07 (1.17E-07) & 1,3 \\
\hline AS-5Hf & 67 & 23 & 9 & 19.05 & 2.79E-04 & 103 & 0.34 & 8.95 & 1.63E-01 (2.84E-02) 1.92E-01 (2.94E-02) 7.92E-07 (1.12E-07) & 1,3 \\
\hline $3 \mathrm{AS}-5 \mathrm{Hf}$ & 70 & 23 & 9 & 18.96 & 2.77E-04 & 100 & 0.37 & 17.11 & 1.58E-01 (2.79E-02) 2.07E-01 (3.12E-02) 7.94E-07 (1.12E-07) & 3 \\
\hline AS-5Hf & 71 & 23 & 9 & 19.07 & 2.57E-04 & 72 & 0.28 & 17.15 & 1.24E-01 (2.45E-02) 1.72E-01 (2.74E-02) 8.61E-07 (1.22E-07) & 13 \\
\hline
\end{tabular}

Notes:

1. Solution based on $\mathrm{H}_{2}$ O. 2. Solution based on $\mathrm{D}_{2} \mathrm{O}$. 3. Coupons, rather than powders, used.

a. IEX = ion exchange rate; rate of Na release to solution based solely by the ion-exchange mechanism.

b. S.A. = Surface area; calculated from dimensions of coupons.

c. $\mathrm{q} / \mathrm{S}=$ ratio of flow rate to specific surface area.

Blank $=$ below detection or indeterminate. 